VERÔNICA CHRISTIANO

FABRICAÇÃO DE CÉLULAS SOLARES MOS UTILIZANDO OXINITRETOS DE SILÍCIO OBTIDOS POR PROCESSAMENTO TÉRMICO RÁPIDO (RTP) 


\title{
VERÔNICA CHRISTIANO
}

Tecnóloga em Materiais Processos e Componentes Eletrônicos, FATECSP, 2008. Mestre em Ciências, Escola Politécnica da USP, 2012.

\section{FABRICAÇÃO DE CÉLULAS SOLARES MOS UTILIZANDO OXINITRETOS DE SILÍCIO OBTIDOS POR PROCESSAMENTO TÉRMICO RÁPIDO (RTP)}

\begin{abstract}
Tese de doutorado apresentado à Escola Politécnica da USP para defesa do título de Doutora em Ciências.
\end{abstract}

São Paulo 


\section{VERÔNICA CHRISTIANO}

Tecnóloga em Materiais Processos e Componentes Eletrônicos, FATECSP, 2008. Mestre em Ciências, Escola Politécnica da USP, 2012.

\section{FABRICAÇÃO DE CÉLULAS SOLARES MOS UTILIZANDO OXINITRETOS DE SILÍCIO OBTIDOS POR PROCESSAMENTO TÉRMICO RÁPIDO (RTP)}

Tese de doutorado apresentado à Escola Politécnica da USP para defesa do título de Doutora em Ciências.

Orientador:

Prof. Dr. Sebastião Gomes dos Santos Filho

Área de concentração:

Microeletrônica

São Paulo 
Este exemplar foi revisado e corrigido em relação à versão original, sob responsabilidade única do autor e com a anuência de seu orientador.

São Paulo, de de

Assinatura do autor:

Christiano, Verônica

Fabricação de Células Solares MOS Utilizando Oxinitretos de Silício por Processamento Térmico Rápido (RTP) / V. Christiano -- versão corr. -- São Paulo, 2017. $119 \mathrm{p}$.

Tese (Doutorado) - Escola Politécnica da Universidade de São Paulo. Departamento de Engenharia de Sistemas Eletrônicos.

1.Célula Solar MOS 2.Oxinitreto de Silício 3.Processamento Térmico Rápido I.Universidade de São Paulo. Escola Politécnica. Departamento de Engenharia de Sistemas Eletrônicos II.t. 
Dedico esta tese:

A meus pais. 


\section{Agradecimentos}

Ao Prof. Dr. Sebastião Gomes dos Santos Filho pela cuidadosa orientação e longas discussões de muito proveito;

Ao Laboratório de Sistemas Integrados LSI/PEE/EPUSP pelas facilidades oferecidas para execução deste trabalho;

Ao laboratório LEFE-IQ/UNESP Araraquara pela realização das medidas XPS;

Aos colegas e amigos do LSI e LME/EPUSP pelas colaborações prestadas em algum momento deste trabalho;

Aos meus pais, familiares e amigos pela compreensão e apoio no decorrer deste trabalho;

A todos que direta ou indiretamente tiveram colaboração neste trabalho, mesmo que por ventura não estejam mencionados. 


\section{RESUMO}

CHRISTIANO, V. 2017. Fabricação de células solares MOS utilizando oxinitretos de silício obtidos por processamento térmico rápido (RTP). 114 f. Tese (Doutorado) - Escola Politécnica, Universidade de São Paulo, São Paulo, 2017.

Neste trabalho foram crescidos filmes finos de oxinitreto de silício $\left(\mathrm{SiO}_{\mathrm{x}} \mathrm{N}_{\mathrm{y}}\right)$ por processamento térmico rápido (RTP) utilizando um forno térmico convencional adaptado, objetivando fabricar células solares MOS com baixo custo agregado e bom rendimento de conversão de baixas intensidades luminosas em energia elétrica de forma reprodutível. A receita de oxinitretação otimizada foi desenvolvida em ambiente misto de $5 \mathrm{~N}_{2}: 1 \mathrm{O}_{2}$ na temperatura de $850^{\circ} \mathrm{C}$ para tempos de processo, na faixa de 10 a 80 s seguido por uma passivação em $2 \mathrm{~L} / \mathrm{min}$ de $\mathrm{N}_{2}$ por 80 s. Os dielétricos crescidos foram caracterizados fisicamente quanto à espessura (entre 1,50 e 2,95nm), à microrugosidade $(<0,95 \mathrm{nmRMS})$ e à concentração de nitrogênio (1,0-2,1\%atm). As características de tunelamento foram investigadas em capacitores MOS e apontaram para a existência de armadilhas interfaciais do tipo $K$ capazes de armazenar cargas positivas. Nas células solares MOS, a corrente de fundo foi característica para todos os processos de oxinitretação empregados $\left(\sim 0,5-2 \mu \mathrm{A} / \mathrm{cm}^{2}\right)$ e apresentaram níveis de resposta à luz incidente na faixa de 1 a $8 \mathrm{~mA} / \mathrm{cm}^{2}$ compatível com aplicações de conversão de energia em ambientes internos e externos (energy harvesting). A característica densidade de corrente $x$ tensão de porta $\left(\mathrm{JxV}_{\mathrm{G}}\right)$ das células solares apresentou um comportamento aproximadamente linear desde a densidade de corrente de curto-circuito (Jsc) até a tensão de curto-circuito (Voc) implicando em potência gerada máximas $\left(P_{G \text { máx }}\right)$ de até centenas de $\mu \mathrm{A} / \mathrm{cm}^{2}$ para $V_{G} \cong V_{o c} / 2$ para uma ampla faixa de intensidade radiante incidente $\left(11,8-105,7 \mathrm{~mW} / \mathrm{cm}^{2}\right)$ alcançando rendimentos de conversão de até $5,5 \%$.

Palavras-Chave: célula solar MOS; oxinitreto; processamento térmico rápido. 


\begin{abstract}
CHRISTIANO, V. 2017. Fabrication of MOS solar cells using silicone oxynitrites grown by Rapid Thermal Processing (RTP). 114 f. Tese (Doutorado) - Escola Politécnica, Universidade de São Paulo, São Paulo, 2017.
\end{abstract}

In this work, silicon oxynitrides $\left(\mathrm{SiO}_{\mathrm{x}} \mathrm{N}_{\mathrm{y}}\right)$ were grown by means of a homemade Rapid Thermal Processing (RTP). The goal was to manufacture MOS solar cells with a reduced price and reasonable light conversion efficiency for low light intensity. The optimized oxidation recipe consisted of using an environment with gas mixture of $5 \mathrm{~N}_{2}: 1 \mathrm{O}_{2}$ at a temperature of $850^{\circ} \mathrm{C}$ and different processing times in the range of 10 to 80 s followed by a passivation step in ultrapure $\mathrm{N}_{2}(2 \mathrm{~L} / \mathrm{min})$ at the same temperature of $850^{\circ} \mathrm{C}$ for $80 \mathrm{~s}$. The oxynitrides were grown with thickness in the range of 1.50 to $2.95 \mathrm{~nm}$ with surface microroughness lower than $0.95 \mathrm{nmRMS}$ and nitrogen concentration in the range of 1.0 to $2.1 \%$ atm. The tunneling characteristics were studied with the aid of MOS capacitor and $K$-type interfacial traps related to $\mathrm{Si}(\mathrm{p}) / \mathrm{Si} \equiv \mathrm{N}$ structure were detected positively charged for $\mathrm{V}_{G}>0$. The background current in the MOS solar cells $\left(\sim 0.5-2 \mu \mathrm{A} / \mathrm{cm}^{2}\right)$ were similar for all samples and the current response to the incident light was in the range of 1 to $8 \mathrm{~mA} / \mathrm{cm}^{2}$, which is compatible with energy conversion for indoor and outdoor environments (energy harvesting). The current density $x$ gate voltage $\left(\mathrm{JxV}_{\mathrm{G}}\right)$ characteristics of the MOS solar cells presented a nearly linear behavior since the short-circuit current density (Jsc) till to the open circuit voltage ( $V_{o c}$ ) so that the maximum generated power was of hundreds of $\mu A / \mathrm{cm}^{2}$ for $V_{G} \cong V_{o c} / 2$ for a large range of radiant intensities $\left(11.8-105.7 \mathrm{~mW} / \mathrm{cm}^{2}\right)$ and achieving efficiency conversion up to $5.5 \%$.

Keywords: solar cell MOS; oxynitrides; rapid thermal processing. 


\section{LISTA DE FIGURAS}

Figura 1.1 - Geração de energia no Brasil em porcentagem................................19

Figura 1.2 - Perspectivas do mercado de energia solar fotovoltaica de

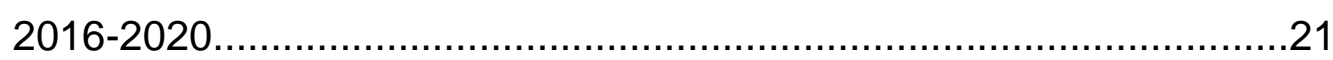

Figura 1.3 - Potência luminosa em ambientes fechados.......................................23

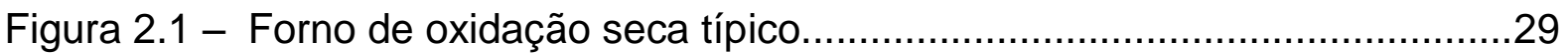

Figura 2.2 - Forno de oxidação úmida típico....................................................30

Figura 2.3 - Forno de oxidação pirogênica típico....................................................

Figura 2.4 - Forno de processamento térmico rápido (RTP)................................33

Figura 2.5 - Diversos processos RTP expressos em janelas de temperatura em função dos tempos de processamento típicos.

Figura 2.6 - Desenho esquemático exibindo os três fluxos envolvidos no modelo de Deal e Grove para crescimento de óxidos em fornos térmicos.........35

Figura 2.7 - Representação gráfica da equação 2.1.3.1 ilustrando os regimes de crescimento linear e parabólico em óxidos crescidos termicamente em ambiente seco e úmido para diversas temperaturas 36

Figura 2.8 - Desenho esquemático exibindo os quatro fluxos envolvidos no modelo proposto por Murali e Murarka para descrever a cinética de crescimento de óxidos finos. 38

Figura 2.9 - Encurvamento das bandas de energia na superfície do silício para tensões de porta menores do que $1,1 \mathrm{eV}$ (a) e para tensões de porta maiores do que $1,1 \mathrm{eV}(\mathrm{b})$

Figura 2.10 -Esquema simplificado do tunelamento assistido por armadilhas.........46

Figura 2.11 - Representação esquemática de células solares de junção PN...........49

Figura 2.12 - Curvas IxV em célula solar de junção PN medida no escuro e em ambiente iluminado.

Figura 2.13 - Curvas IxV e PxV em módulo de uma célula solar típica sob iluminação. 51

Figura 2.14-Corte transversal da célula solar MOS com $\mathrm{SiO} \times \mathrm{N}_{\mathrm{y}}$ .52

Figura 2.15-Densidade de Corrente $x$ tensão de porta em uma célula solar MOS (amostra 866) produzida com óxido de porta dentro da banda 1,0-1,5nm, sob iluminação padrão que simula a energia luminosa média incidente 
do sol segundo o padrão AM1,5 (12,6 a 15,1 mW/cm²) comparada à uma célula solar de junção PN fabricada pela NASA também iluminada na mesma condição. .54

Figura 3.1 - Esquema do forno convencional adaptado para o processamento térmico rápido $(\mathrm{RTP})$. .56

Figura 3.2 - (a) controlador universal NOVUS N1100-485 e (b) conexões indicadas no painel traseiro. .60

Figura 3.3 - Representação esquemática adotada do setup empregado para obtenção dos perfis de temperatura.

Figura 3.4 - Imagem TEM transversal de uma amostra de oxinitreto de silício com espessura física de 2,2nm.

Figura 3.5 - Esquema de evaporação térmica para formação da área de porta dos capacitores MOS

Figura 3.6 - Estrutura física dos capacitores MOS.

Figura 3.7 - Desenho esquemático do equipamento de medida CV para capacitores MOS.

Figura 3.8 - Desenho esquemático do equipamento de medida IV para células solares MOS.

Figura 3.9 - Espectros típicos de emissão da lâmpada LED (a) e lâmpada halógena comparada ao espectro solar sem influência da atmosfera (b). 72

Figura 4.1 - Ilustração do deslocamento do tubo de quartzo em $10 \mathrm{~cm}$ para fora em relação ao banco de resistências. .75

Figura 4.2 - Imagem ampliada do perfil de temperatura para 80s de tempo de processo nas temperaturas de $700^{\circ} \mathrm{C}$ e $850^{\circ} \mathrm{C}$ nas situações sem deslocamento do tubo de quartzo ( $\mathrm{a}$ e b) e com deslocamento do tubo de quartzo (c e d), respectivamente. .76

Figura 4.3 - Medidas de temperatura a 90\% da subida (medida a partir do momento em que a amostra é posicionada no centro do forno), considerando o tubo de quartzo nas situações sem deslocamento e com deslocamento de $10 \mathrm{~cm}$, para: a) $700^{\circ} \mathrm{C} \mathrm{e} \mathrm{b)} 850^{\circ} \mathrm{C}$. .78

Figura 4.4 - Perfis temporais de temperatura para o forno pré-aquecido a $1150^{\circ} \mathrm{C}$, tubo de quartzo com deslocamento de $10 \mathrm{~cm}$ e tempo de processo 
equivalente 70 s, com saída: a) rápida (normal - realizada em $5 \mathrm{~s}$ ) ou b) lenta $(\mathrm{L})$.

Figura 4.5 - Medidas de tempo de subida e descida para o forno pré-aquecido a 1150 ${ }^{\circ} \mathrm{C}$. .80

Figura 4.6 - Comparação entre as espessuras das amostras do G2 (a) com o grupo G3 (b), obtidas a 700 e $850^{\circ} \mathrm{C}$

Figura 4.7 - Imagens de AFM nos modos contato (a) e contato intermitente (b) da superfície da amostra G3-700-10.

Figura 4.8 - Rugosidade RMS em função do tempo de processo para 700 e $850^{\circ} \mathrm{C}$

Figura 4.9 - Espectro XPS para a lâmina oxinitretada na temperatura de $850^{\circ} \mathrm{C}$ onde estão indicados os picos correspondentes às ligações $\mathrm{N}-\mathrm{O}$ e SiO. .88

Figura 4.10 -Curvas CV com características típicas de capacitores MOS produzidos em ambiente misto com diferentes proporções de $\mathrm{N}_{2}: \mathrm{O}_{2}$ e diferentes áreas de porta $\left(A_{g 1}=2,12 \times 10^{-2} \mathrm{~cm}^{2}\right.$ e $A_{g 2}=(250 \times 250) \mu m^{2}=6,25 \times 10^{-}$ $\left.{ }^{4} \mathrm{~cm}^{2}\right)$ .92

Figura 4.11 -Curvas $\mathrm{JxV}_{\mathrm{G}}$ com características típicas de células solares MOS sem luz (a) e sob iluminação (b) de lâmpada halógena $\left(105,7 \mathrm{~mW} / \mathrm{cm}^{2}\right) \mathrm{com}$ diversos tempos de processamento e geometria 50x100 e desenho esquemático da região de depleção formada devido aos centros $\mathrm{K}$ positivamente carregados com $Q_{i}(c)$

Figura 4.12-Curvas $\mathrm{JxV}_{\mathrm{G}}$ utilizando luz halógena para diversos tempos de processamento e geometrias: a) $50 \times 50$; b) $50 \times 100$; c) $100 \times 100$ e; d) $100 \times 150$

Figura 4.13 -Curvas $\mathrm{JxV}_{\mathrm{G}}$ utilizando a fonte luminosa halógena posicionada a 3, 6 e $9 \mathrm{~cm}$ da célula solar, para diversos tempos de processamento e

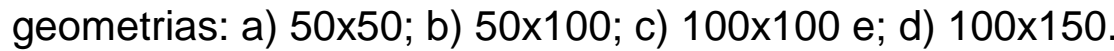
101

Figura 4.14 -PGmáx médio em função das dimensões da célula a) "L" e b) "D”, e c) da distância célula-lâmpada........................................................102

Figura 4.15 -PGmáx versus Pin (potência incidente) ........................................103 
Figura 4.16 -Curvas $\mathrm{JxV}_{\mathrm{G}}$ típicas utilizando lâmpada halógena como fonte luminosa a 6 e $9 \mathrm{~cm}$ da célula solar, com geometria $50 \times 100$ e tempos de processamento: a) $10 \mathrm{~s} \mathrm{e}$; b) $80 \mathrm{~s}$ .104

Figura 4.17-Curvas $\mathrm{JxV}_{\mathrm{G}}$ típicas para células MOS processadas por 10s (RTP adaptado) e Rap. (forno convencional) utilizando lâmpada halógena distante em $3 \mathrm{~cm}$ da célula solar, para diversas geometrias: a) 50x50; b) 50×100; c) $100 \times 100$ e; d) $100 \times 150$ 105

Figura 4.18 -Curvas $\mathrm{Jx} \mathrm{V}_{\mathrm{G}}$ típicas de célula solar MOS produzida por 80 s distante em $3 \mathrm{~cm}$ da fonte de luz (halógena ou led), para resistividade do substrato dentro das faixas de $0,2-1$ e $1-10 \Omega \mathrm{cm}$, para diversas geometrias: a)

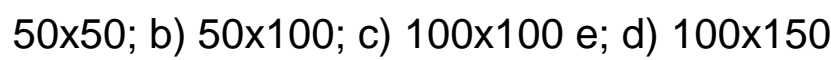
106 


\section{LISTA DE TABELAS}

Tabela 3.1 - Geometria das células solares MOS: largura de linha (L), distância entre linhas $(D)$, número de linhas $\left(N^{\circ} L\right)$, área $\left(A_{g}\right)$ e perímetro.

Tabela 3.2 - Intensidade radiante incidente por unidade de área () para lâmpada halógena $(d=3,6,9 \mathrm{~cm})$ e para a lâmpada LED branca $(d=3 \mathrm{~cm}) \ldots . . .73$

Tabela 4.1 - Temperaturas medidas na entrada do forno, a 90\% da rampa de subida do processo (centro) e novamente na entrada do forno após a saída da lâmina, estando o forno pré-aquecido a 700 ou $850^{\circ} \mathrm{C}$, para o tubo de quartzo sem deslocamento.

Tabela 4.2 - Temperaturas medidas na entrada do forno, a 90\% da rampa de subida do processo (centro) e no novamente na entrada do forno após a saída da lâmina, estando o forno pré-aquecido a 700 ou $850^{\circ} \mathrm{C}$, para o tubo de quartzo com deslocamento de $10 \mathrm{~cm}$ .77

Tabela 4.3 - Temperaturas medidas na entrada do forno, a $90 \%$ da rampa de processo (centro) e na entrada do forno após a saída da lâmina com termopar, com tubo de quartzo deslocado de $10 \mathrm{~cm}$ e sem deslocamento .80

Tabela 4.4 - Espessura média: G1 (teste) .82

Tabela 4.5 - Espessura média: G2 (tubo de quartzo sem deslocamento). 83

Tabela 4.6 - Espessura média de lâminas produzidas a 700 ou $850^{\circ} \mathrm{C}$ : amostras G3 (com deslocamento na boca do forno).

Tabela 4.7-Espessura média de lâminas produzidas a $1150^{\circ} \mathrm{C}$ em diversas condições gasosas: amostras G3 (com deslocamento na boca do forno).

Tabela 4.8 - Porcentagens atômicas de Si $2 p, 0$ 1s, N 1s, Si ${ }^{4+}$. e O-Si-O juntamente com o cálculo da relação $\mathrm{Si} / \mathrm{O}$

Tabela 4.9 - Espessuras médias das amostras oxidadas no forno RTP adaptado e convencional em função do tempo de processo

Tabela 4.10 - Potência gerada máxima ( $\left.P_{G m a ́ x}\right)$, densidade de corrente $\left(\mathrm{J}_{\mathrm{m}}\right)$ e tensão de porta $\left(V_{m}\right)$ no ponto de máximo da potência, em função das distâncias da lâmpada halógena em relação à célula solar $(3,6$ e $9 \mathrm{~cm})$. 


\section{LISTA DE ABREVIATURAS}

AFM

AM

Al

$\mathrm{Ar}$

BBT

BTT

$\mathrm{Cl}$

CV

DI

$\mathrm{F} 1$

F2

F3

F4

G1

G2

G3

$\mathrm{HCl}$

$\mathrm{HF}$

$\mathrm{H}_{2}$

$\mathrm{H}_{2} \mathrm{O}$

$\mathrm{H}_{2} \mathrm{O}_{2}$

IF-USP

IQ-UNESP

IV

JBBT

JBTT

JSRH

JV

LAMFI

LED

LEFE
Atomic Force Microscopy ou Microscopia de força atômica

Massa de ar padrão para luminosidade incidente em células solares

Alumínio

Argônio

Mecanismo de tunelamento de banda a banda (Band To Band)

Mecanismo de tunelamento de banda a armadilha (Band To Trap)

Circuito Integrado

Capacitância x tensão

Deionizada

Fluxo de espécies oxidantes na interface ambiente/óxido

Fluxo de espécies oxidantes atravessando a cama de óxido

Fluxo de espécies oxidantes chegando na interface óxido/substrato

Fluxo responsável pelo início do crescimento na oxidação rápida

Grupo 1 - amostras teste

Grupo 2 - amostras sem deslocamento na boca do forno

Grupo 3 - amostras com deslocamento na boca do forno

Ácido Clorídrico

Ácido Fluorídrico

Hidrogênio

Água

Peróxido de Hidrogênio

Instituto de Física da Universidade de São Paulo

Instituto de Química da Universidade Estadual de São Paulo

Corrente $\mathrm{x}$ tensão

Densidade de corrente de tunelamento de banda a banda

Densidade de corrente de tunelamento de banda a armadilha

Densidade de corrente do modelo Shockley-Read-Hall

Densidade-de-corrente $\mathrm{x}$ tensão

Laboratório de Análise de Materiais por Feixe lônico

Light Emission Diode ou Diodo emissor de luz

Laboratório de Espectroscopia de Fotoelétrons 
LFF Laboratório de Filmes Finos

LPD Liquid Phase Deposition ou Deposição em fase líquida

LSI Laboratório de Sistemas Integrados

MOS Metal-Óxido-Semicondutor

$\mathrm{N}_{2} \quad$ Nitrogênio

$\mathrm{NH}_{4} \mathrm{OH} \quad$ Hidróxido de Amônia

$\mathrm{O}_{2} \quad$ Oxigênio

RCA Radio Corporation of America - limpeza padrão dos laboratórios RCA

RMS Root Mean Square ou valor médio quadrático

RTP Rapid Thermal Processing ou Processamento térmico rápido

$\mathrm{SRH} \quad$ Mecanismo de tunelamento Shockley-Read-Hall

Si Silício

$\mathrm{SiO}_{2} \quad$ Óxido de silício

$\mathrm{SiO}_{\mathrm{x}} \mathrm{N}_{\mathrm{y}} \quad$ Óxido nitreto de silício

TEM Transmission Electron Microscopy ou Microscopia Eletrônica de Transmissão

XPS X-ray Photoelectron Spectroscopy ou Espectroscopia de raios-X por emissão de fotoelétrons 


\section{LISTA DE SÍMBOLOS}

\begin{tabular}{|c|c|c|}
\hline$A_{g}$ & $\mathrm{~cm}^{2}$ & Área do Capacitor \\
\hline $\mathrm{B} / \mathrm{A}$ & & Constante de crescimento linear do modelo Deal-Grove \\
\hline B & & Constante de crescimento parabólico do modelo Deal-Grove \\
\hline$d$ & $\mathrm{~cm}$ & Distância entre fonte luminosa e célula solar MOS \\
\hline$C^{*}$ & $\mathrm{~cm}^{-3}$ & Concentração de oxigênio na interface $\mathrm{Si} / \mathrm{SiO}_{2}$ \\
\hline $\mathrm{C}_{0}$ & $\mathrm{~cm}^{-3}$ & Concentração intrínseca de oxigênio no silício \\
\hline D & $\mu \mathrm{m}$ & Distância entre linhas \\
\hline Dox & $\mu \mathrm{m}$ & Coeficiente de difusão de oxigênio durante a oxidação térmica \\
\hline$E_{c}$ & $\mathrm{eV}$ & Energia do Nível de Condução \\
\hline $\mathrm{E}_{\mathrm{I}}$ & $\mathrm{eV}$ & Energia do Nível Intrínseco \\
\hline$E_{g}$ & $\mathrm{eV}$ & Energia da Faixa Proibida \\
\hline Ет & $\mathrm{eV}$ & Energia do Nível de Trap \\
\hline Ev & $\mathrm{eV}$ & Energia do Nível de Valência \\
\hline \multirow[t]{2}{*}{$f$} & $\mathrm{~Hz}$ & Frequência do Equipamento Utilizado para Medição de \\
\hline & & Capacitância e Condutância \\
\hline $\mathrm{F}$ & $\mathrm{V} / \mathrm{cm}$ & Campo elétrico local no silício \\
\hline FF & & Fator de preenchimento em células solares \\
\hline $\mathrm{F}_{\mathrm{N}}$ & & Fator de normalização do tempo de processo \\
\hline $\mathrm{Fsi}_{\mathrm{Si}}$ & $\mathrm{V} / \mathrm{cm}$ & Campo elétrico na região de depleção \\
\hline$G_{\text {trap }}$ & & Taxa de geração de portadores nas armadilhas \\
\hline$G_{\text {Dit }}$ & & Taxa de geração de portadores via estados de interface \\
\hline $\mathrm{h}$ & J.s & Constante de Planck \\
\hline lo & $\mathrm{W} / \mathrm{cm}^{2}$ & Intensidade radiante incidente sobre a célula solar \\
\hline J & $\mathrm{A} / \mathrm{cm}^{2}$ & Densidade de Corrente \\
\hline Jsc & $\mathrm{A} / \mathrm{cm}^{2}$ & Densidade de Corrente de curto-circuito \\
\hline Jun & $\mathrm{A} / \mathrm{cm}^{2}$ & Densidade de Corrente de tunelamento \\
\hline $\mathrm{K}_{\Gamma}$ & & Constante da taxa de reação volumétrica $\left(\mathrm{V}_{\Gamma}=\mathrm{k}_{\Gamma} . \mathrm{C}\right)$ \\
\hline $\mathrm{K}^{0}$ & & Centro $\mathrm{K}$ neutro quando ocupado por um elétron \\
\hline $\mathrm{K}^{+}$ & & Centro K positivo quando desocupado \\
\hline $\mathrm{K}^{-}$ & & Centro K negativo quando ocupado por dois elétron \\
\hline$L$ & $\mu \mathrm{m}$ & Largura de linha \\
\hline
\end{tabular}




\begin{tabular}{|c|c|c|}
\hline $\mathrm{m}$ & $g$ & Massa Efetiva do Portador \\
\hline $\mathrm{m}^{*}$ & $g$ & Massa Efetiva do Elétron \\
\hline $\mathrm{n}$ & $\mathrm{cm}^{-3}$ & Concentração de Elétrons \\
\hline$n_{i}$ & $\mathrm{~cm}^{-3}$ & Concentração Intrínseca de Portadores \\
\hline $\mathrm{N}_{\mathrm{c}}$ & $\mathrm{cm}^{-3}$ & Densidade de Estados de Saturação no Nível de Condução \\
\hline $\mathrm{N} v$ & $\mathrm{~cm}^{-3}$ & Densidade de Estados de Saturação no Nível de Valência \\
\hline $\mathrm{N}_{\mathrm{t}}$ & $\mathrm{cm}^{-2}$ & Concentração de Traps \\
\hline $\mathrm{N}_{1}$ & & $\begin{array}{l}\text { Número de moléculas oxidantes incorporadas por unidade de } \\
\text { volume na camada } R_{D}\end{array}$ \\
\hline $\mathrm{p}$ & $\mathrm{cm}^{-3}$ & Concentração de Lacunas \\
\hline $\mathrm{P}(\mathrm{Si})$ & & Integração da taxa de tunelamento por toda a região de depleção \\
\hline$P_{\text {in }}$ & $\mathrm{W} / \mathrm{cm}^{2}$ & Potência incidente \\
\hline q & $\mathrm{C}$ & Carga do Elétron \\
\hline $\mathrm{R}_{\mathrm{D}}$ & & Taxa de reação enriquecida na interface $\mathrm{Si} / \mathrm{SiO}_{2}$ \\
\hline $\mathrm{t}$ & $\mathrm{s}$ & Tempo de crescimento do óxido \\
\hline $\mathrm{T}$ & ${ }^{\circ} \mathrm{C}$ & Temperatura \\
\hline$V_{\text {th }}$ & $\mathrm{cm} / \mathrm{s}$ & Velocidade Térmica \\
\hline$U$ & & Taxa de geração de pares elétron-lacuna na região de depleção \\
\hline$U_{\text {Dit }}$ & & $\begin{array}{l}\text { Taxa de geração de pares elétron-lacuna via estados de } \\
\text { interface }\end{array}$ \\
\hline$U_{\text {SRH }}$ & & Taxa de geração convencional do modelo SRH \\
\hline$V(\lambda)$ & $\mathrm{V}$ & Tensão proveniente da luminosidade monocromática \\
\hline $\mathrm{V}_{\mathrm{FB}}$ & $\mathrm{V}$ & Tensão de Faixa Plana \\
\hline$V_{G}$ & $\mathrm{~V}$ & Tensão de Porta \\
\hline Voc & $\mathrm{V}$ & Tensão de circuito aberto \\
\hline Vox & $\mathrm{V}$ & Tensão no Óxido de Porta \\
\hline Xo & $\mathrm{nm}$ & Espessura do óxido crescido termicamente (Deal-Grove) \\
\hline$x_{i}$ & $\mathrm{~nm}$ & Espessura inicial de crescimento do óxido (Murali-Murarka) \\
\hline W & $\mu \mathrm{m}$ & Largura da Região de Depleção Profunda \\
\hline$\delta$ & $\mathrm{nm}$ & $\begin{array}{l}\text { Espessura da camada gasosa rica em oxigênio no início do } \\
\text { crescimento de filmes com espessura inferior a } 3 \mathrm{~nm}\end{array}$ \\
\hline$\Delta \lambda$ & $\mathrm{nm}$ & Faixa de comprimento de onda emitido pela fonte luminosa \\
\hline$\eta$ & $\%$ & Eficiência em conversão de energia luminosa para energia \\
\hline
\end{tabular}


elétrica

$\lambda \quad \mathrm{nm} \quad$ Comprimento de onda

s Tempo de validade do modelo Deal-Grove

$\tau_{n}$

s $\quad$ Tempo de Vida dos Elétrons

$\tau_{p}$

s Tempo de Vida das Lacunas

$\sigma_{p} \quad \mathrm{~cm}^{2} \quad$ Seção Transversal de Captura de Traps por Lacuna

бn

cm $^{2} \quad$ Seção Transversal de Captura de Traps por Elétrons 


\section{SUMÁRIO}

1. INTRODUÇÃO

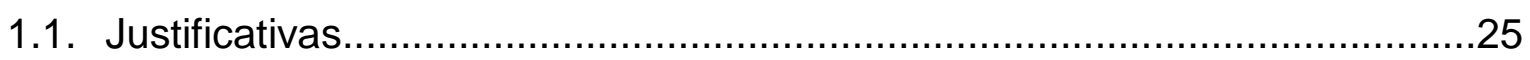

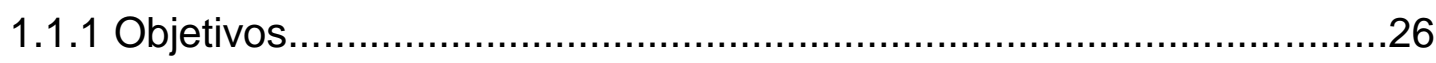

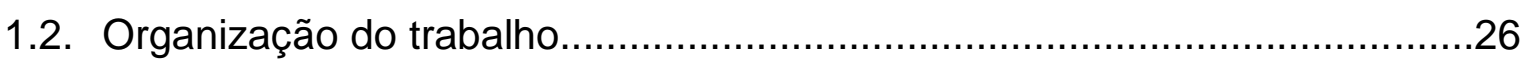

2. REVISÃO SOBRE TECNOLOGIA DE OBTENÇÃO DE ÓXIDOS DE PORTA PARA CÉLULAS SOLARES MOS E MECANISMOS DE TUNELAMENTO..........28

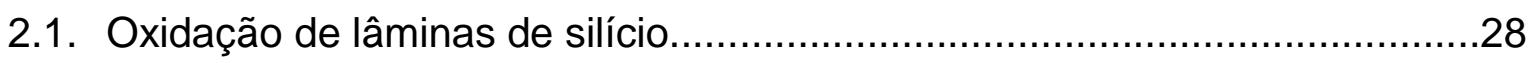

2.1.1. Os tipos de oxidação térmica.......................................................29

2.1.2. Oxidação por Processamento Térmico Rápido (RTP)......................32

2.1.3. Cinética de oxidação térmica........................................................34

2.2 Mecanismos de geração de portadores.................................................... 40

2.2.1. Tunelamento Shochkley-Read-Hall (SRH)...................................41

2.2.2. Tunelamento de banda a armadilha (Band-to-Traps ou BTT).........43

2.2.3. Tunelamento de banda a banda (Band-to-Band ou BBT)...............44

2.3. Tunelamento assistido por armadilhas.......................................................

2.4. Armadilhas associadas à incorporação de nitrogênio no dielétrico de porta.. 47

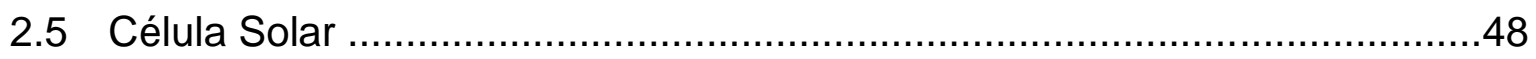

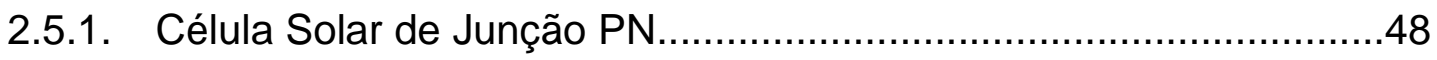

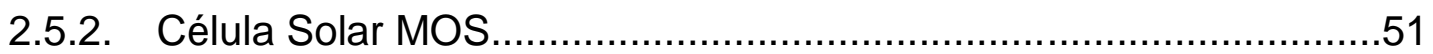

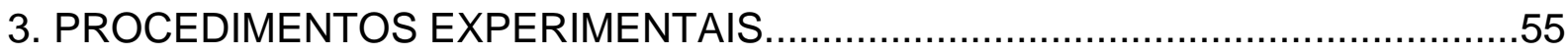

3.1. Adaptação de um equipamento de oxidação térmica convencional para processamento térmico rápido (RTP).

3.1.1. Adaptações de um forno convencional para realizar o processamento

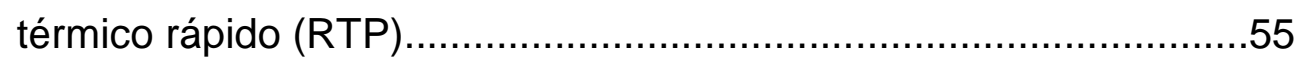

3.1.2. Preparo das amostras e oxidação por RTP...................................57

3.1.2.1. Oxidação térmica convencional e rápida............................59

3.1.3. Medida de temperatura no substrato de $\mathrm{Si}$ durante o processo

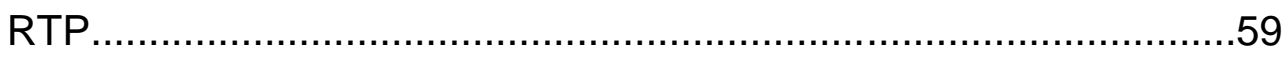

3.1.4. Espessura, microrugosidade e concentração de $\mathrm{N}_{2} \ldots \ldots \ldots \ldots \ldots \ldots \ldots \ldots \ldots . . . . .61$

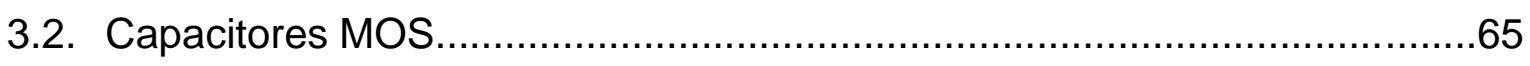

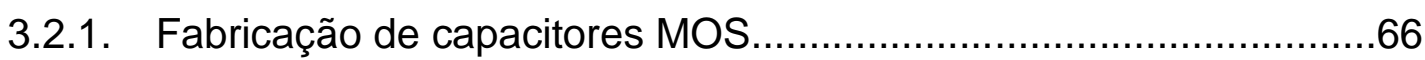


3.2.2. Medidas elétricas em capacitores MOS........................................68

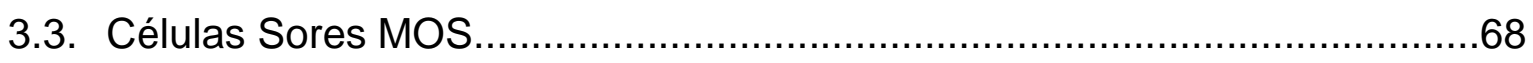

3.3.1. Fabricação das células solares MOS............................................69

3.3.2. Caracterização das células solares MOS......................................70

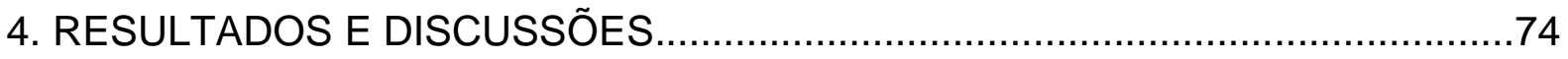

4.1. Extração dos perfis temporais de temperatura durante os processos RTP

4.2. Resultados da espessura dos oxinitretos crescidos em função da temperatura

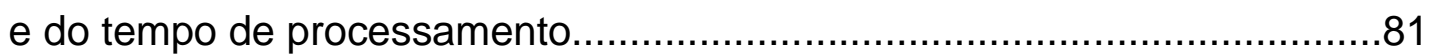

4.2.1. Grupo 1 (G1): Testes iniciais de oxidação........................................

4.2.2. Grupo 2 (G2): Oxinitretação (tubo de quartzo sem deslocamento)..82 4.2.3. Grupo 3 (G3): Oxinitretação (tubo de quartzo deslocado em

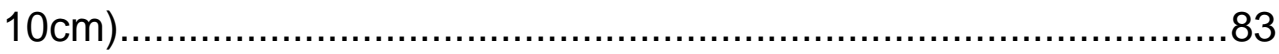

4.3. Obtenção da concentração de nitrogênio nos oxinitretos de silício...............88

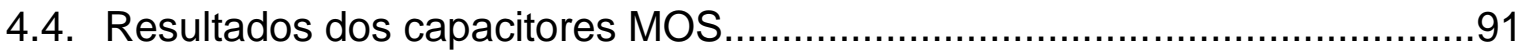

4.5. Resultados das células solares MOS fabricadas.........................................94

5. CONCLUSÕES E PERSPECTIVAS FUTURAS........................................107

5.1. Conclusões sobre a obtenção de oxinitretos crescidos por processamento térmico rápido. 107

5.2. Conclusões sobre os capacitores MOS...............................................108

5.3. Conclusões sobre as células solares MOS operando no modo inversão

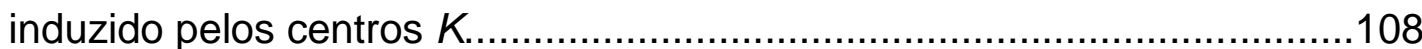

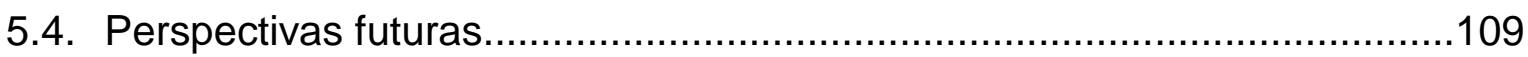

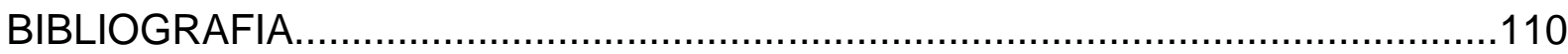

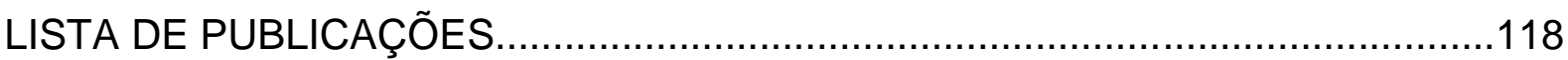




\section{INTRODUÇÃO}

Nos dias atuais, não se pode pensar no desenvolvimento de uma nação sem considerar a sustentabilidade em suas mais variadas formas. Com isso, o crescimento na demanda energética mundial implica na preocupação constante quanto à redução dos poluentes lançados na atmosfera, associados às fontes de energia nãorenováveis, geralmente devido à queima de material fóssil (SYNERGYST, 2009; SWANSON, 2006).

Dados do Ministério de Minas e Energia do Brasil apontam que, em 2015, na matriz energética mundial havia a utilização de apenas $14,2 \%$ de fontes renováveis, enquanto que, no Brasil, esse índice era de 41,2\% (figura 1). Estes indicadores acentuam a importância da pesquisa e desenvolvimento com relação à geração de energia utilizando fontes de energia renováveis convencionais e alternativas, como por exemplo, a energia solar fotovoltaica a qual é pouco explorada no país (Ministério de Minas e Energia, 2016).

Figura 1.1 - Geração de energia no Brasil em porcentagem.
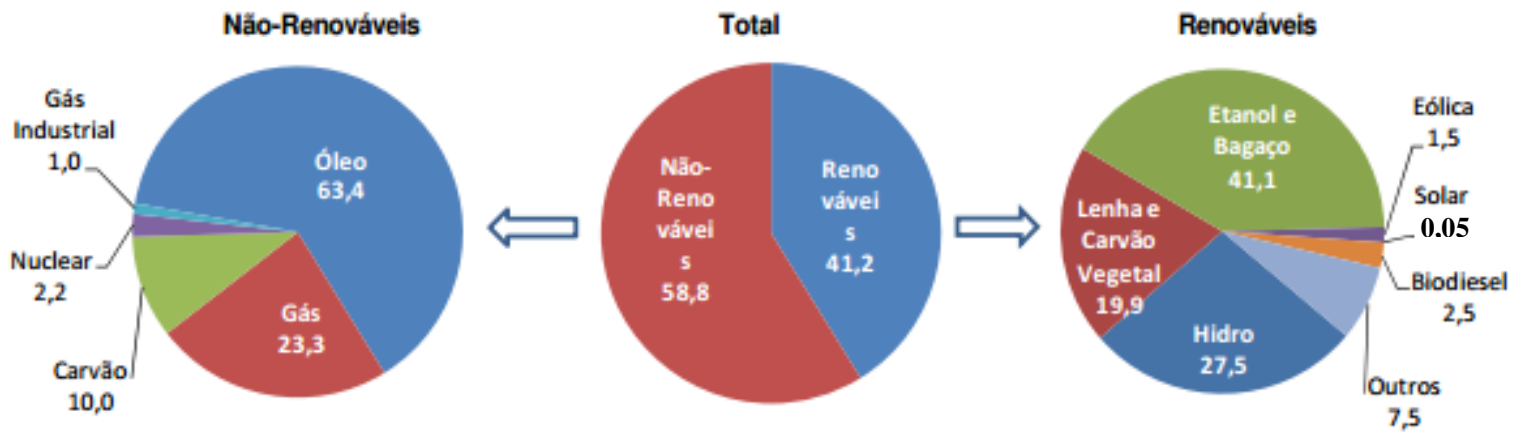

Fonte - Adaptado (Ministério de Minas e Energia, 2016).

A produção de energia solar fotovoltaica não se apresenta competitiva quando comparada à energia elétrica convencional, proveniente de usinas hidrelétricas, a qual pode ter impactos ambientais consideráveis, mas que em geral são desconsiderados. Esta perspectiva vem se alterando significativamente em alguns países nos últimos anos devido às políticas de incentivo no sentido de que os sistemas fotovoltaicos conectados à rede elétrica (sistemas on-grid) recebam subsídios governamentais. 
Os principais mercados de energia fotovoltaica mundial compreendem países da Europa (Alemanha, Espanha e Itália), da Ásia (China e Japão), da África do Sul e os Estados Unidos da América (IEA PVPS, 2015). No Brasil, devido à sua vasta extensão territorial, a geração de energia fotovoltaica tem estado centrada no atendimento de localidades isoladas, distantes dos locais de geração de energia elétrica convencional e comunidades carentes (GALDINO, 2006), mas recentemente, têm ocorrido diversas iniciativas no sentido de aumentar a sua participação na matriz energética incluindo incentivos federais (SCHMELA, 2016).

Atualmente, o "SolarPower Europe", um dos órgãos que representa a Associação Industrial Fotovoltaica da Europa, publicou algumas perspectivas gerais para o mercado global de energia fotovoltaica até o ano de 2020 (figura 1.2) as quais apontam que o Brasil atingirá um crescimento de geração fotovoltaica de $149 \%$, estimando sua capacidade total média de produção em 6.509 MW (SCHMELA, 2016). 
Figura 1.2 - Perspectivas do mercado de energia solar fotovoltaica de 2016-2020.

\begin{tabular}{|c|c|c|c|c|}
\hline & $\begin{array}{c}2015 \\
\text { Capacidade Total } \\
\text { (MW) }\end{array}$ & $\begin{array}{l}2020 \\
\text { Estimativa da Capacidade } \\
\text { Total Media (MW) }\end{array}$ & $\begin{array}{c}2016-2020 \\
\text { Nova Capacidade } \\
\text { (MW) }\end{array}$ & $\begin{array}{c}2016-2020 \\
\text { Taxa de Crescimento } \\
\text { Anual (MW) }\end{array}$ \\
\hline China & 43,381 & 130,381 & 87,000 & $25 \%$ \\
\hline USA & 25,910 & 85,310 & 59,400 & $27 \%$ \\
\hline India & 5,048 & 57,398 & 52,350 & $63 \%$ \\
\hline Japan & 34,347 & 63,347 & 29,000 & $13 \%$ \\
\hline Pakistan & 610 & 9,985 & 9,375 & $75 \%$ \\
\hline Mexico & 205 & 9,080 & 8,875 & $114 \%$ \\
\hline Australia & 5,093 & 12,248 & 7,155 & $19 \%$ \\
\hline Brasil & 69 & 6,509 & 6,440 & $149 \%$ \\
\hline Korea & 3,421 & 9,821 & 6,400 & $23 \%$ \\
\hline Egypt & 16 & 4,859 & 4,843 & $2149 \%$ \\
\hline Philippines & 156 & 3,956 & 3,800 & $91 \%$ \\
\hline Canada & 2,371 & 6,056 & 3,685 & $21 \%$ \\
\hline Chile & 854 & 4,509 & 3,655 & $39 \%$ \\
\hline Thailand & 1,444 & 4,654 & 3,210 & $26 \%$ \\
\hline Algeria & 268 & 3,053 & 2,785 & $63 \%$ \\
\hline Taiwan & 1,176 & 3,726 & 2,550 & $26 \%$ \\
\hline South Africa & 1,122 & 3,457 & 2,335 & $25 \%$ \\
\hline Saudi Arabia & 100 & 2,285 & 2,185 & $87 \%$ \\
\hline UAE & 24 & 1,786 & 1,763 & $138 \%$ \\
\hline Israel & 870 & 2,220 & 1,350 & $21 \%$ \\
\hline
\end{tabular}

Fonte: Adaptado (SCHMELA, 2016).

Como consequência da expansão do mercado fotovoltaico verifica-se atualmente um avanço significativo de pesquisas e de novas tecnologias associadas a uma considerável redução dos custos de produção (IEA PVPS, 2015). No geral, os custos de fabricação de um painel fotovoltaico convencional dependem do método de fabricação da junção $\mathrm{PN}$, do tipo de substrato - cerca de $90 \%$ silício do tipo multicristalino (mc-Si, 53\%) ou monocristalino (c-Si, 37\%) - e do quanto se deseja alcançar de eficiência em conversão de energia (CUEVAS, 2004; DHANDA, 2017).

Por outro lado, como apontado por Schmela (2016), a energia solar fotovoltaica não abrange exclusivamente os painéis fotovoltaicos utilizados na geração de energia elétrica para a alimentação de sistemas isolados ou para sistemas fotovoltaicos 
conectados à rede elétrica (SCHMELA, 2016). O conceito de energia solar fotovoltaica pode ser empregado em algumas aplicações específicas, como por exemplo, Energy Harvesting, (tradução literal: "colheita de energia"), que pode ser definida como a aquisição de energia elétrica através da conversão de energia em diferentes níveis luminosos proveniente de ambientes interiores ou exteriores, podendo ser utilizados painéis, convencionais ou não.

Sistemas fotovoltaicos convencionais podem ser definidos como aqueles que permanecem expostos ao ambiente exterior e convertem a energia solar em energia elétrica. Enquanto que, as células solares não convencionais, são aquelas que respondem às energias luminosas menos intensas podendo converter inclusive a energia de espectros abaixo do visível em torno de 300nm (perto do ultravioleta) ou em torno de $1100 \mathrm{~nm}$ (perto do infravermelho) e, assim, esses sistemas não convencionais poderiam ser empregadas, tanto em ambientes internos como em ambientes externos. Existem também células solares não convencionais que podem ser fabricadas em substratos amorfos com resposta espectral mais próxima da faixa visível de 300 a 600nm sendo também apropriadas para uso em ambientes internos (EVANCZUK, 2015).

A figura 1.3 ilustra as faixas típicas de potência produzidas em diversos tipos de ambientes (loja de departamento, supermercado, sala de reuniões, escritório, armazém, etc.), sendo possível a obtenção de densidades de corrente desde valores mais baixos do que os praticados para as células convencionais. As possíveis aplicações para células solares não convencionais incluem a alimentação de sistemas integrados miniaturizados subcutâneos, circuitos de marca-passos (BEREUTER, 2016), circuitos eletrônicos para casas inteligentes (TANABE, 2013) ou, até mesmo para o monitoramento de banco de dados (MATHEWS, 2015). 
Figura 1.3 - Potência luminosa em ambientes fechados.

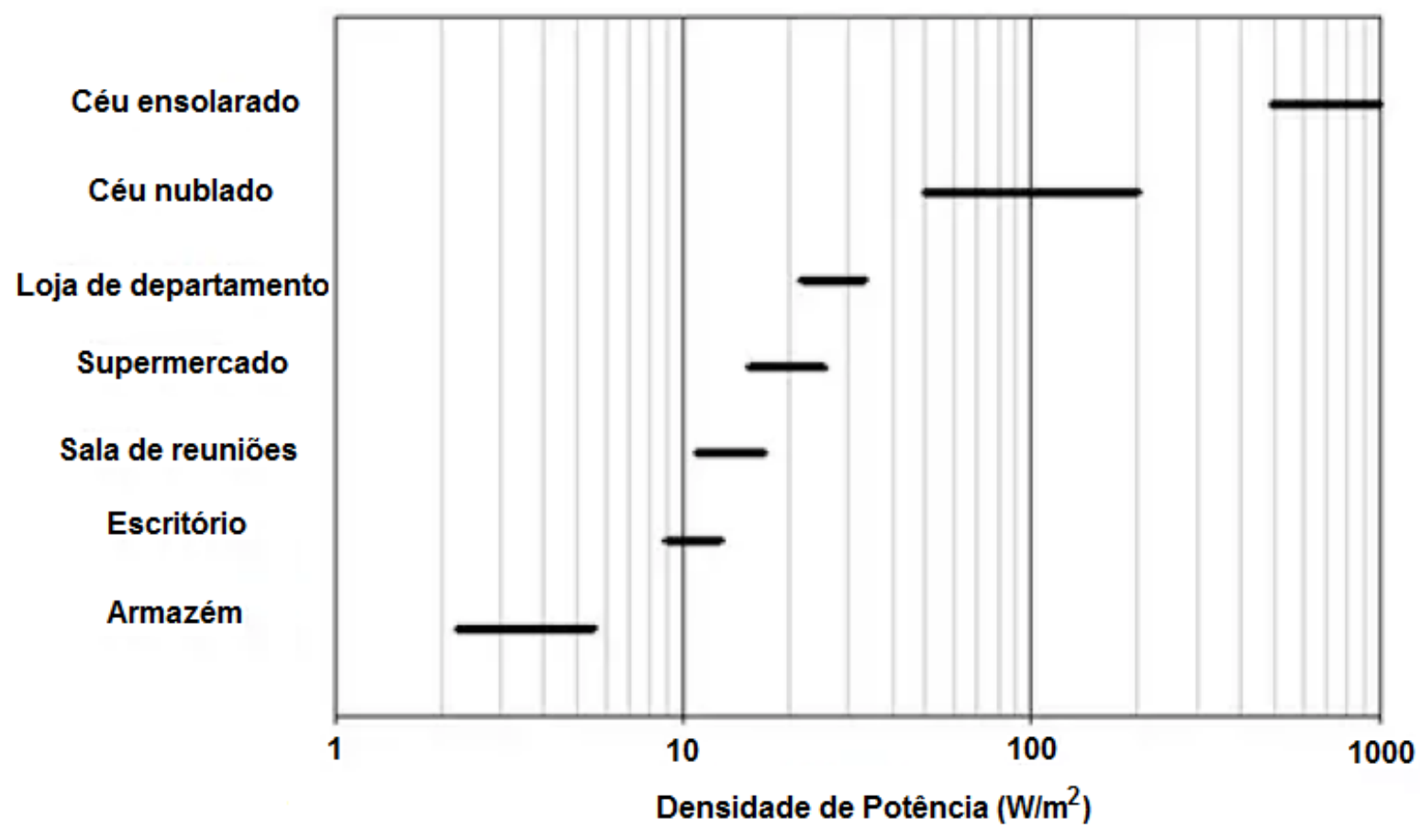

Fonte: Adaptado (EVANCZUK, 2015).

As células solares não convencionais podem ser construídas utilizando a tecnologia MOS (Metal-Óxido-Semicondutor), por apresentarem simplicidade de fabricação e um baixo custo associado (CHEN, 2002). O método de fabricação baseia-se na utilização de um filme óxido isolante muito fino, da ordem de $2 \mathrm{~nm}$, entre metal e semicondutor de forma que a corrente de tunelamento seja suficientemente alta para algumas aplicações específicas (SHEWCHUN, 1997).

Entretanto, diversos parâmetros importantes devem ser considerados na obtenção dos filmes de óxido ultrafinos, incluindo em primeiro lugar o controle da qualidade e, em segundo lugar, o controle da uniformidade em espessura. A qualidade de fabricação, por sua vez, costuma estar associada a um controle adequado da contaminação por metais $\left(<1 \times 10^{10} \mathrm{~cm}^{-2}\right)$ e por material particulado $\left(<10 / \mathrm{cm}^{2}\right)$ durante o processo de obtenção desses óxidos (SANTOS, 1996; 1995; 1995(b)).

As etapas de limpeza química de superfícies de metais e semicondutores são de fundamental importância na fabricação de células solares MOS de alta eficiência (CHEN, 2002; SANTOS, 1996). É importante conhecer e controlar a evolução das superfícies de silício ao longo das diversas etapas de limpeza e de processamento 
sob o ponto de vista tanto de contaminação metálica superficial como também de terminação superficial (sítios, ligações químicas e rugosidade) (KERN, 1970; 1990; 1991; HEYNS, 1991; 1994). A contaminação metálica superficial não devidamente removida das lâminas de silício contribui para, na maioria dos casos, deteriorar o rendimento de fabricação dos óxidos ultrafinos (SANTOS, 1995). Observa-se na literatura que o tipo de acabamento superficial influi diretamente na cinética da oxidação do silício, nos mecanismos de ruptura da rigidez dielétrica e nos mecanismos de fuga e tunelamento (SANTOS, 1996).

As técnicas de deposição em fase líquida (LPD: Liquid-Phase Deposition) (YEH, 1994; 1995) e oxidação anódica (CHEN, 2002) tem sido empregadas como métodos de preparação de óxido de silício para células solares MOS. No entanto, no caso LPD, o tempo de preparação é longo e não existe um controle exato da espessura (CHEN, 2002; YEH, 1994; 1995). Já no caso da oxidação anódica, apesar do tempo de preparação ser, substancialmente, menor, a qualidade dos óxidos obtidos depende do banho empregado durante o crescimento anódico e dos tratamentos térmicos pósmetalização empregados (CHEN, 2002).

A técnica de processamento térmico rápido (RTP: Rapid Thermal Processing) tem sido empregada na difusão de junções $\mathrm{PN}$ e na passivação de superfície em células solares de junção PN resultando em células solares com eficiência próxima de até 18\% (DOSHI, 1998; WEI, 2016). No entanto, pouca atenção tem sido dada para células solares MOS com dielétrico obtido por processamento térmico rápido. Em particular, o RTP e a nitretação térmica rápida (RTN: Rapid Thermal Nitridation) têm sido propostas como processos alternativos à técnica de oxidação térmica convencional para obter óxidos de porta MOS de elevada qualidade com espessuras inferiores a $3 \mathrm{~nm}$ (TOQUETTI, 2005; SANTOS, 1995(c); NULMAN, 1986; MOSLEHI, 1989; CHIOU, 1990; CHANG, 2004; 2004(b); GAVARTI, 2005). 


\subsection{Justificativas}

Haja vista a necessidade da redução de poluentes emitidos no mundo, associados à produção de energia elétrica, é inquestionável que a pesquisa e o desenvolvimento referentes à utilização de fontes renováveis e alternativas para a geração de energia avancem (Ministério de Minas e Energia, 2016). A energia solar fotovoltaica mostrase com amplo potencial de utilização (SCHMELA, 2016), não apenas em ambientes externos, mas inclusive, em ambientes de baixa intensidade luminosa, para aplicações específicas de Energy Harvesting, como por exemplo, a alimentação de circuitos que necessitem de potências da ordem de miliwatts ou microwatts (EVANCZUK, 2015).

Nas células solares MOS, a qualidade do filme dielétrico de porta e a reprodução de seu crescimento são os pontos de maior destaque (DEPAS, 1993). Assim, as características elétricas de oxinitretos e óxidos de silício tornam-os tecnologicamente aplicáveis nesses dispositivos (LU, 1995).

Adicionalmente, Depas (1993) reporta que através de processamento térmico rápido (RTP) é possível obter óxidos de alta qualidade, com espessura e microrugosidade reprodutíveis. Outros autores argumentam sobre os benefícios de acrescentar o nitrogênio durante o crescimento dos dielétricos por RTP, mostrando que uma pequena quantidade de nitrogênio distribuída próximo à interface óxidosemicondutor proporciona melhora na corrente de fuga (diminuição), na resistência à difusão de boro (aumento), além de, também melhorar a reprodutibilidade dos filmes (LU, 1995; BEYER, 1996; YAO, 1994; CHANG, 2004(b)).

Baseado no que foi exposto anteriormente, neste trabalho foram fabricadas células solares MOS, com óxidos de silício com espessura inferior a 3nm, através de processamento térmico rápido em forno de oxidação térmica convencional visando a sua aplicação para Energy Harvesting em condições de baixa intensidade luminosa (locais fechados). 


\subsubsection{Objetivos}

O objetivo geral desse trabalho foi fabricar células solares MOS não convencionais com baixo custo agregado, reprodutíveis e com bom rendimento de conversão para intensidades luminosas comuns em ambientes fechados para aplicação em energy harvesting.

Os objetivos específicos foram:

- estudar os parâmetros de crescimento dos óxidos obtidos por processamento térmico rápido (RTP);

- comparar as características das células solares convencional com as células solares MOS fabricadas e;

- propor a utilização de células solares MOS não convencionais para aplicação em energy harvesting visando à conversão de energia luminosa em energia elétrica dentro de ambientes fechados.

\subsection{Organização do trabalho}

Esta tese de doutorado foi organizada em 5 capítulos onde uma breve descrição de cada um deles foi feita como segue:

Capítulo 2: Revisão Bibliográfica.

Uma revisão bibliográfica foi realizada neste capítulo com intuito de apresentar uma visão geral do processo de oxidação térmica de lâminas de silício. Os tipos de oxidação foram descritos sucintamente: seca, úmida, pirogênica e por processamento térmico rápido (RTP). Uma descrição da estrutura dos fornos utilizados em cada tipo de oxidação foi também exibida. A cinética de crescimento de óxidos em lâminas de silício foi apresentada. Na sequência, foi feita uma descrição dos mecanismos de tunelamento através de filmes finos (espessura < 3nm) e foram apresentadas as características de funcionamento de células solares de junção PN e do tipo MOS. 
Capítulo 3: Parte experimental.

Iniciou com uma apresentação detalhada da estrutura do forno de oxidação térmica convencional que foi adaptado para o processamento térmico rápido. O perfil de temperatura na lâmina de silício durante todo o processo de oxidação também foi descrito neste capítulo. Além disso, foi apresentada a limpeza química empregada (SANTOS, 1996) na fabricação das células solares do tipo MOS. Finalmente, foi apresentada uma descrição detalhada dos procedimentos adotados para a fabricação de capacitores e células solares MOS, incluindo as técnicas de caracterização física e elétrica utilizadas.

Capítulo 4: Análise e discussão dos resultados.

Os resultados experimentais foram apresentados neste capítulo. Primeiramente, delimitou-se à espessura associada a cada condição de crescimento analisada. A questão da incorporação de nitrogênio nos filmes de $\mathrm{SiO}_{2}$ foi abordada, detalhadamente, através da técnica de espectroscopia de raios-X por emissão de fotoelétrons (XPS). A microrugosidade de alguns dos filmes foi obtida por microscopia de força atômica (AFM), discutida e analisada. Segundo, os capacitores MOS foram investigados através de curvas capacitância-tensão. Finalmente, as células solares MOS não convencionais foram analisadas através das curvas densidade de correntetensão, mensuradas em diferentes condições de luminosidade.

Capítulo 5: Conclusões e perspectivas futuras.

As conclusões foram apresentadas em três etapas, a saber: a análise do crescimento dos óxidos de porta, as características de funcionamento de capacitores MOS através de curvas capacitância-tensão e a caracterização das células solares MOS não convencionais através da análise detalhada de curvas corrente-tensão, associando-as a aplicações de conversão de energia luminosa em elétrica para aplicação em Energy Harvesting, especificamente, na alimentação de dispositivos na faixa de miliwatts ou microwatts de potência. Adicionalmente, foram apresentadas algumas perspectivas futuras para realização de possíveis continuações do presente trabalho. 


\section{REVISÃO SOBRE TECNOLOGIA DE OBTENÇÃO DE ÓXIDOS DE PORTA PARA CÉLULAS SOLARES MOS E MECANISMOS DE TUNELAMENTO}

Neste capítulo é apresentada uma revisão bibliográfica sobre a tecnologia de obtenção de óxidos de porta, os mecanismos de tunelamento em óxidos finos (com espessuras inferiores a $3 \mathrm{~nm}$ ) e as características das células solares de junção PN e do tipo MOS.

\subsection{Oxidação de lâminas de silício}

Na microeletrônica, uma etapa de processo amplamente utilizada para a formação de óxido de silício $\left(\mathrm{SiO}_{2}\right)$ é a oxidação térmica convencional. Nesse processo ocorre a reação entre o silício e o oxigênio cuja taxa de crescimento do óxido fica maior à medida que se aumenta a temperatura, tipicamente na faixa de 700 a $1000^{\circ} \mathrm{C}$, em fornos especiais ultra-limpos para evitar a presença de contaminantes (CAMPBELL, 2001).

$\mathrm{O} \mathrm{SiO}_{2}$ é termicamente bastante estável e, por isso, tem sido utilizado amplamente na fabricação de circuitos integrados como máscara para difusão de dopantes, máscara para implantação iônica, isolação de dispositivos e óxido de porta em dispositivos MOS.

O ambiente de oxidação térmica pode ser constituído por oxigênio $\left(\mathrm{O}_{2}\right)$ puro (seco), por oxigênio proveniente de vapor de água $\left(\mathrm{H}_{2} \mathrm{O}\right)$, por apenas vapor de água ou em um ambiente pirogênico (oxigênio e hidrogênio $\left(\mathrm{H}_{2}\right)$ ). A taxa de crescimento em ambiente úmido é maior do que a taxa de crescimento em ambiente seco embora o crescimento sem a presença do vapor d'água apresente melhores características elétricas em dispositivos da tecnologia MOS (Metal-Óxido-Semicondutor), (CAMPBELL, 2001).

Os tipos de oxidação térmica de silício estão associados, primordialmente, ao ambiente oxidante adotado durante o processo de crescimento dos filmes, sendo estes: a) oxidação seca: com oxigênio puro; b) oxidação úmida ou a vapor: com vapor de água; c) oxidação pirogênica: com oxigênio e hidrogênio que reagem em alta 
temperatura formando vapor de água e d) oxidação térmica rápida: realizado em ambiente de oxigênio com aquecimento rápido por meio de lâmpadas halógenas.

\subsubsection{Os tipos de oxidação térmica}

As oxidações: seca, úmida e pirogênica são realizadas em fornos de oxidação convencional. O aquecimento durante o processo de oxidação costuma ser realizado com a ajuda de bancos de resistências posicionadas ao longo do comprimento do forno. Na parte interna dos fornos há um tubo de quartzo dentro do qual é posicionado um carregador de amostras que contem as lâminas a serem oxidadas.

$\mathrm{Na}$ oxidação seca, o fluxo de oxigênio (ambiente oxidante) passa internamente pelo tubo de quartzo, entrando em contato com as lâminas de silício a serem oxidadas (figura 2.1). Portanto, o oxigênio reage com o silício da lâmina (aquecida) para formar o óxido de silício.

$\mathrm{Si}($ sólido $)+\mathrm{O}_{2} \rightarrow \mathrm{SiO}_{2}($ sólido $)$

(oxidação seca)

Figura 2.1 - Forno de oxidação seca típico.

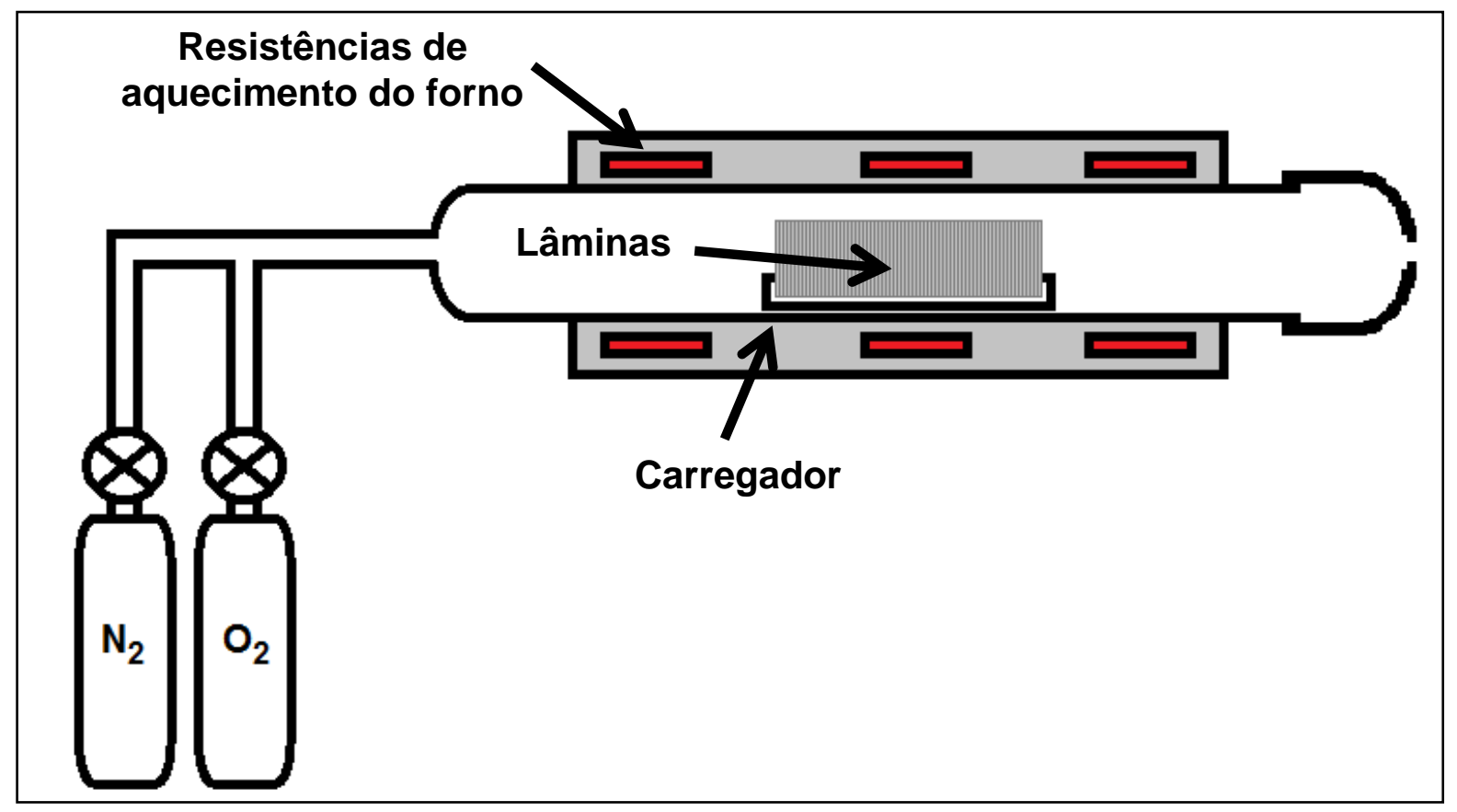

Fonte: Autor. 
No entanto, após a formação de uma fina camada de $\mathrm{SiO}_{2}$, o oxigênio difunde-se através da camada de óxido já formada e continua reagindo com o silício do substrato, aumentando a espessura de $\mathrm{SiO}_{2}$.

Na oxidação úmida, o fluxo de oxigênio (ou outro gás de arraste) é direcionado para um borbulhador contendo água deionizada aquecida a $90^{\circ} \mathrm{C}$ e o vapor de água, proveniente do encontro do fluxo de $\mathrm{O}_{2}$ com a água aquecida, é direcionado ao interior do tubo de quartzo na forma de um ambiente úmido oxidante (figura 2.2).

Si (sólido $)+2 \mathrm{H}_{2} \mathrm{O} \rightarrow \mathrm{SiO}_{2}($ sólido $)+2 \mathrm{H}_{2}$

(oxidação úmida)

Figura 2.2 - Forno de oxidação úmida típico.

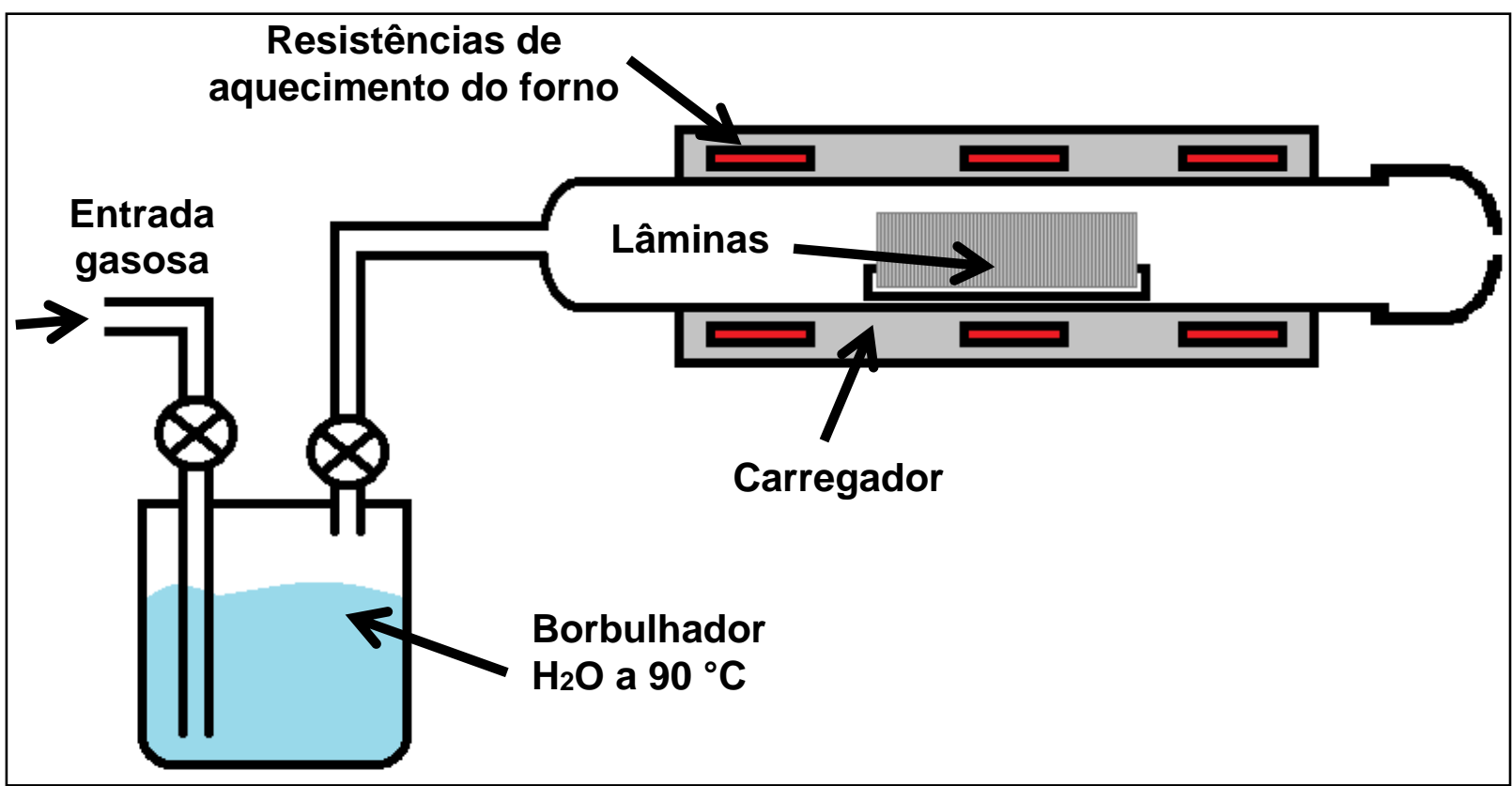

Fonte: Autor.

Devido às altas temperaturas utilizadas no processo de oxidação térmica, o vapor de água dissocia-se em hidrogênio e forma ligações de O-H. A difusão dessas ligações ocorre rapidamente ao entrar em contato com a superfície das lâminas de silício e promove o crescimento de uma camada de $\mathrm{SiO}_{2}$ com presença de cadeias Si-O-Si incompletas ao longo da extensão do filme. A presença de hidrogênio nos 
filmes crescidos enfraquece a rede de ligações $\mathrm{Si}-\mathrm{O}-\mathrm{Si}$ culminando em um aumento da difusividade das espécies de $\mathrm{O}-\mathrm{H}$ se comparada à difusão de $\mathrm{O}_{2}$ na oxidação seca.

A oxidação úmida apresenta maior taxa de oxidação do que a oxidação seca. Mas, o filme nela formado têm átomos de oxigênio que não participam das cadeias o que pode comprometer a utilização deste óxido em dispositivos MOS.

A oxidação pirogênica (figura 2.3) é semelhante à oxidação seca. Porém, o ambiente gasoso é composto por oxigênio puro misturado ao hidrogênio e ao nitrogênio (gás diluente). $O$ hidrogênio reage com o oxigênio formando moléculas de água (vapor de água) que, por sua vez, ao entrarem em contato com a superfície do silício iniciam o crescimento do óxido de silício como descrito para a oxidação úmida. Deve-se tomar um cuidado rigoroso com a proporção molar da mistura de $\mathrm{H}_{2} / \mathrm{O}_{2}$, pois caso esta seja maior do que 2, a mistura torna-se explosiva ao ser injetada em um forno aquecido (SOUZA, 2006).

$$
2 \mathrm{H}_{2}+\mathrm{O}_{2} \rightarrow \mathrm{H}_{2} \mathrm{O}
$$

$\mathrm{Si}($ sólido $)+2 \mathrm{H}_{2} \mathrm{O} \rightarrow \mathrm{SiO}_{2}($ sólido $)+2 \mathrm{H}_{2}$ (oxidação pirogênica)

Figura 2.3 - Forno de oxidação pirogênica típico.

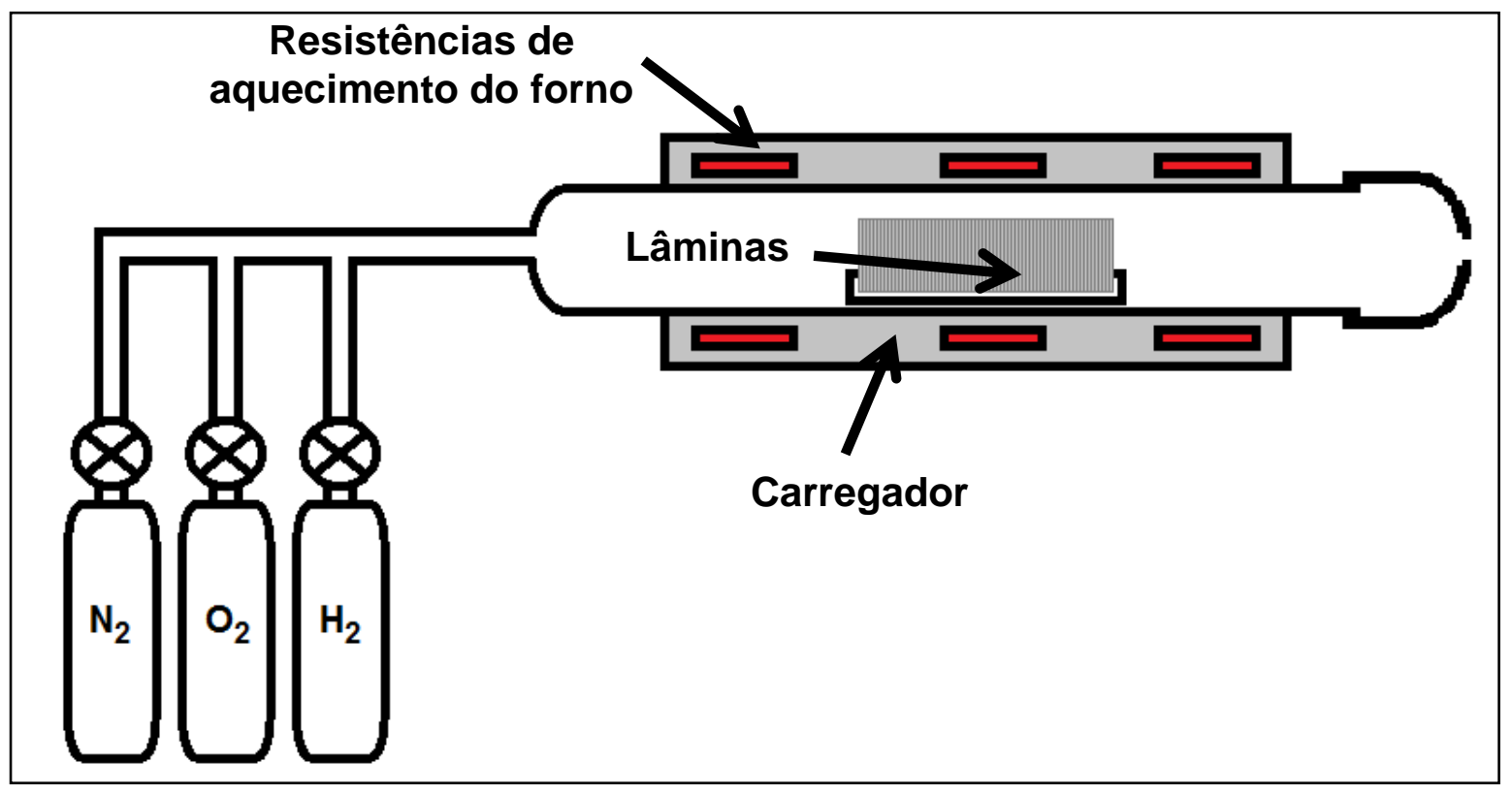

Fonte: Autor. 
Alguns autores acreditam que através de oxidação úmida seja possível crescer óxidos de porta MOS de alta qualidade baseado em indícios de que o tempo de vida médio de capacitores MOS crescidos em ambientes úmidos pode ser aumentado em relação ao dos óxidos crescidos em ambiente seco. A utilização de ambientes pirogênicos é reportada para a realização de oxidação úmida por apresentar características intermediárias entre a oxidação seca e a oxidação úmida, com a vantagem do melhor controle de pureza e limpeza do conjunto comparado à oxidação úmida (SOUZA, 2006).

\subsubsection{Oxidação por Processamento Térmico Rápido (RTP)}

A oxidação de lâminas de silício por processamento térmico rápido (RTP) tem sido empregada alternativamente ao forno de oxidação térmica convencional. $O$ crescimento de óxidos de alta qualidade deve-se ao controle da temperatura, o que possibilita obter óxidos uniformes em espessura e reprodutíveis (DEATON, 1992; CAMPBELL, 2001).

Nos fornos RTP (figura 2.4), é possível oxidar apenas uma lâmina de silício por vez. A lâmina é posicionada em um carregador de quartzo, suportado por três pinos de apoio muito finos feitos em quartzo a fim de assegurar uma massa térmica muito pequena proveniente do contato entre os pinos e a lâmina e, portanto, obtém-se temperaturas radiais uniformes durante o processo. O carregador de quartzo é posicionado dentro de um tubo de quartzo, por onde fluirá o gás de processo. No caso apresentado na figura 2.4, a lâmina de silício está posicionada entre dois bancos de lâmpadas halógenas (SANTOS, 1996; CAMPBELL, 2001). 
Figura 2.4 - Forno de processamento térmico rápido (RTP).

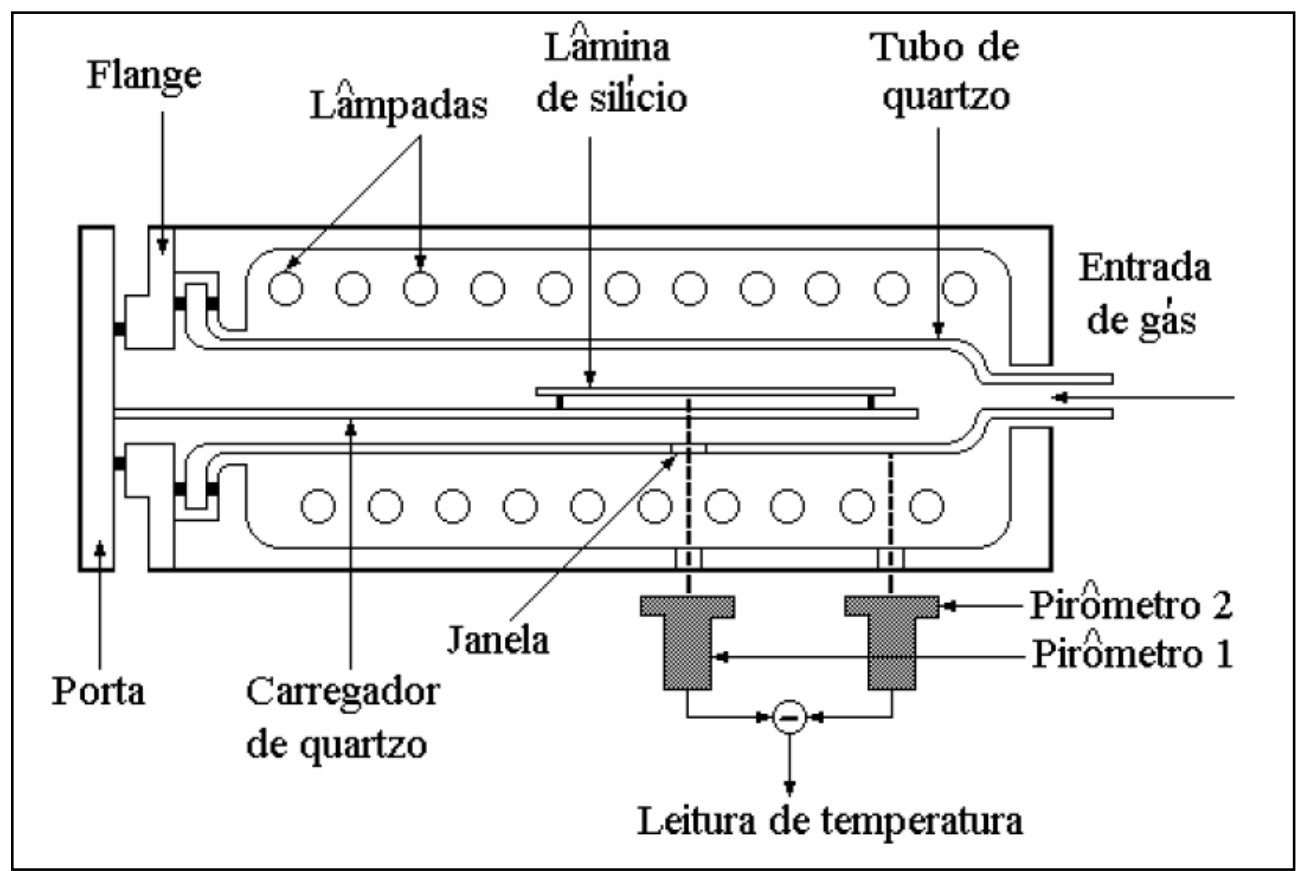

Fonte: (SANTOS, 1996).

As lâmpadas halógenas, na parte superior e inferior do tubo de quartzo, são a fonte de radiação para aquecer a lâmina a ser processada. Quando a energia irradiada atravessa o tubo de quartzo e atinge a lâmina, a temperatura desta é aumentada uniformemente até atingir a temperatura de processo pré-definida (tipicamente na faixa de 350 á $1200^{\circ} \mathrm{C}$, figura 2.5 ). Desta forma, a lâmina é recozida de forma isotérmica, e o controle de temperatura na lâmina é realizado através de pirômetros ópticos e, também, através termopares colados nas lâminas que poderão funcionar como base aquecedora para amostras menores. 
Figura 2.5 - Diversos processos RTP expressos em janelas de temperatura em função dos tempos de processamento típicos.

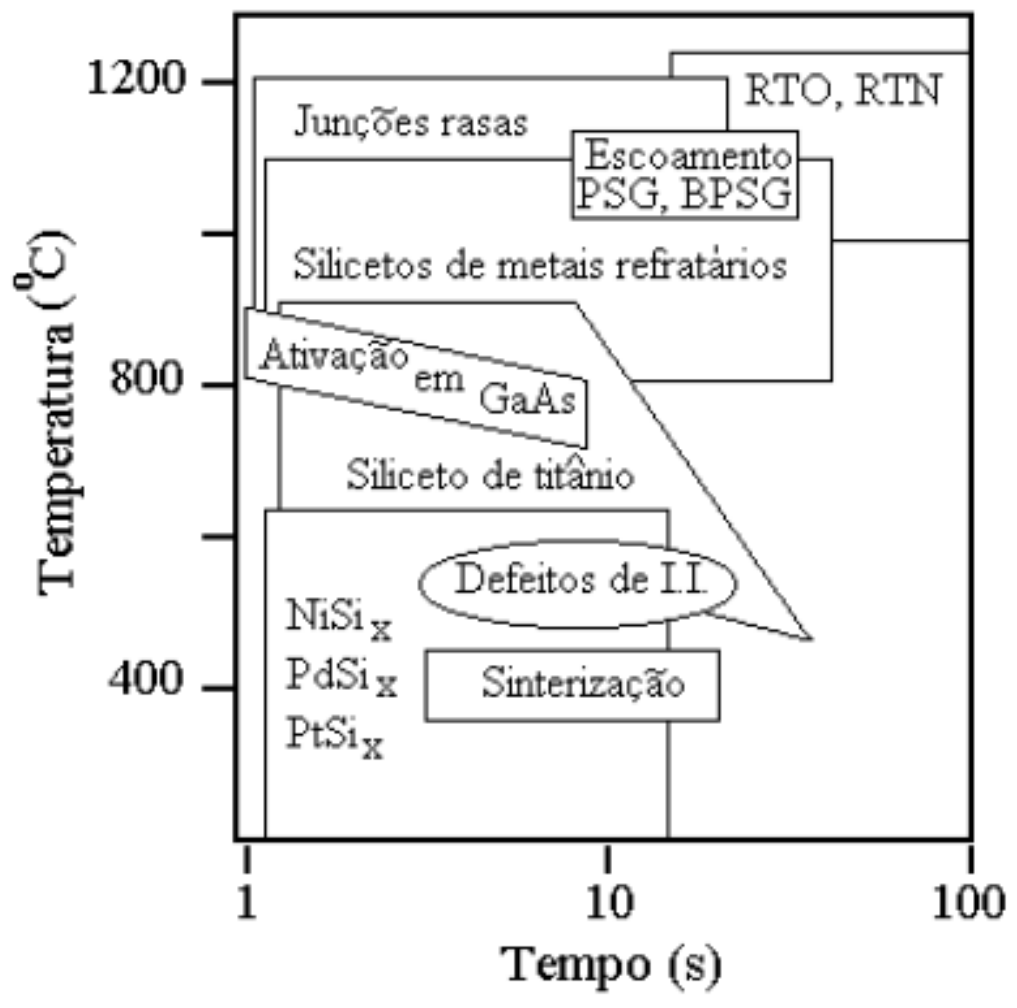

Fonte: (SANTOS, 1996).

As vantagens que o RTP apresenta sobre a oxidação térmica convencional incluem: o menor volume do ambiente de processos, a operação com as paredes do forno frias, tempos de processamento menores, taxas de aquecimento e resfriamento até cerca de $200^{\circ} \mathrm{C} / \mathrm{s}$ e rápida comutação de gases de processo (SOUZA, 2006; CAMPBELL, 2001; SANTOS, 1996).

\subsubsection{Cinética de oxidação térmica}

Um modelo de cinética de oxidação térmica, amplamente consolidado, foi proposto por Deal e Grove (1965). Esse modelo apresenta excelente ajuste para a grande maioria de dados experimentais disponíveis obtidos em fornos de oxidação térmica convencional, com temperatura variando na faixa de 700 á $1200^{\circ} \mathrm{C}$, pressão parcial 
de $0,1 \mathrm{a} 1 \mathrm{~atm}$, espessuras na faixa de 30 a 2000nm e em ambiente seco $\left(\mathrm{O}_{2}\right.$ puro $)$ e úmido (vapor de água).

Durante a reação em ambiente oxidante, ocorre uma expansão em volume do $\mathrm{SiO}_{2}$ (figura 2.6), que corresponde à espessura crescida mais $44 \%$ composto pelo silício consumido do substrato. $\mathrm{Na}$ formação de $\mathrm{SiO}_{2}$ (figura 2.6), têm-se três fluxos estacionários envolvidos: o primeiro fluxo corresponde às espécies oxidantes atravessando a interface ambiente/óxido (F1), o segundo fluxo é das espécies oxidantes atravessando a camada de óxido por difusão (F2) e o terceiro fluxo está relacionado a reação na interface óxido/substrato (F3).

Figura 2.6 - Desenho esquemático exibindo os três fluxos envolvidos no modelo de Deal e Grove para crescimento de óxidos em fornos térmicos.

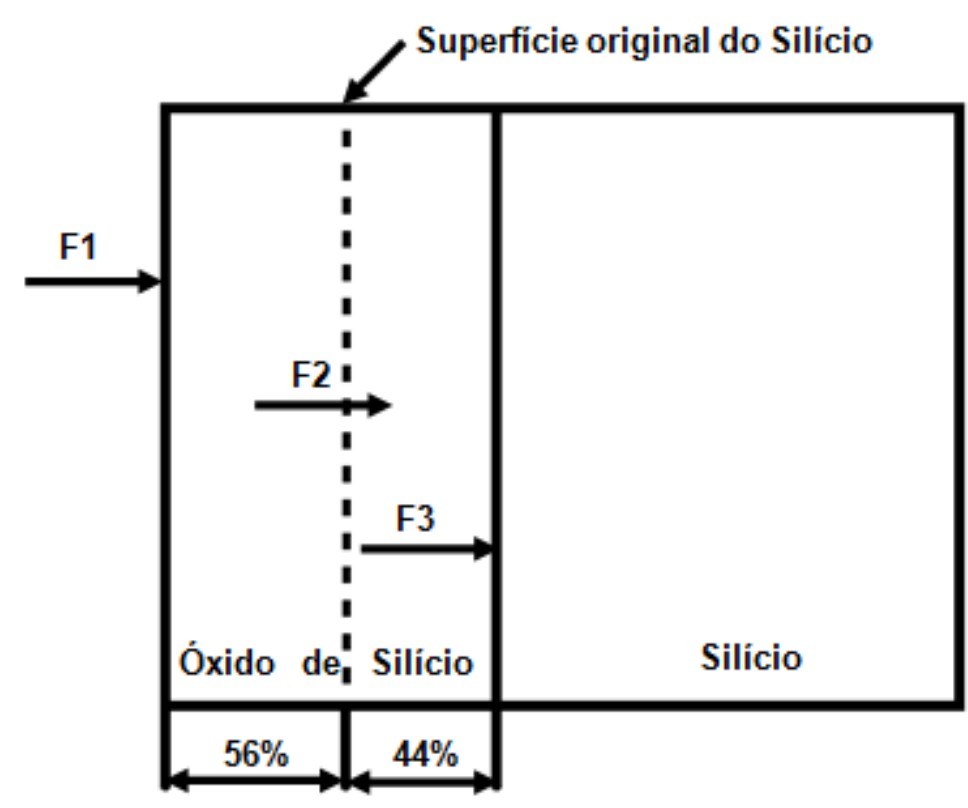

Fonte: Autor.

Considerando que os três fluxos descritos estejam em equilíbrio estacionário, Deal e Grove (1965) chegaram a uma equação que descreve a cinética de crescimento conforme segue:

$$
X_{0}^{2}+A \cdot X_{0}=B \cdot(t+\tau)
$$


Resolvendo a equação quadrática indicada em 2.1.3.1, resulta:

$$
\frac{X_{o}}{A / 2}=\left[1+\frac{t+\tau}{A^{2} / 4 B}\right]^{1 / 2}-1
$$

A equação 2.1.3.2 fornece uma relação da espessura do óxido térmico crescido em função do tempo de processo (figura 2.7). Onde Xo é a espessura do óxido crescido termicamente, $t+\tau$ é o tempo no qual o filme é crescido, $\tau$ é o tempo no qual o modelo de Deal e Grove passa a ser válido, A e B são parâmetros de ajuste função da temperatura.

Figura 2.7 - Representação gráfica da equação 2.1.3.1 ilustrando os regimes de crescimento linear e parabólico em óxidos crescidos termicamente em ambiente seco e úmido para diversas temperaturas.

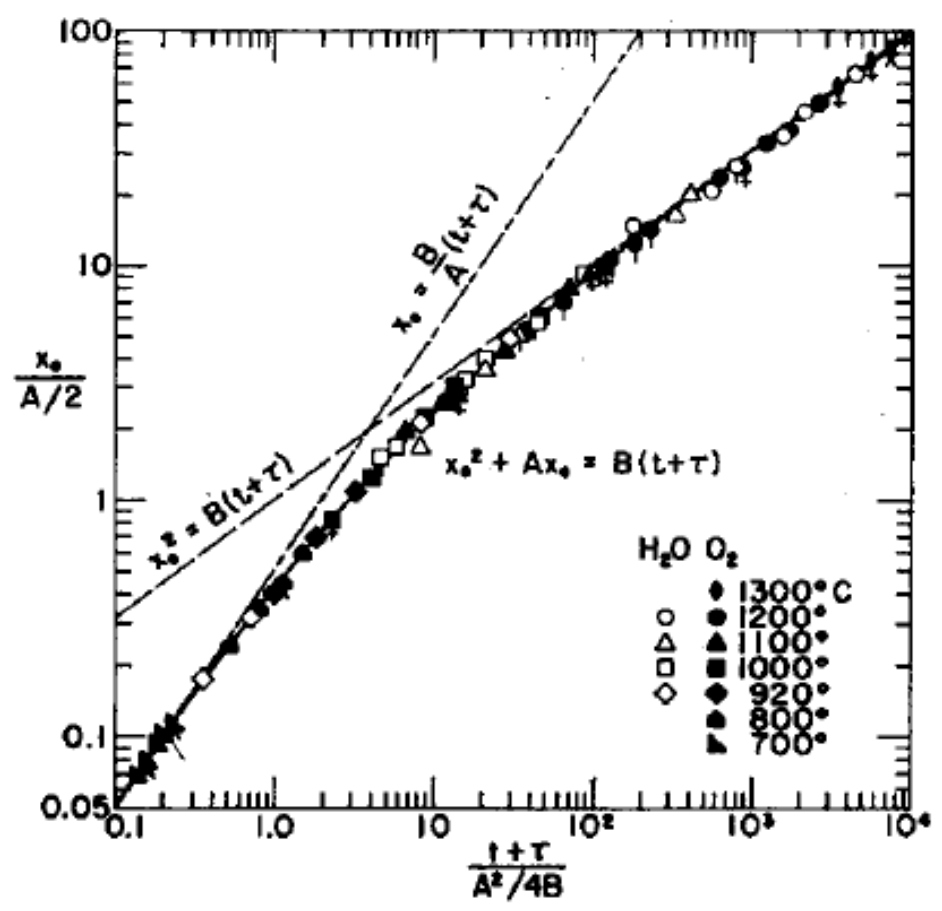

Fonte: (DEAL, 1965).

Para tempos de processo curtos, ocorre um crescimento predominantemente linear, limitado pela taxa de reação superficial das espécies oxidantes (equação 
2.2.1.3). Em contrapartida, para tempos de processo longos, ocorre um crescimento parabólico, limitado pela difusão das espécies oxidantes (equação 2.1.3.4).

$$
\begin{aligned}
& X_{0}=\frac{B}{A} \cdot(t+\tau) \\
& X_{0}^{2}=B \cdot(t+\tau)
\end{aligned}
$$

Portanto, B/A é a chamada constante de crescimento linear e B é conhecida por constante de crescimento parabólico. Sendo o fator de normalização do tempo de processo ( $\mathrm{FN}_{\mathrm{N}}$ que comparece na equação 2.1.3.5 e que delimita aproximadamente os regimes dominados por reação superficial e de difusão na camada :

$$
F_{N}=\frac{A^{2}}{4 . B}
$$

Embora no gráfico exibido na figura 2.7 esteja previsto a oxidação inicial rápida através do termo " $\tau$ ", o modelo descrito por Deal e Grove, não se aplica a filmes finos (<30 nm). Os quais são requeridos em diversas aplicações na microeletrônica, incluindo as células solares MOS.

Para levar em consideração este fenômeno de oxidação inicial rápida em filmes finos, apresentamos na sequência um modelo apresentado por Murali e Murarka que descreve uma taxa de oxidação enriquecida controlada pela difusão inicial rápida de oxigênio no silício durante os estágios iniciais do processo de oxidação, onde a superfície da lâmina oferece pouca resistência à difusão de espécies (MURALI, 1986; CAMPBELL, 2001).

Este modelo considera que há inicialmente uma camada rica em oxigênio, com espessura " $\delta$ ", devido à difusão rápida de espécies dentro do substrato de silício em altas temperaturas, na região subsuperficial, implicando em uma taxa de crescimento global enriquecida. 
$\mathrm{Na}$ figura 2.8, é apresentada uma visualização dos fluxos considerados no crescimento de filmes finos, sendo que F1, F2 e F3 correspondem aos mesmos fluxos descritos para o modelo de Deal e Grove e o fluxo F4 é responsável pela oxidação inicial rápida, no início do crescimento do filme, podendo este ser igualado à taxa de reação enriquecida na interface $\mathrm{Si} / \mathrm{SiO}_{2}(\mathrm{~F} 4=\mathrm{RD})$.

Figura 2.8 - Desenho esquemático exibindo os quatro fluxos envolvidos no modelo proposto por Murali e Murarka para descrever a cinética de crescimento de óxidos finos.

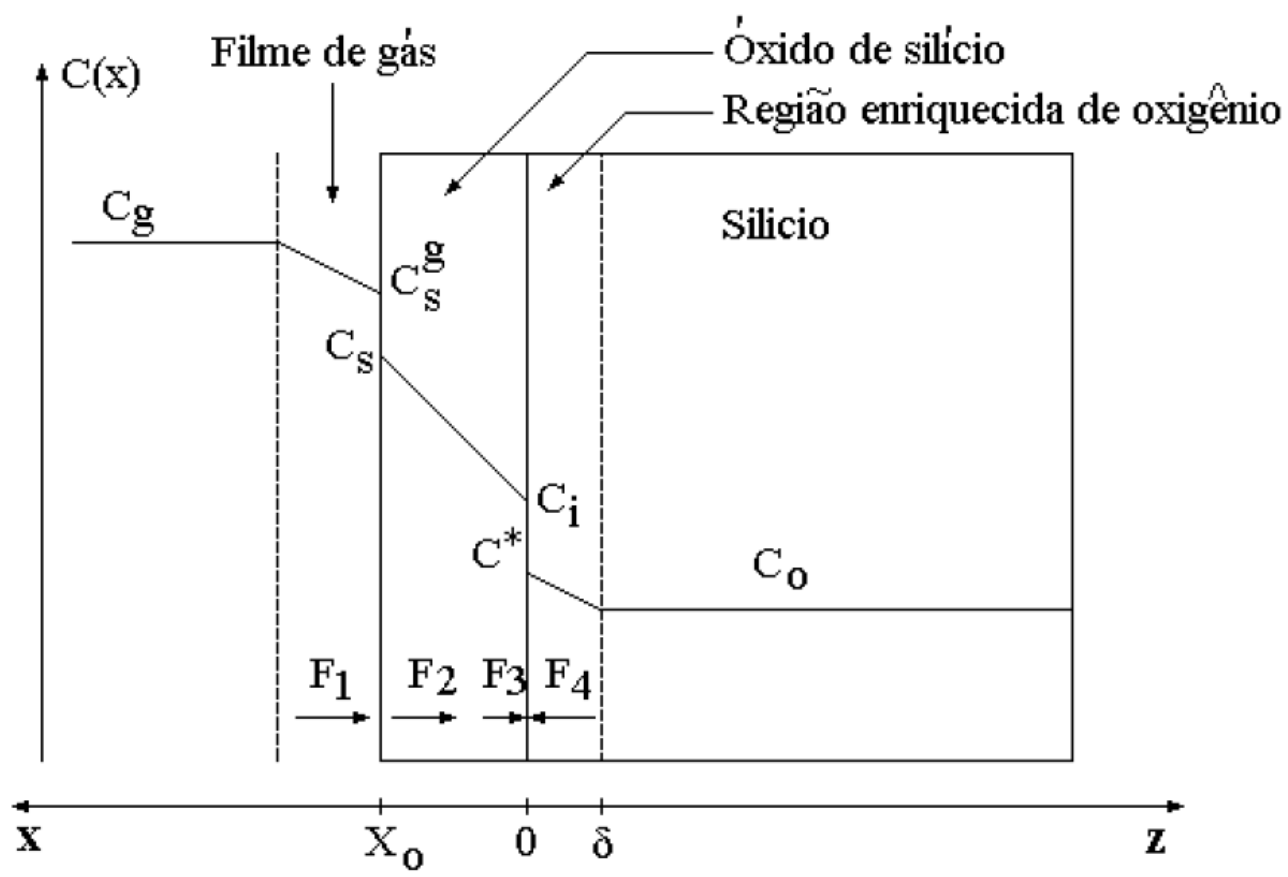

Fonte: (MURALI, 1986).

Assim, a equação genérica que descreve o crescimento da espessura em função do tempo de processo (MURALI, 1986):

$$
\frac{d X_{o}}{d t}=\frac{K_{s} C_{i}}{N_{1}}+\frac{R_{D}}{N_{1}}
$$

onde o primeiro termo do segundo membro da equação equivale à taxa de crescimento linear do modelo de Deal e Grove $(B / A), N_{1}$ é o número de moléculas 
oxidantes incorporadas por unidade de volume na camada do óxido e RD é a taxa de reação enriquecida na interface $\mathrm{Si} / \mathrm{SiO}_{2}$.

Primeiramente, é possível definir a taxa de reação enriquecida na interface $\mathrm{Si} / \mathrm{SiO}_{2}$ $\left(R_{D}\right)$, considerando que o perfil espacial de oxigênio não varie no silício durante o tempo de oxidação inicial rápida e que a reação entre silício e oxigênio seja homogênea:

$$
R_{D}=\left(K_{r} \cdot D_{o x}\right)^{1 / 2} \cdot\left(C^{*}-C_{o} / \cosh \left(M^{1 / 2}\right)\right) / \tanh \left(M^{1 / 2}\right)
$$

onde, $\mathrm{K}_{\mathrm{r}}$ é a constante da taxa de reação volumétrica $\left(\mathrm{V}_{\mathrm{r}}=\mathrm{K} \mathrm{r}\right.$. C), $\mathrm{C}^{*}$ é a concentração de oxigênio na interface $\mathrm{Si} / \mathrm{SiO}_{2}$ do lado do substrato, $\mathrm{C}_{0}$ é a concentração intrínseca de oxigênio no silício, $M=\left(K_{r} \cdot \delta^{2}\right) / D_{o x}$ e $D_{o x}$ é o coeficiente de difusão de oxigênio durante a oxidação, sendo definido por:

$$
D_{o x}=D_{o} \cdot e^{-E_{a} / K T}
$$

onde, $D_{o}=0,17 \mathrm{~cm}^{2} / \mathrm{s}$ e $E_{a}=2,54 \mathrm{eV}$ (MURALI,1986).

Desta forma, Murali e Murarka definem que a espessura do óxido em função do tempo de processo equivale a:

$$
X_{o}=X_{i}+\frac{R_{D}}{N_{1}} t
$$

onde $X_{i}$ é a espessura de óxido inicial.

Em segundo lugar, pode ser obtida a taxa de reação enriquecida dinâmica na interface $\mathrm{Si} / \mathrm{SiO}_{2}\left(\mathrm{R}_{\mathrm{D}}(\mathrm{t})\right)$ durante a transição de regime de oxidação inicial rápida para 
crescimento linear. Para isto, Araujo (1989) considerando o modelo de Murali e Murarka representado pela figura 2.8, mas inovando no sentido que a região subsurperficial de oxigênio apresenta um ciclo autolimitado. Em outras palavras, o oxigênio dentro do silício seria consumido à medida que a espessura do óxido aumentasse de forma a impedir a difusão rápida de mais oxigênio pra dentro do silício, tendo como resultado o desaparecimento do oxigênio na camada subsuperficial do silício. Com isso, a taxa de oxidação associada ao fluxo $\mathrm{F}_{4}\left(R_{D}(\mathrm{t})\right)$ tende a zero para tempos elevados e é dada por (ARAUJO,1989):

$$
R_{D}(t)=\frac{D_{o x} \cdot C^{*}}{\left(\pi \cdot D_{o x} \cdot t\right)^{1 / 2}} \cdot \sum_{n=0}^{\infty} \exp \left(\frac{-\delta^{2} \cdot(4 n+1)^{2}}{4 \cdot D_{o x} \cdot t}\right)
$$

onde " $\delta$ " é a espessura da camada subsuperficial e os outros parâmetros já foram descritos anteriormente.

Por outro lado, a espessura em função do tempo de processo é descrita por (ARAUJO, 1989):

$$
X_{o}(t)=X_{i}+\frac{A}{B} t+\frac{1}{N_{1}} \int_{0}^{t} R_{D}(t)
$$

\subsection{Mecanismos de geração de portadores}

Em óxidos e oxinitretos de silício ultrafinos (espessura $<3 \mathrm{~nm}$ ), a corrente na porta torna-se significativa à medida que diminuímos a espessura, permitindo a aplicação desses materiais em LEDs, fotodetectores e células solares (LIN, 2001). A seguir, são apresentados os principais mecanismos de geração de portadores, encontrados na literatura (GROVE, 1967; HURKX, 1992; YOU, 1999), incluindo a influência da dopagem de substratos de silício nesses mecanismos (LIN, 2001). 


\subsubsection{Tunelamento Shockley-Read-Hall (SRH)}

Dispositivos MOS com espessura de óxido inferior a 3nm, quando submetidos às tensões de porta suficientemente elevadas, apresentam corrente de tunelamento de portadores minoritários dominada pela geração desses portadores minoritários na interface $\mathrm{Si} / \mathrm{SiO}_{2}$ e na região de depleção. Inicialmente, considerando um capacitor MOS operando em depleção, o modelo convencional de Shockley-Read-Hall (SRH) que descreve a taxa de geração de pares elétron-lacuna pode ser descrito pelas equações de interface e de corpo, respectivamente, como segue (GROVE, 1967):

$$
\begin{aligned}
& U_{D i t}=\frac{\sigma_{p} \cdot \sigma_{n} \cdot v_{t h}\left(p n-n_{i}^{2}\right) \cdot N_{t}}{\sigma_{n}\left[n+N_{c} \exp \left(-\frac{E_{c}-E_{t}}{k T}\right)\right]+\sigma_{p}\left[p+N_{v} \exp \left(-\frac{E_{v}-E_{t}}{k T}\right)\right]} \\
& U=\frac{\left(p n-n_{i}^{2}\right)}{\tau_{n}\left[n+n_{i} \exp \left(-\frac{E_{T}-E_{i}}{k T}\right)\right]+\tau_{p}\left[p+n_{i} \exp \left(-\frac{E_{T}-E_{i}}{k T}\right)\right]}
\end{aligned}
$$

onde, $v$ th é a velocidade térmica, $N_{c}$ e $N_{v}$ são, respectivamente, as densidades de estados de saturação das bandas de condução e da banda de valência, $\mathrm{n}_{\mathrm{i}}$ é a densidade intrínseca de portadores, Ет é o nível médio de energia das armadilhas no meio da banda proibida, $\sigma_{n}$ e $\sigma_{p}$ são, respectivamente, as seções de captura associadas às armadilhas para elétrons e lacunas, $n$ e p são, respectivamente, as densidades de elétrons e lacunas e; $\tau_{n}$ e $\tau_{p}$ são, respectivamente, os tempos de vida de para elétrons e lacunas.

A densidade de corrente de inversão (JSRH) do modelo SRH pode ser determinada pela integração da taxa de geração líquida por toda a região de depleção somada à integração em energia dentro da faixa proibida da taxa de geração interfacial associada aos estados de interface: 


$$
J_{S R H}=q \cdot \int_{o}^{W} U d x+q \cdot \int_{E_{v}}^{E_{c}} U_{D i t} d E
$$

onde W é a largura da região de depleção, U é a taxa de geração de pares elétronlacuna na região de depleção e U Dit é a taxa de geração de pares elétron-lacuna via estados de interface.

Em dispositivos MOS, o modelo SRH é adequado a substratos com baixa dopagem $\left(<10^{16} \mathrm{~cm}^{-3}\right)$, apresentando fraca dependência com a tensão de porta (LIN, 2001).

Para dispositivos com substratos de maior dopagem $\left(10^{18}\right.$ a $\left.10^{20} \mathrm{~cm}^{-3}\right)$, há redução da largura da região de depleção, e os mecanismos de tunelamento de banda para armadilha (armadilhas no substrato e estados de interface) e banda a banda dominam a corrente de tunelamento (LIN, 2001). Quando os dispositivos são submetidos a pequenas tensões de porta, o modelo de tunelamento de banda a armadilha dentro do silício é dominante devido ao reduzido encurvamento das bandas de energia na superfície do silício (<1,1eV), como mostrado na figura 2.9.a. Entretanto, se a tensão de porta for suficientemente alta de forma a gerar um maior encurvamento na superfície do silício (> 1,1eV) o mecanismo de tunelamento de banda a banda tornase dominante dentro do silício (figura 2.9b). 
Figura 2.9 - Densidade de corrente de tunelamento devido ao encurvamento das bandas de energia na superfície do silício menores do que $1,1 \mathrm{eV}$ (a) e maiores do que $1,1 \mathrm{eV}$ (b).

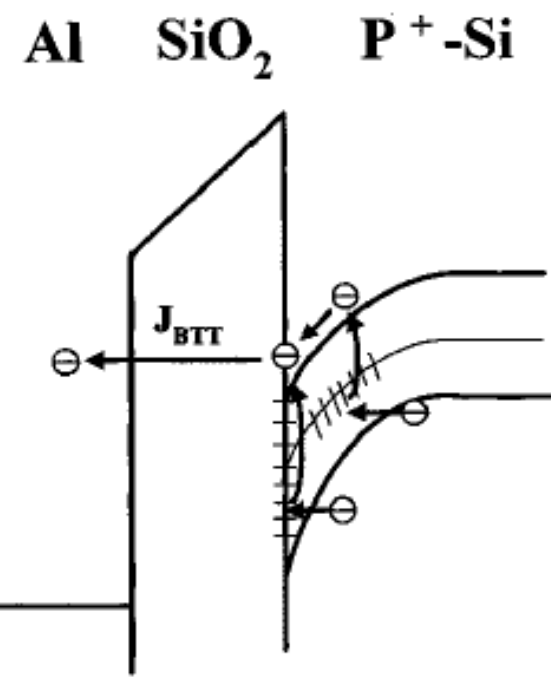

(a)

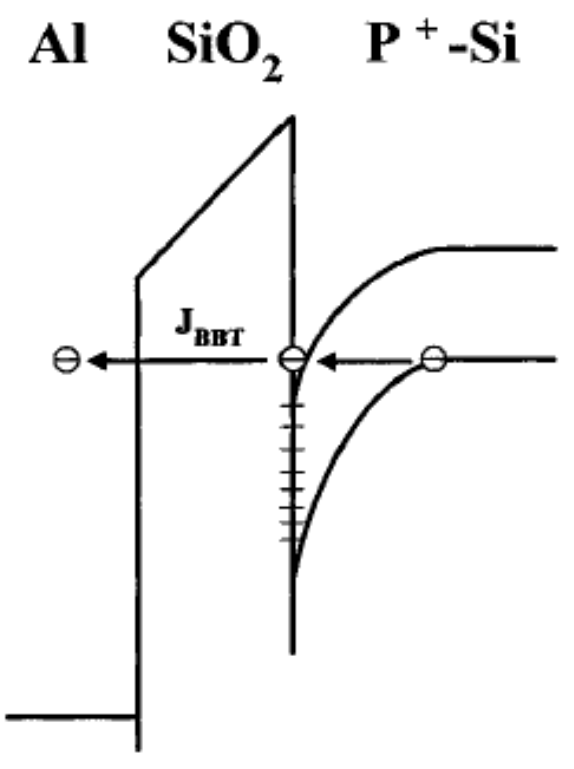

(b)

Fonte: (LIN, 2001).

Em ambos os casos indicados na figura 2.9, a densidade de corrente de tunelamento depende da tensão de porta, enquanto que no modelo $\mathrm{SRH}$, esta dependência é fraca (LIN, 2001).

\subsubsection{Tunelamento de banda a armadilha (Band-to-Traps ou BTT)}

Para descrever o modelo de corrente de tunelamento de banda para armadilha, Hurkx et al (1992), propuseram um modelo de recombinação modificado que inclui o tunelamento de lacunas e de elétrons, com taxa de geração via armadilhas $\left(G_{\operatorname{trap}}(\mathrm{x})\right)$ dada por:

$$
G_{\text {trap }}(x)=(1+\Gamma(x)) U_{S R H}(x)
$$

onde $U_{S R H}(x)$ é a taxa de geração convencional do modelo $\mathrm{SRH}$ e $\Gamma(\mathrm{x})$ é dado por: 


$$
\begin{aligned}
& \Gamma=2 \sqrt{3 \pi} \frac{|F|}{F_{\Gamma}} \exp \left(F / F_{\Gamma}\right)^{2} \\
& F_{\Gamma}=\frac{\sqrt{24 m^{*}(k T)^{3}}}{q \hbar}
\end{aligned}
$$

onde $F$ é o campo elétrico local no silício e $\mathrm{m}^{*}$ é a massa efetiva dos portadores.

Alguns elétrons podem tunelar da banda de valência para as armadilhas ativas no substrato na região de depleção (localizados próximo ao meio do bandgap), depois sobem para a banda de condução e, então, tunelam para o eletrodo de porta. Outros elétrons, próximos à interface $\mathrm{Si} / \mathrm{SiO}_{2}$ podem tunelar da banda de valência para os estados de interface, ao invés de tunelarem para as armadilhas.

Para campos elétricos fracos $\left(F<10^{5} \mathrm{~V} / \mathrm{cm}\right)$ na temperatura ambiente, $\Gamma$ é muito menor do que 1 e a equação 2.2.2.4 se reduz ao modelo SRH convencional. Ainda, a densidade de corrente de tunelamento ( $\mathrm{J}_{\mathrm{BTT}}$ ) no modelo banda-a-armadilha é dada por:

$$
J_{B T T}=q \cdot \int_{o}^{W} G_{\text {trap }}(x) d x+q \cdot \int_{E_{v}}^{E_{c}} G_{D i t} d E
$$

onde o primeiro termo da equação 2.2.2.4, representa o tunelamento de banda a armadilha e o segundo termo, o tunelamento de banda a interface, definido por $\mathrm{SRH}$.

\subsubsection{Tunelamento de banda a banda (Band-to-Band ou BBT)}

You et al. (1999) propuseram um modelo bidimensional para a corrente de tunelamento banda-a-banda. O efeito do campo elétrico lateral é desconsiderado e a densidade de corrente de tunelamento ( ( $\mathrm{BBBT}_{\mathrm{BB}}$ ) no modelo banda-a-banda pode ser 
obtida através da integração da taxa de tunelamento $\mathrm{P}\left(\mathrm{E}_{\mathrm{Si}}\right)$ por toda a região de depleção:

$$
J_{B B T}=q \cdot \int_{o}^{W} P\left(E_{S i}\right) d x=q \cdot \int_{E_{1}}^{E_{2}} P\left(E_{S i}\right) \cdot \frac{d x}{d E_{S i}} d F_{S i}
$$

onde a taxa de tunelamento $\mathrm{P}\left(\mathrm{F}_{\mathrm{Si}}\right)$ pode ser determinada como:

$$
P\left(E_{S i}\right)=\frac{q^{2} m^{1 / 2} F_{S i}^{e}}{18 \pi \hbar E_{g}^{1 / 2}} \cdot \exp \left(-\frac{\pi m^{1 / 2} E_{g}^{3 / 2}}{2 \hbar q F_{S i}}\right)
$$

onde $E_{g}$ é a largura em energia do bandgap do silício, $F_{S i}$ é o campo elétrico na região de depleção e m é a massa efetiva do elétron.

A dependência da largura em energia do bandgap com a temperatura é usada para simular a dependência da temperatura no modelo banda-a-banda. A largura em energia do bandgap do silício pode ser obtida por (SZE, 1981):

$$
E_{g}(T)=E_{g}(0)-\frac{\alpha \cdot T^{2}}{(T+\beta)}
$$

onde $E_{g}(0)=1,17 ; \alpha=4,74 \times 10^{-4} ; \beta=636$ para o silício.

A largura em energia do bandgap do silício reduz para temperaturas elevadas e a corrente de tunelamento banda-a-banda aumenta em função desse aumento de temperatura. 


\subsection{Tunelamento assistido por armadilhas}

Diferentemente dos outros mecanismos de tunelamento citados até agora, o tunelamento assistido por armadilhas ao invés de ocorrer dentro do material semicondutor (silício), ocorre dentro do óxido de porta sendo que a densidade de corrente resultante pode ser intensa $\left(>10 \mathrm{~mA} / \mathrm{cm}^{2}\right)$ desde que a concentração dessas armadilhas atinja valores $\left(\mathrm{N}_{\mathrm{t}}\right)$ maiores do que cerca de $10^{12} \mathrm{~cm}^{-2}$ (GEHRING, 2003).

Dessa forma, se a concentração de armadilhas for elevada $\left(\mathrm{N}_{\mathrm{t}}>10^{12} \mathrm{~cm}^{-2}\right)$, é interessante destacar que mesmo tendo um óxido de porta mais espesso $(>2 \mathrm{~nm})$ é possível obter uma alta densidade de corrente no dispositivo $\left(>10 \mathrm{~mA} / \mathrm{cm}^{2}\right.$ para $\mathrm{V}_{\mathrm{g}} \approx$ $1 \mathrm{~V})$, comparáveis aos dielétricos de porta bem mais finos $(\cong 1,0-1,5 \mathrm{~nm})$ onde 0 fenômeno de tunelamento direto é dominante ( $>10 \mathrm{~mA} / \mathrm{cm}^{2}$ para $V_{g} \approx 1 \mathrm{~V}$ ), (GODFREY, 1978). Isto significa que o tunelamento entre armadilhas em óxidos de porta mais espessos $(>2 \mathrm{~nm}$ ) pode apresentar um comportamento semelhante ao que ocorre em óxidos de porta mais finos sem presença de armadilhas onde predomina o mecanismo de tunelamento direto. A figura 2.10 ilustra a situação em que os elétrons tunelam através das armadilhas localizadas na banda proibida do óxido de porta em direção ao metal de porta.

Figura 2.10 - Esquema simplificado do tunelamento assistido por armadilhas

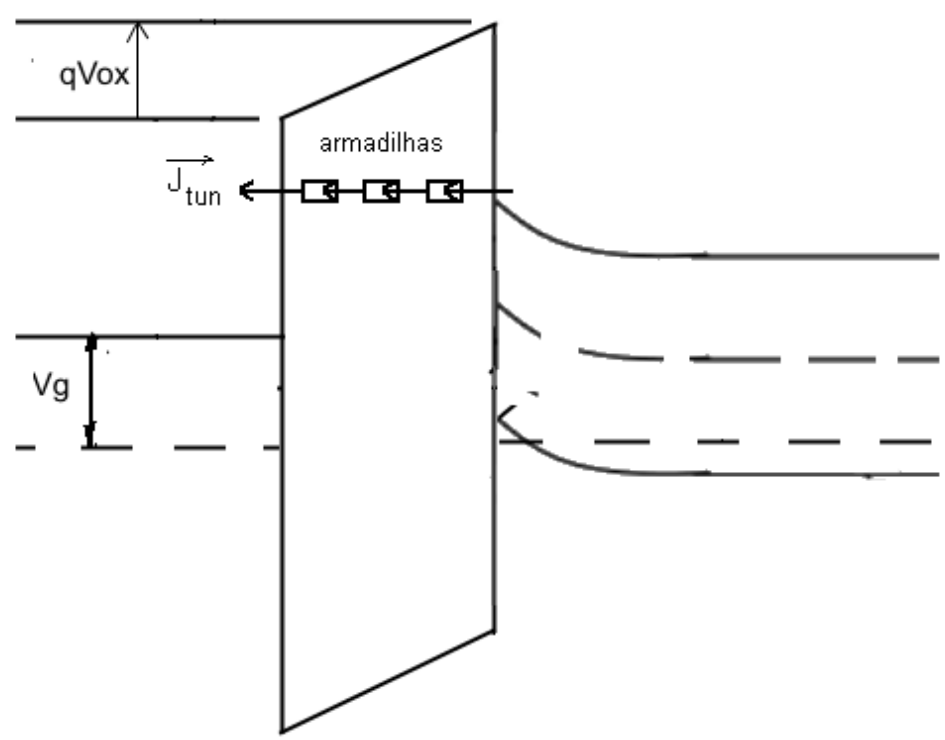

Fonte: Adaptado de (PULFREY, 1978). 
Outro fato importante que não pode ser deixado de lado é que o tunelamento assistido por armadilhas através do óxido pode vir acompanhado de qualquer um dos outros três tipos de tunelamento ( $\mathrm{SRH}, \mathrm{BTT}, \mathrm{BBT}$ ) como desencadeadores da presença de elétrons na banda de condução do semicondutor (LIN, 2001).

\subsection{Armadilhas associadas à incorporação de nitrogênio no dielétrico de porta}

A literatura (YANG, 2014) reporta que o nitrogênio costuma ficar predominantemente localizado na interface dielétrico-silício durante processos de oxinitretação e, também, pode promover níveis elevados de armadilhas dentro do dielétrico crescido devido à quebra das cadeias Si-O-Si. A existência de ligações incompletas na interface dielétrico-silício (dangling bonds) cria uma grande quantidade de defeitos (estados de superfície) entre as bandas de condução e de valência que agem como centros de recombinação SRH (YANG, 2014). Em particular, a presença das ligações incompletas do tipo $\mathrm{Si} \equiv \mathrm{N}$ na interface dielétrico-silício geram os chamados centros $K$ que podem armazenar cargas de todas as polaridades dependendo da forma de ocupação pelos elétrons: $K^{\circ}$ (neutro quando ocupado por um elétron), $K^{+}$(positivo quando desocupado) e $K^{-}$(negativo quando ocupado por dois elétrons) (YANG, 2014). Também, é importante destacar que os centros $K$ agem com armadilhas anfóteras que podem armadilhar ou um elétron ou uma lacuna de acordo com as equações 2.4.1 e 2,4.2 a seguir (YANG, 2014):

$$
\begin{aligned}
& K^{0}+e^{-} \rightarrow K^{-} \\
& K^{0}+h^{+} \rightarrow K^{+}
\end{aligned}
$$

Dadas as características particulares das ligações SiN na interface dielétrico-silício, o estado de preenchimento das armadilhas de interface será fortemente dependente da dopagem da lâmina de silício. Por exemplo, se a estrutura MOS estiver operando 
na situação de banda plana e a dopagem for tipo $P$, as armadilhas de interface estarão predominantemente preenchidas com lacunas.

\subsection{Célula Solar}

A seguir será apresentado o funcionamento das células solares de junção PN, descrevendo suas principais características físicas e parâmetros analisados. $\mathrm{Na}$ sequência será mostrado o funcionamento básico das células solares de tecnologia MOS, que é objeto de estudo do presente trabalho.

\subsubsection{Célula Solar de Junção PN}

Os painéis fotovoltaicos são compostos por associações de células fotovoltaicas para a conversão da energia da radiação solar em energia elétrica. Nesse tipo de célula representada esquematicamente na figura 2.11, a luz incidente é convertida em corrente elétrica através do efeito fotovoltaico. Sua estrutura corresponde ao diodo, de junção PN em áreas extensas que passa a ser chamado de célula solar de junção PN. Basicamente, essas células solares são compostas, além da junção PN em áreas extensas, também de uma grade metálica para contato elétrico. Nas células comerciais, há ainda, uma camada de material antirreflexivo, por cima do contato frontal, para evitar a reflexão e aumentar a absorção de luz pela célula solar. (VILLALVA, 2012). 
Figura 2.11 - Representação esquemática de células solares de junção PN.

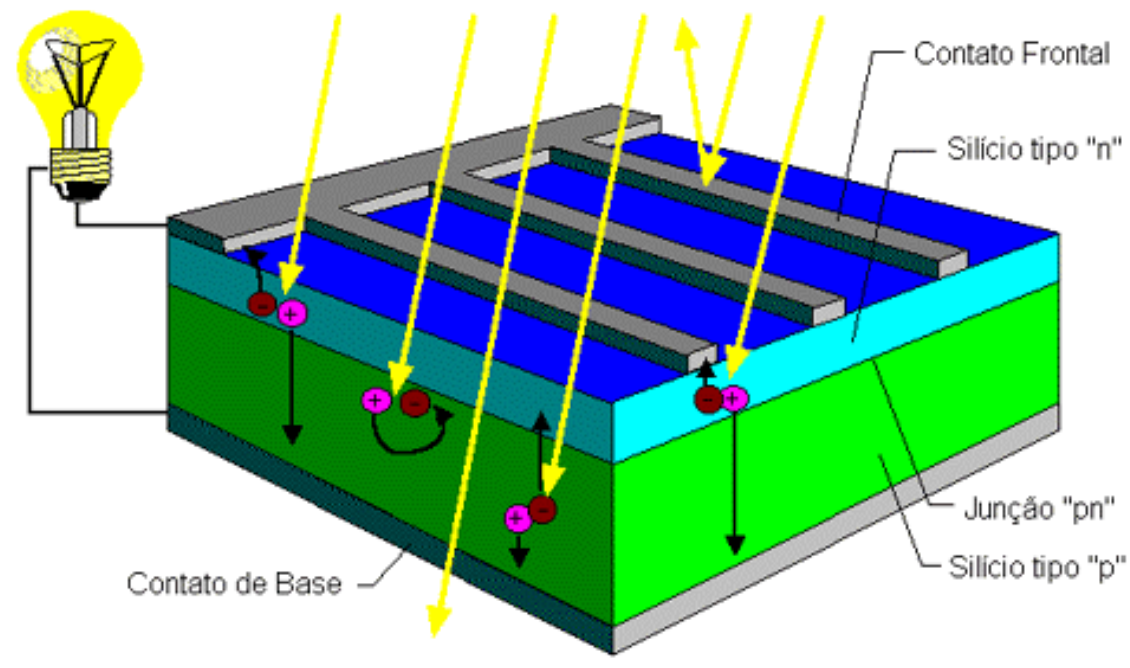

Fonte: (CRESESB, 2017).

A caracterização elétrica das células solares costuma ser feita com a ajuda de curvas de corrente-tensão $(\mathrm{IxV})$ as quais apresentam um comportamento característico idêntico ao do diodo semicondutor na ausência de luz e, na presença de luz (Figura 2.12), soma-se uma corrente de geração que desloca a característica IxV para dentro do quarto quadrante. Por conveniência, a parte da característica IxV presente no quarto quadrante que define a operação da célula solar como elemento gerador costuma ser rebatida para o primeiro quadrante (Figura 2.13) permitindo a extração de uma série de parâmetros importantes conforme segue:

Figura 2.12 - Curva IXV em célula solar de junção PN medida no escuro e em ambiente iluminado.

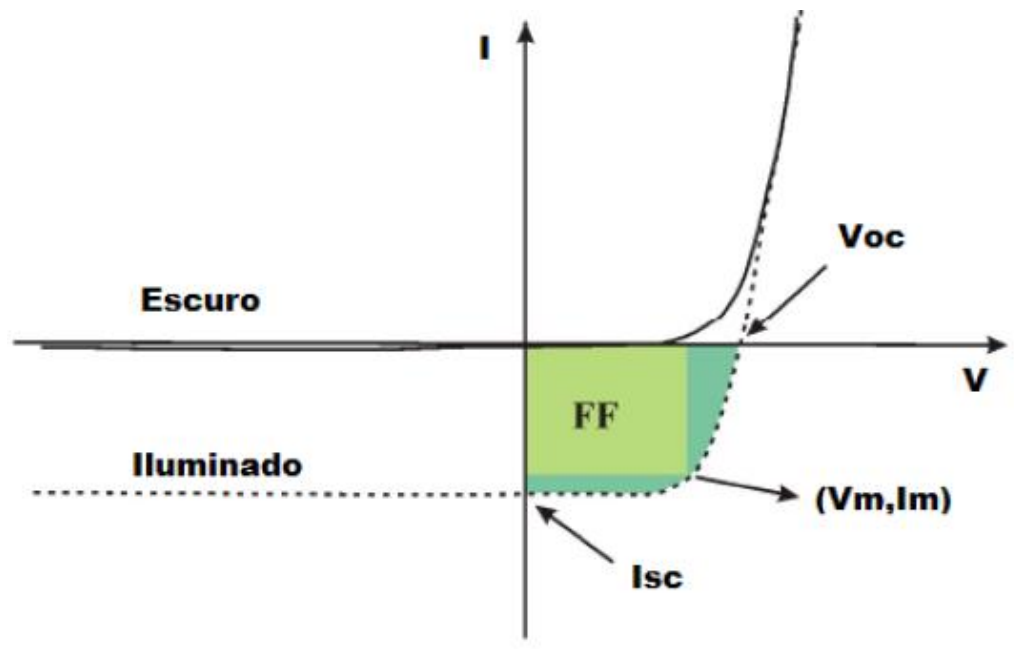

Fonte: Adaptado de (IBALDO, 2010). 
- Voc - tensão de circuito aberto medida nos terminais da célula solar na ausência de carga;

- Isc - corrente de curto-circuito medida com carga nula;

- $\mathrm{V}_{\mathrm{m}}$ - tensão correspondente ao ponto de potência máxima na característica IxV;

- Im - corrente correspondente ao ponto de potência máxima na característica IxV;

- $\mathrm{P}_{\mathrm{m}}$ - potência máxima fornecida pela célula solar sob uma determinada irradiância e temperatura (adota-se padrão internacional AM1,5G a $25^{\circ} \mathrm{C}$, característico à exposição em um dia típico ensolarado, correspondente a uma irradiância de $1000 \mathrm{~W} / \mathrm{cm}^{2}$ );

- FF - fator de forma ou fator de preenchimento que é obtido por:

$$
F F=\frac{V_{m} I_{m}}{V_{O C} I_{S C}}
$$

- $\eta$ - eficiência corresponde ao quão eficiente é uma célula solar do ponto de vista de converter a potência luminosa incidente em energia elétrica. Pode ser obtida por meio da seguinte relação:

$$
\eta=\frac{P_{m}}{P_{\text {in }}}
$$

onde $P_{\text {in }}$ é a potência da radiação incidente e $P_{m}$ é a potência máxima fornecida pela célula, como definido anteriormente. 
Figura 2.13 - Curvas IxV e PxV em módulo de uma célula solar típica sob iluminação.

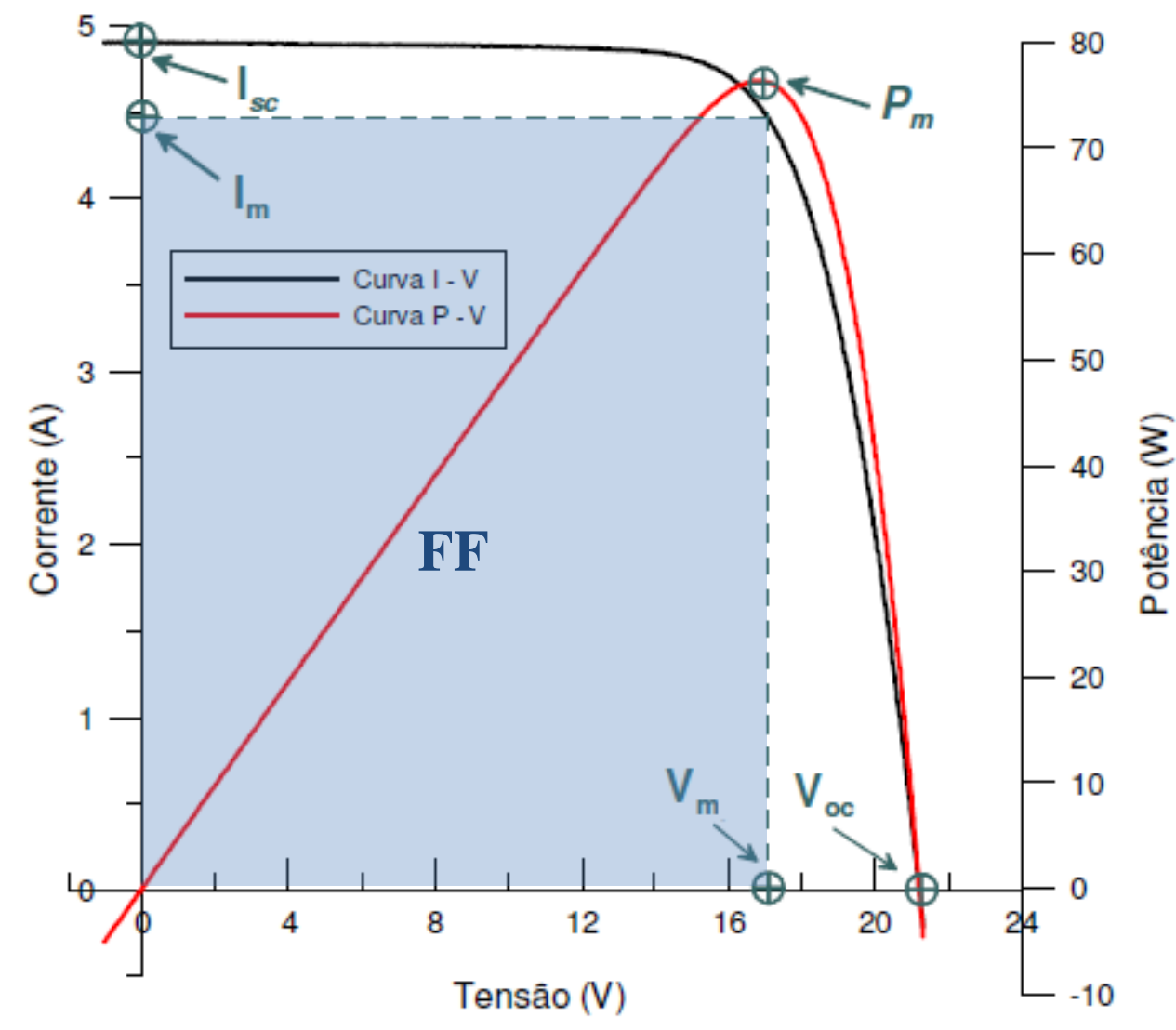

Fonte: Adaptado de (GASPARIN, 2009).

Cabe ressaltar que embora as células solares de junção PN sejam as células solares convencionais empregadas nos painéis fotovoltaicos, seu processo de obtenção é complexo no sentido de que é necessário texturizar o substrato para obter uma junção PN na qual seja possível controlar a velocidade de recombinação de portadores e, além disso, costuma-se adicionar uma camada antirrefletora para aumentar a absorção de radiação solar a fim de aumentar o rendimento de conversão da célula solar de junção PN (SZE, 1981; HAR-LAVAN, 2013; DHANDA, 2017).

\subsubsection{Células Solares MOS}

As células solares MOS têm, basicamente, a estrutura que caracteriza sua tecnologia de obtenção Metal-Óxido-Semicondutor (MOS). O layout típico das células solares MOS está ilustrado na Figura 2.14, na qual se utiliza um material transparente 
antirreflexo, usado como cobertura sobre o contato metálico frontal, tal como nas células solares de junção PN.

Figura 2.14 - Corte transversal da célula solar MOS com $\mathrm{SiO}_{x} \mathrm{~N}_{\mathrm{y}}$.

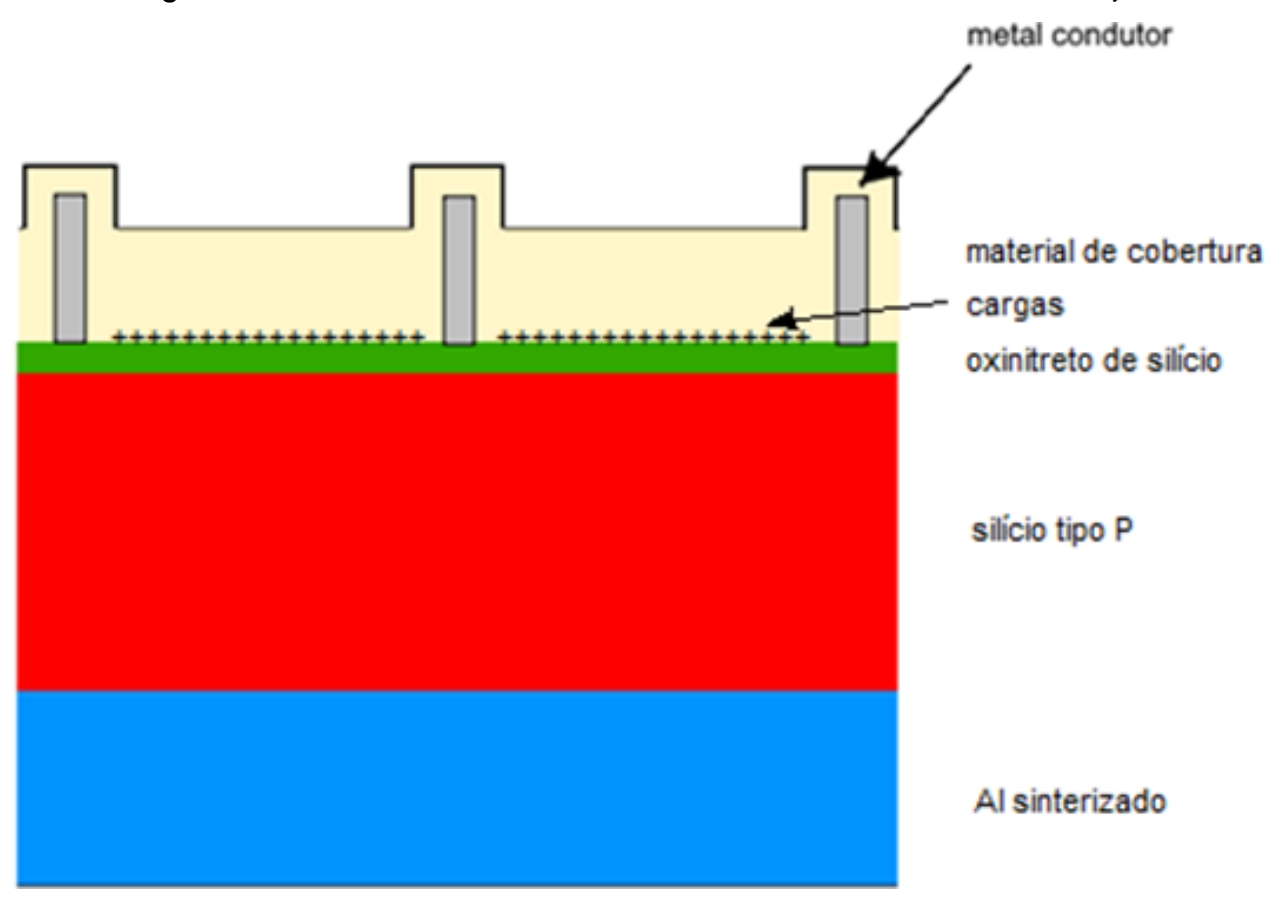

Fonte: Adaptado de (HAR-LAVAN, 2013).

A obtenção da qualidade e eficiência das células solares MOS também é realizada em função das curvas características elétricas IxV. GODFREY, em 1978, fez uma extensa revisão das características de células solares MOS com base na extração de parâmetros de curvas densidade-de-corrente $x$ tensão (JxV), normalmente, padronizadas para a irradiância de $100 \mathrm{~mW} / \mathrm{cm}^{-2}$ (equivalente ao padrão internacional de medida para a indústria fotovoltaica $A M 1,5 G$ ), permitindo a definição de sua eficiência de conversão de energia luminosa para energia elétrica $(\eta)$, conforme segue:

$$
\eta=\frac{J_{S C} x V_{O C} x F F}{P_{i n}}
$$


onde $J_{s c}$ é a densidade de corrente de curto circuito, $V_{o c}$ é a tensão de circuito aberto, FF é o fator de preenchimento e $P$ in é a potência incidente.

A figura 2.15 mostra as características $\mathrm{J}-\mathrm{V}$ típicas de uma célula solar MOS (amostra 866) sob iluminação padrão que simula a energia luminosa média em uma célula solar no espaço segundo o padrão AM1 (12,6 a 15,1 $\left.\mathrm{mW} / \mathrm{cm}^{2}\right)$ comparada à uma célula solar padrão de junção PN fabricada pela NASA também iluminada na mesma condição (GODFREY, 1978). O dielétrico de porta da célula MOS da figura 2.13 apresenta espessura na faixa de 1,0 a $1,5 \mathrm{~nm}$ de forma que, sob iluminação, o mecanismo da corrente de tunelamento é do tipo direto (GODFREY, 1978) conforme mostrado no item 2.2. Por outro lado, um dos grandes problemas apontados na literatura para esse tipo de célula solar MOS com corrente limitada pelo tunelamento direto através do óxido é a reprodutibilidade e uniformidade da espessura do dielétrico ao longo de amostras em áreas extensas de alguns $\mathrm{cm}^{2}$ (HAR-LAVAN, 2013).

Para óxidos suficientemente finos $(<2 \mathrm{~nm})$, costuma ocorrer o tunelamento direto através do óxido de porta como já ilustrado na figura 2.9 (LIN, 2001). As densidades de corrente atingidas através da estrutura MOS dependerão fundamentalmente da espessura do dielétrico assim como de outros fatores, por exemplo, a distribuição de armadilhas no óxido de porta que pode determinar um mecanismo predominante assistido por armadilhas (GODFREY, 1978). 
Figura 2.15 - Densidade de corrente $x$ tensão de porta em uma célula solar MOS (amostra 866) produzida com óxido de porta na faixa de 1,0-1,5nm, sob iluminação padrão que simula a energia luminosa média incidente do sol segundo no padrão AM1 (12,6 a 15,1 mW/cm²) comparada à uma célula solar de junção PN fabricada pela NASA também iluminada na mesma condição.

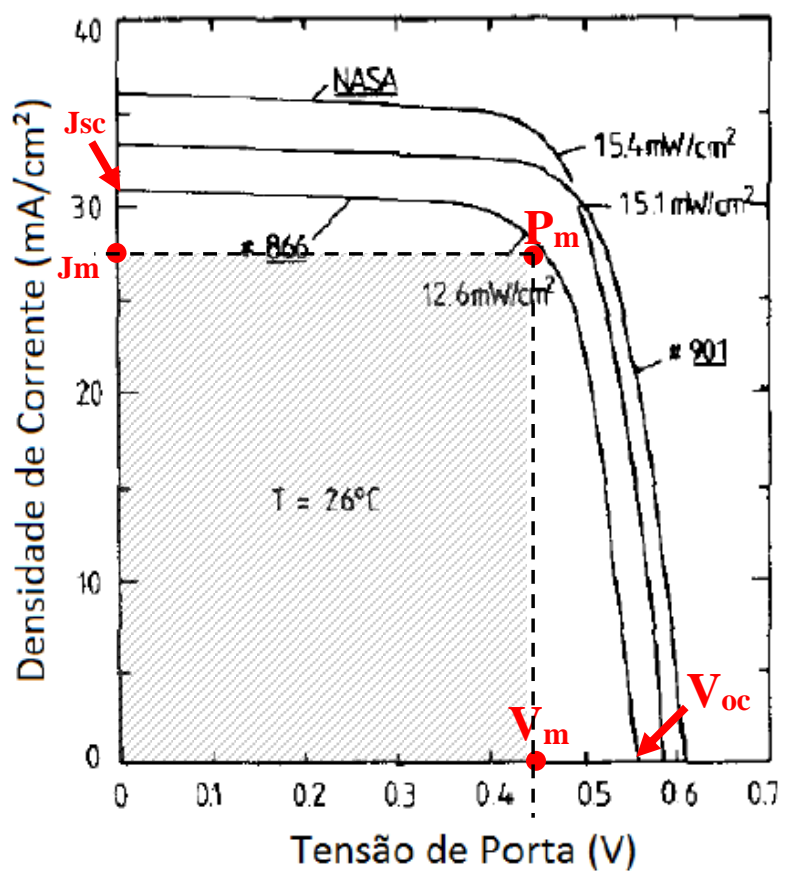

Fonte: Adaptado de (GODFREY, 1978).

Tanto as células solares de junção PN como as de tecnologia MOS, ambas apresentam grande complexidade no quesito reprodutibilidade conforme destacado na literatura (SZE, 1981; HAR-LAVAN, 2013; DHANDA, 2017).

Nos itens subsequentes desta tese será proposta um novo tipo de célula solar MOS com funcionamento não convencional, reprodutível, com baixo custo e aplicável em Energy Harvesting. 


\section{PROCEDIMENTOS EXPERIMENTAIS}

As diferenças entre os processos de oxidação térmica e de oxidação por processamento térmico rápido (RTP) foram descritas no capítulo 2. Com base nessa revisão bibliográfica, segue a descrição de um equipamento RTP adaptado em um forno de oxidação térmica convencional.

O preparo geral das amostras de silício é descrito partindo de sua limpeza química e dos parâmetros adotados para o crescimento dos óxidos de silício enriquecidos com nitrogênio. Adicionalmente, é feita uma descrição do esquema adotado para a realização de um mapeamento de temperatura para as diversas temperaturas de processo.

Quanto aos dispositivos, capacitor MOS e célula solar MOS, também é descrito o processo de fabricação, etapa a etapa, e os métodos e equipamentos utilizados nas caracterizações físicas e elétricas.

\subsection{Adaptação de um equipamento de oxidação térmica convencional para processamento térmico rápido (RTP)}

A seguir são descritos os procedimentos adotados para realização da etapa de processamento térmico rápido utilizando um forno de oxidação térmica convencional adaptado, incluindo a descrição do aparato adicional que foi necessário. $\mathrm{Na}$ sequência, é mostrado o procedimento empregado na calibração das temperaturas empregadas neste trabalho com a ajuda de um termopar de cromel-alumel fixado em lâmina de silício com cola cerâmica.

\subsubsection{Adaptação de um do forno convencional para realizar a etapa de processamento térmico rápido (RTP)}

A primeira fase dos experimentos consistiu no projeto e fabricação de um aparato de quartzo que possibilitasse adaptar o forno de oxidação térmica convencional, 
localizado no Laboratório de Sistemas Integrados (LSI), em um sistema para processamento térmico rápido (RTP), figura 3.1.

Figura 3.1 - Esquema do forno convencional adaptado para o processamento térmico rápido (RTP).

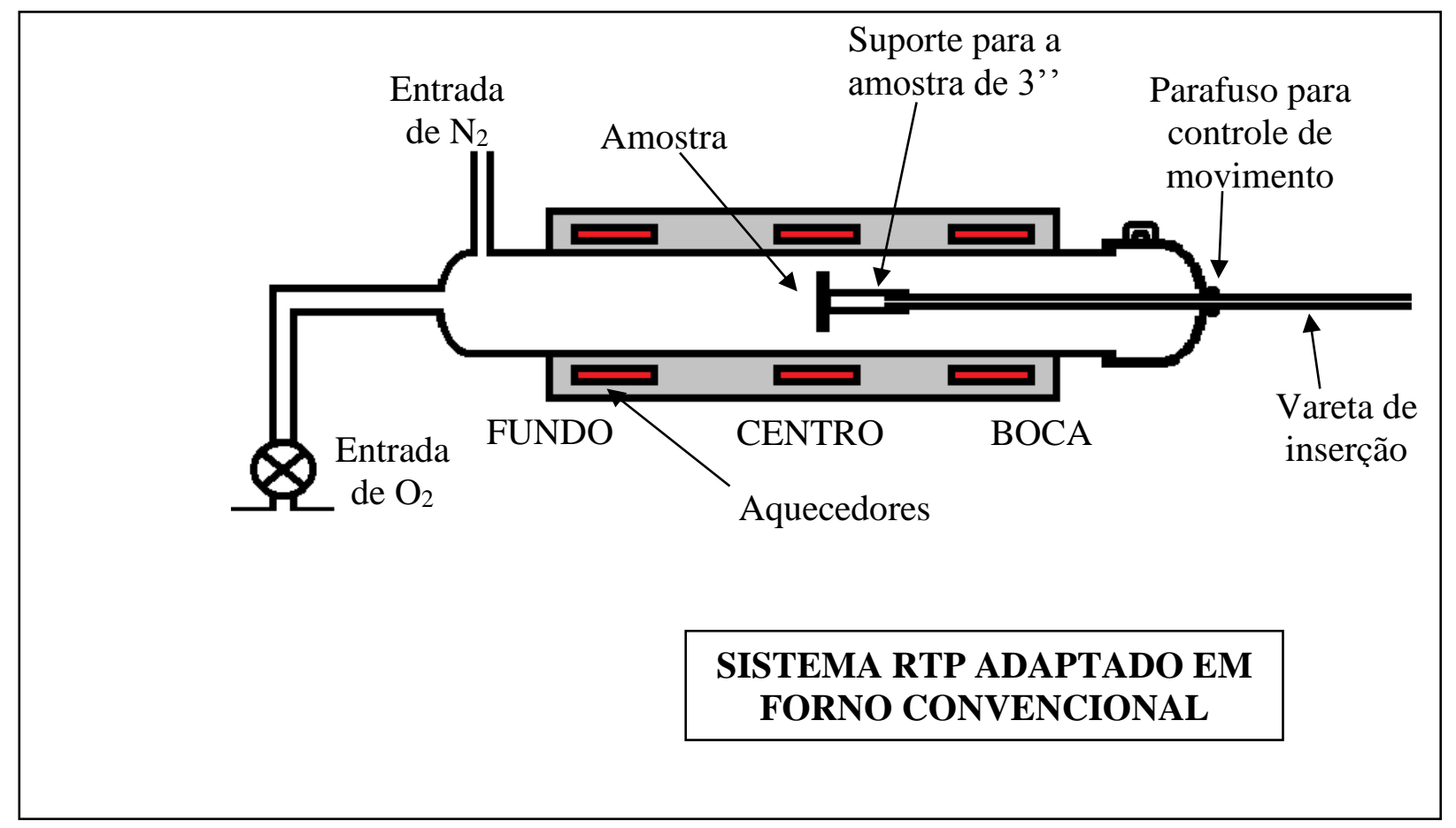

Fonte: Autor.

O aparato de quartzo é formado por um tubo que fecha a boca do forno, sendo que neste, há um orifício através do qual é inserido uma vareta de quartzo oca, para que seja realizado o movimento de inserção e retirada da amostra. Na extremidade da vareta, que fica na parte interna do forno é fixado um porta-amostras de quartzo com apoios de pequena massa térmica para uma única lâmina de 3 polegadas, como indicado na figura 3.1. Além disso, há um parafuso entre o fechamento da boca do forno e a vareta de quartzo que permite travar a movimentação da mesma.

Como já mencionado, no porta-amostras foi feito com 3 pequenos apoios (pinos) de quartzo, que suportam uma única amostra. Isso possibilita um aumento de temperatura uniforme em todo o diâmetro da amostra com perda desprezível de calor através dos apoios, e por consequência, permite obter boa uniformidade em espessura no óxido crescido (SANTOS, 1996). 
Portanto, cabe ressaltar que o sistema RTP adaptado para um forno convencional (figura 3.1), é uma inovação tecnológica que mantem a característica da baixa massa térmica associada ao porta-amostras assim como acontece nos fornos RTP comerciais. Além desse fato, a adaptação proposta é mais acessível devido ao seu baixo custo de implementação comparado com o custo de um forno RTP comercial.

\subsubsection{Preparo das amostras e oxinitretação por RTP}

No preparo das amostras de silício, inicialmente foi realizada uma limpeza química capaz de remover metais, compostos orgânicos e particulados. Em 1970, W. Kern reportou a limpeza química conhecida por RCA, que possibilita a obtenção de óxidos com características elétricas satisfatórias, tais como, baixa concentração de carga efetiva no óxido, baixa densidade de estado de interface e elevado campo elétrico de ruptura (KERN, 1970).

A limpeza química RCA é formada por 2 etapas. Na limpeza padrão 1 (standard cleaning 1), há a remoção de contaminantes superficiais, sendo orgânicos ou particulados. Esta etapa é composta por um banho em solução de amônia, peróxido de hidrogênio e água DI (1 $\left.\mathrm{NH}_{4} \mathrm{OH}(38 \%)+1 \mathrm{H}_{2} \mathrm{O}_{2}(37 \%)+5 \mathrm{H}_{2} \mathrm{O}\right)$.

A segunda etapa é conhecida por limpeza padrão 2 (standard cleaning 2), e remove contaminantes metálicos da superfície da lâmina. Isto ocorre em solução de ácido clorídrico, peróxido de hidrogênio e água $\mathrm{DI}\left(1 \mathrm{HCl}(38 \%)+1 \mathrm{H}_{2} \mathrm{O}_{2}(37 \%)+5 \mathrm{H}_{2} \mathrm{O}\right)$.

Concluída a limpeza RCA, as lâminas devem ser imersas em solução diluída (dip) em ácido fluorídrico $\left(80 \mathrm{H}_{2} \mathrm{O}+1 \mathrm{HF}(49 \%)\right)$ a qual atua com uma etapa de limpeza pré-oxidação, pois elimina o óxido nativo presente na lâmina, deixando-a hidrofóbica e com sítios superficiais de Si-H, Si-F e Si-CHx. (SANTOS, 1996; VERHAVERBEKE, 1994).

A limpeza química adotada consistiu em uma receita RCA com proporções modificadas que foram reportadas por Toquetti (2005) como sendo menos críticas para obter camadas dielétricas de elevada qualidade. Os seguintes banhos foram empregados:

a) $400 \mathrm{ml} \mathrm{H} \mathrm{H}_{2} \mathrm{O} 25 \mathrm{ml} \mathrm{NH}{ }_{4} \mathrm{OH}(38 \%)+175 \mathrm{ml} \mathrm{H}_{2} \mathrm{O}_{2}(37 \%)$;

b) $400 \mathrm{ml} \mathrm{H} 2 \mathrm{O}+100 \mathrm{ml} \mathrm{HCl}(37 \%)$; 
c) Dip em solução diluída de $\mathrm{HF}$ na proporção $80: 1$ realizado por $100 \mathrm{~s}\left(80 \mathrm{H}_{2} \mathrm{O}\right.$ $+1 \mathrm{HF}(49 \%))$;

As soluções $a$ e $b$ foram utilizadas aquecidas a $90^{\circ} \mathrm{C}$ e o tempo de permanência das amostras em cada uma destas soluções foi de $15 \mathrm{~min}$. Entre cada um dos banhos foi realizado um enxágue em água deionizada (DI) por 5 min, exceto após o dip em $\mathrm{HF}$, no qual, o tempo de enxágue foi de 3 min.

$\mathrm{Na}$ sequência, as amostras foram direcionadas para a etapa de oxidação térmica. O forno estava previamente aquecido em uma das três temperaturas adotadas (700, 850 ou $1150^{\circ} \mathrm{C}$ ) e, em ambiente inerte. As etapas adotadas para realizar a oxidação por RTP seguem descritas:

- Após o encaixe da amostra no aparato que vai a boca do forno (tubo para o fechamento da boca do forno + vareta oca de quartzo + suporte para lâmina de 3 polegadas), este conjunto foi posicionado na boca do forno, onde permaneceu por 5 min, para que a amostra alcançasse uma temperatura inicial mais elevada do que a temperatura ambiente (o valor dessa temperatura inicial será apresentado no item 3.1.3) ;

- Contabilizados 4 min de permanência do aparato de quartzo na boca do forno, o fluxo de oxigênio foi ligado, ou seja, 1 min antes de iniciar o RTP. Na maioria das amostras, foi empregado um ambiente misto de $\mathrm{N}_{2}$ e $\mathrm{O}_{2}$ (nas proporções $4 \mathrm{~N}_{2}: 3 \mathrm{O}_{2}$ e $5 \mathrm{~N}_{2}: 1 \mathrm{O}_{2}$ ) ou então apenas com 1,5L/min de $\mathrm{O}_{2}$;

- Através do manuseio da vareta de inserção, a amostra posicionada no suporte foi 'empurrada' para o centro do forno em $5 \mathrm{~s}$, para ser oxidada em tempos prédefinidos $\left(0,10,20,40,80\right.$ e 160 s para 700 e $850^{\circ} \mathrm{C}$ ou 70 e 140 s para $\left.1150^{\circ} \mathrm{C}\right)$ e, em alguns casos, as amostras foram passivadas por $80 \mathrm{~s}$ em ambiente inerte de $\mathrm{N}_{2}$ puro;

- Após completar o tempo de oxidação, a retirada da amostra do centro do forno ocorreu de duas maneiras diferentes: a) retirada rápida em $5 \mathrm{~s}$, onde a vareta era 'puxada' em direção à boca do forno em $5 \mathrm{~s}$ e o fluxo de $\mathrm{O}_{2}$ desligado após o retorno; ou b) retirada lenta em $5 \mathrm{~min}$, neste caso, encerrava-se o fluxo de $\mathrm{O}_{2}$ para que a vareta fosse 'puxada' de $30 \mathrm{~s}$ em $30 \mathrm{~s}$, cerca de $2,5 \mathrm{~cm}$, até alcançar a boca do forno; 
- Antes da retirada da amostra com o aparato que fecha a boca, aguardava-se 5 min para que a temperatura da amostra decrescesse ainda em ambiente inerte.

A oxidação por RTP seguiu as etapas descritas anteriormente, onde se iniciou o processo na boca do forno (posição convencional), ou com distanciamento de $10 \mathrm{~cm}$ a partir da entrada do tubo de quartzo, conforme descrito no item 3.1.3.

\subsubsection{Oxidação térmica rápida}

Adicionalmente, a oxidação térmica foi realizada com forno de oxidação seca (sem adaptação) preaquecido a $700^{\circ} \mathrm{C}$ e as características de crescimento foram:

- Rap. (rápido): a lâmina foi mantida na entrada do forno por $5 \mathrm{~min}$ em ambiente de $\mathrm{N}_{2}+\mathrm{O}_{2}(1,5 \mathrm{~L} / \mathrm{min})$. Na sequência, o $\mathrm{N}_{2}$ foi desligado e foi feita a inserção rápida da lâmina por 5 s até o centro do forno onde permaneceu por $300 \mathrm{~s}$, em seguida, foi feita a retirada rápida em $5 \mathrm{~s}$ até a entrada do forno onde permaneceu por mais $5 \mathrm{~min}$ em ambiente de $\mathrm{N}_{2}$.

\subsubsection{Medida de temperatura no substrato de Si durante o processo RTP}

Para o levantamento dos perfis de temperatura no processo RTP, foi montada no porta-amostra de quartzo uma lâmina comercial com termopar tipo $\mathrm{K}$ fixado com cola cerâmica em sua superfície. Por meio do aparato formado por lâmina + termopar colado adquirido junto à Sens Array Corporation (modelo 1501), foi possível realizar medidas de temperatura na faixa de -90 a $1370^{\circ} \mathrm{C}$ como precisão de $\pm 1,1^{\circ} \mathrm{C}$. Porém, para temperaturas acima $500^{\circ} \mathrm{C}$ tomou-se o cuidado de trabalhar apenas em ambiente inerte, para que não houvesse degradação do termopar em ambiente oxidante ativada por temperatura. Para medidas realizadas acima de $1100^{\circ} \mathrm{C}$, repetidas por mais de 60 vezes, houve variações na calibração do termopar de no máximo $\pm 0,2^{\circ} \mathrm{C}$.

Um controlador universal (NOVUS, modelo N1100-485) foi conectado ao termopar tipo K, para que fossem aferidos os valores de temperatura (figura 3.2.a). 
Considerando o circuito interno do controlador universal (figura 3.2.b), primeiramente ligou-se a alimentação do circuito, nas saídas 1-2. Na sequência, o termopar tipo K que havia sido colado na lâmina, foi conectado às saídas 10-11 e, por fim, acoplou-se um resistor de $100 \Omega$ nas saídas 7-8, a fim de obter até $2 \mathrm{~V}$ de tensão de saída como parâmetro de medida da temperatura $\left(2 \mathrm{~V}=1000^{\circ} \mathrm{C}\right)$.

Figura 3.2 - (a) controlador universal NOVUS N1100-485 e (b) conexões indicadas no painel traseiro.

a)

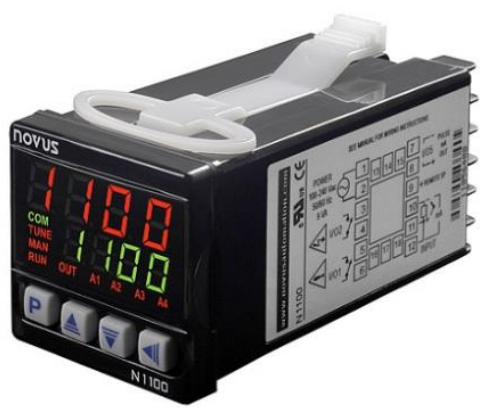

b)

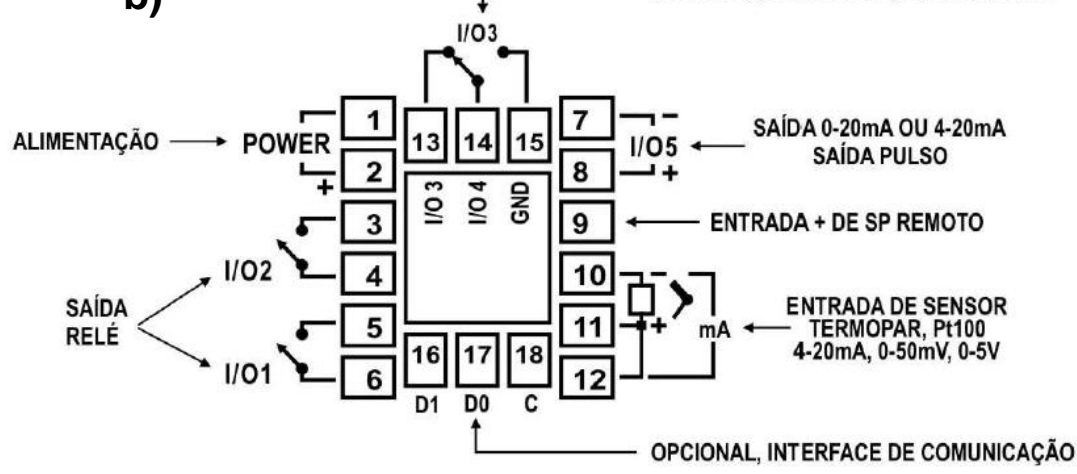

Fonte: (NOVUS, 2013)

Ao resistor acoplado nas saídas 7-8 do controlador universal, conectou-se um osciloscópio digital (ICELmanaus, modelo OS-5022C), a fim de gravar o perfil temporal de temperatura medido durante o processo RTP.

$\mathrm{Na}$ figura 3.3, é apresentado um diagrama esquemático da disposição da lâmina com o termopar tipo K, o controlador universal e o osciloscópio digital, utilizados para o mapeamento dos perfis temporais de temperatura durante os processos RTP. As medições foram inicialmente realizadas em ambiente inerte $\left(\mathrm{N}_{2}\right)$ com a lâmina localizada na entrada do forno, como será descrito no item 3.2. A gravação dos dados foi realizada através de um dispositivo de conexão USB. 
Figura 3.3 - Representação esquemática adotada do setup empregado para obtenção dos perfis de temperatura.

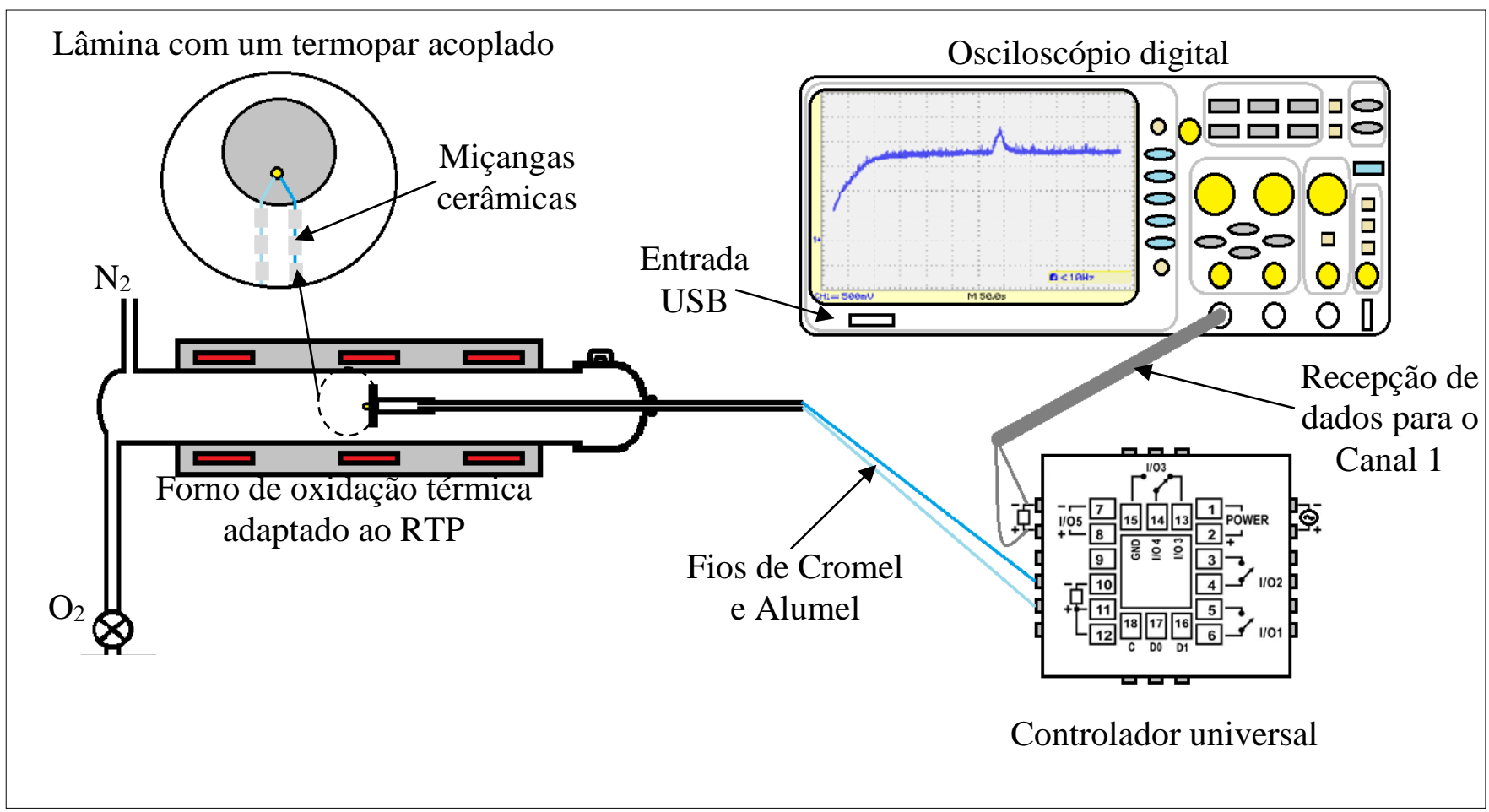

Fonte: Autor.

\subsubsection{Espessura, microrugosidade e concentração de $\mathrm{N}_{2}$}

Os parâmetros inicialmente analisados nos filmes crescidos por RTP foram espessura, concentração de $\mathrm{N}_{2}$ e microrugosidade. Para determinação destes parâmetros utilizou-se as técnicas: elipsometria, espectroscopia de raios-X por emissão de fotoelétrons (XPS) e microscopia de força atômica (AFM).

O elipsômetro utilizado para a determinação de espessura nos óxidos foi o AUTOEL II da Rudoulph Research, Inc., o qual utiliza um software residente para a determinação de espessuras. Foi fixado um índice de refração de 1,460 para o substrato de silício, a fim de assegurar convergência e precisão na obtenção da espessura inferior a $5 \mathrm{~nm}$ em óxidos finos. Foram empregados dois comprimentos de onda ( $\lambda=632,8$ e $450 \mathrm{~nm}$ ), os quais viabilizaram medidas de espessura com valores muito próximos (Erro relativo < 1\%). Desta forma, optou-se por apresentar os valores médios de espessura obtidos com $\lambda=632,8 \mathrm{~nm}$. 
Neste ponto é importante justificar a razão pela qual o índice de refração foi fixado em 1,460 que é porque nesta situação a espessura obtida apresenta precisão adequada para os óxidos de silício crescido no âmbito do presente trabalho ( 2nm). $\mathrm{Na}$ técnica de elipsometria um feixe de luz polarizada linearmente incide sobre a estrutura constituída pelo filme dielétrico + substrato e é refletido tanto na superfície do filme quanto na interface entre o filme e o substrato (AutoEI, 1989). Os feixes refletidos serão normalmente reduzidos em amplitude e defasados com relação ao feixe incidente. Além disso, os feixes de luz refletidos também irão interagir entre si sendo que esta interação dependerá fundamentalmente das amplitudes relativas dos feixes, das diferenças de caminho entre as duas superfícies e das fases relativas entre os feixes. O resultado desta interação são máximos e mínimos de intensidade como função do comprimento de onda e da posição espacial (RUNYAN, 1975). Estas mudanças de propriedades do feixe após a reflexão (amplitude e fase) dependem fundamentalmente das propriedades do filme em análise (índice de refração e espessura).

Em elipsometria definem-se os ângulos " $\Delta$ " e " $\Psi$ " conforme segue:

$\Delta=\Delta_{\mathrm{p}}-\Delta_{\mathrm{s}}$

e

$\Psi=\operatorname{Tan}^{-1} \frac{\mathrm{R}_{\mathrm{p}}}{\mathrm{R}_{\mathrm{S}}}$

onde $R_{p}$ e $R_{S}$ são, respectivamente, os coeficientes de reflexão das componentes de luz polarizada "p" e "s", e $\Delta p, s$ são os deslocamentos de fase para as componentes de luz polarizada "p" e "s".

Através de ajustes adequados do polarizador do feixe de luz incidente e do analisador do feixe de luz refletido, faz-se a determinação experimental dos parâmetros " $\Delta$ " e " $\Psi "$ (AutoEl, 1989) os quais estão diretamente relacionados com a 
espessura e o índice de refração do filme sobre um substrato com índice de refração conhecido $(n+j k)$. O equacionamento que relaciona os parâmetros " $\Delta "$ e " $\Psi "$ com a espessura e o índice de refração do filme é bem conhecido (ZAININGER, 1964). No caso específico da medida de espessura e do índice de refração de filmes finos (< $5 \mathrm{~nm})$, sabe-se que o valor de $\Psi$ tende a ser pequeno $(<20)$ resultando em imprecisão na convergência das equações elipsométricas que são função de " $\Delta$ " e " $\Psi "$ (ZAININGER, 1964) na obtenção da espessura e índice de refração. Este é o caso do equipamento AUTO-EL II da Rudolph Research, Inc. que foi utilizado neste trabalho e que possui um programa computacional interno que depende da referida convergência. Este problema é contornado fixando-se o índice de refração que no caso do óxido de silício é de 1,460, o que permite a obtenção da espessura do óxido com boa precisão após a convergência na resolução das equações elipsométricas (AutoEl, 1989).

Por outro lado, uma forma de avaliar a acurácia na medida de espessura por elipsometria com índice de refração fixo é comparar com a espessura física medida por microscopia eletrônica de transmissão transversal (TEM) após o processo de oxinitretação de acordo com resultados do nosso grupo de pesquisa (GSIDE/LSI/EPUSP). A figura 3.4 mostra uma micrografia TEM típica de oxinitreto de silício crescido por processamento térmico rápido. A espessura física medida por TEM resultou $(2,20 \pm 0,05) \mathrm{nm}$ ao passo que a espessura obtida através de elipsometria no comprimento de onda de $632,8 \mathrm{~nm}$ e índice de refração fixo de 1,460 foi de $(2,1 \pm$ $0,1) \mathrm{nm}$, portanto, muito ligeiramente menor que a espessura TEM com erro relativo menor do que $5 \%$ (TOQUETTI, 2005). 
Figura 3.4 - Imagem TEM transversal de uma amostra de oxinitreto de silício com espessura física de

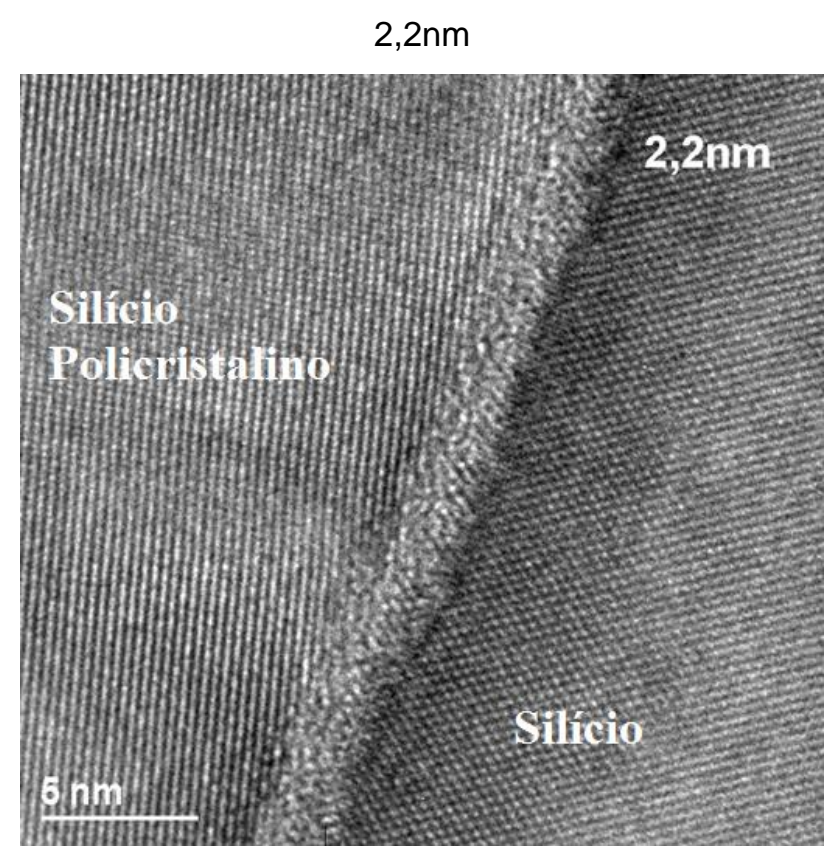

Fonte: (TOQUETTI, 2005).

A literatura (AOYAMA, 1998) reporta que o processo de oxinitretação do silício resulta em uma camada interfacial rica em nitrogênio junto à interface $\mathrm{Si} / \mathrm{SiO}_{2}$. Esta camada, por não ser constituída de $\mathrm{SiO}_{2}$ estequiométrico, e sim de um composto nãoestequiométrico $\mathrm{SiO}_{x} \mathrm{~N}_{y}$, tem seu índice de refração alterado. Como a técnica de elipsometria mede a espessura efetiva de $\mathrm{SiO}_{2}$, ou seja, a espessura da camada que possui índice de refração igual a 1,460, o valor de espessura medido para oxinitreto de silício resulta menor comparado com a camada de óxido de silício como ocorreu no caso que foi descrito.

Tendo em vista o contexto apresentado, efetuou-se de forma padronizada 9 medidas de espessura por elipsometria em cada lâmina de 3 polegadas de diâmetro e obtive-se a espessura média mais o desvio padrão. As medições por lâmina foram realizadas no centro da lâmina e as demais distanciadas $2 \mathrm{~cm}$ ao redor do centro. Neste ponto, cabe ressaltar o cuidado tomado na apresentação de dados com erro reduzido $(<1 \%)$ relativo à medida por elipsometria adotando índice de refração fixo em 1,460, além do cuidado com a acurácia da técnica, ou seja, a comparação entre as espessuras obtidas por elipsometria e TEM.

A espectroscopia de raios-X por emissão de fotoelétrons (XPS) foi realizada em um espectrômetro comercial UNI-SPECS UHV com pressão base abaixo de $5 \times 10^{-7} \mathrm{~Pa}$, 
localizado no Laboratório de Espectroscopia de Fotoelétrons (LEFE) do Instituto de Química da Universidade Estadual de São Paulo (IQ-UNESP), em Araraquara. A linha $M g K \alpha$ foi utilizada ( $h v=1253,6 \mathrm{eV}$ ) como fonte de ionização e a energia de passagem do analisador foi ajustada para $10 \mathrm{eV}$. A composição da camada da superficial $(<5 \mathrm{~nm})$ foi determinada pelas proporções relativas das áreas de picos corrigidas pelos fatores de sensitividade atômica de Scofield com uma precisão de $\pm 5 \%$ (SCOFIELD, 1976), a fim de observarmos a concentração de $\mathrm{N}_{2}$.

Ainda, no XPS, o ruído inelástico dos espectros de alta resolução Si 2p, O 1s C 1s e N 1s foi subtraído utilizando o método de Shirley (SHIRLEY, 1972) e a energia de ligação dos espectros foi corrigida usando a componente de hidrocarbonetos fixa em $285,0 \mathrm{eV}$. Os espectros foram deconvoluídos utilizando uma função do tipo Voigtiana, com combinações Gaussianas (70\%) e Lorentzianas (30\%). A largura à meia altura variou entre 1,2 e 2,1eV, e a posição dos picos foi determinada com uma precisão de $\pm 0,1 \mathrm{eV}$.

Na microscopia de força atômica (AFM), utilizou-se o NanoScope III da empresa Brucker, localizado no Laboratório de Filmes Finos (LFF) do Instituto de Física da Universidade de São Paulo (IF-USP). Foram empregados os modos contato e contato intermitente tapping mode, com varreduras horizontais de $10 \mu \mathrm{m}$ e $1 \mu \mathrm{m}$, em ambos os modos utilizou-se uma ponta com força de $0,5 \mathrm{~N} / \mathrm{m}$ e uma mesa redutora de ruídos (necessária para trabalharmos com filmes finos). Para obtenção dos perfis de alturas dos quais a rugosidade RMS das amostras foi extraída. A planarização das imagens foi realizada através de um filtro chamado flatten, pertencente ao próprio software do equipamento.

\subsection{Capacitores MOS}

A seguir estão descritos os procedimentos empregados na fabricação dos capacitores e células solares MOS e os procedimentos empregados na caracterização elétrica dos mesmos. 


\subsubsection{Fabricação de capacitores MOS}

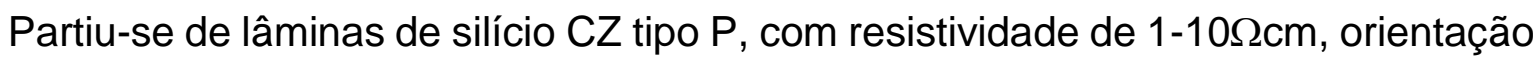
$<100>$ as quais foram limpas quimicamente por receita modificada seguido por oxidação térmica para o crescimento do óxido de porta, ambas descritas no subitem 3.1.2 deste capítulo.

Os parâmetros da oxidação térmica rápida utilizados para o crescimento destes óxidos consideram o processo de carregamento de amostras com entrada e saída rápidas (em 5s), em um forno aquecido a $850^{\circ} \mathrm{C}$, para a diversas proporções de ambiente gasoso proveniente de mistura entre nitrogênio e oxigênio descritas (4:3, $3: 1,5: 1$ e 10:1), para 80 ou 160 s de tempo de processamento. Adicionalmente, algumas amostras passaram por uma passivação de $80 \mathrm{~s}$ em ambiente de $\mathrm{N}_{2}$, imediatamente, após o tempo de processamento descrito.

Imediatamente após a oxidação térmica rápida, depositou-se $200 \mathrm{~nm}$ de alumínio à 6×10-6torr de pressão e $150 \mathrm{~mA}$ de corrente, por evaporação térmica, em equipamento metalizador Auto 306 Edwards. Para a formação da área de porta nos capacitores MOS, utilizou-se uma máscara mecânica com pequenas áreas circulares de 2,13×10${ }^{2} \mathrm{~cm}^{2}$ (figura 3.5). 
Figura 3.5 - Esquema de evaporação térmica para formação da área de porta dos capacitores MOS.

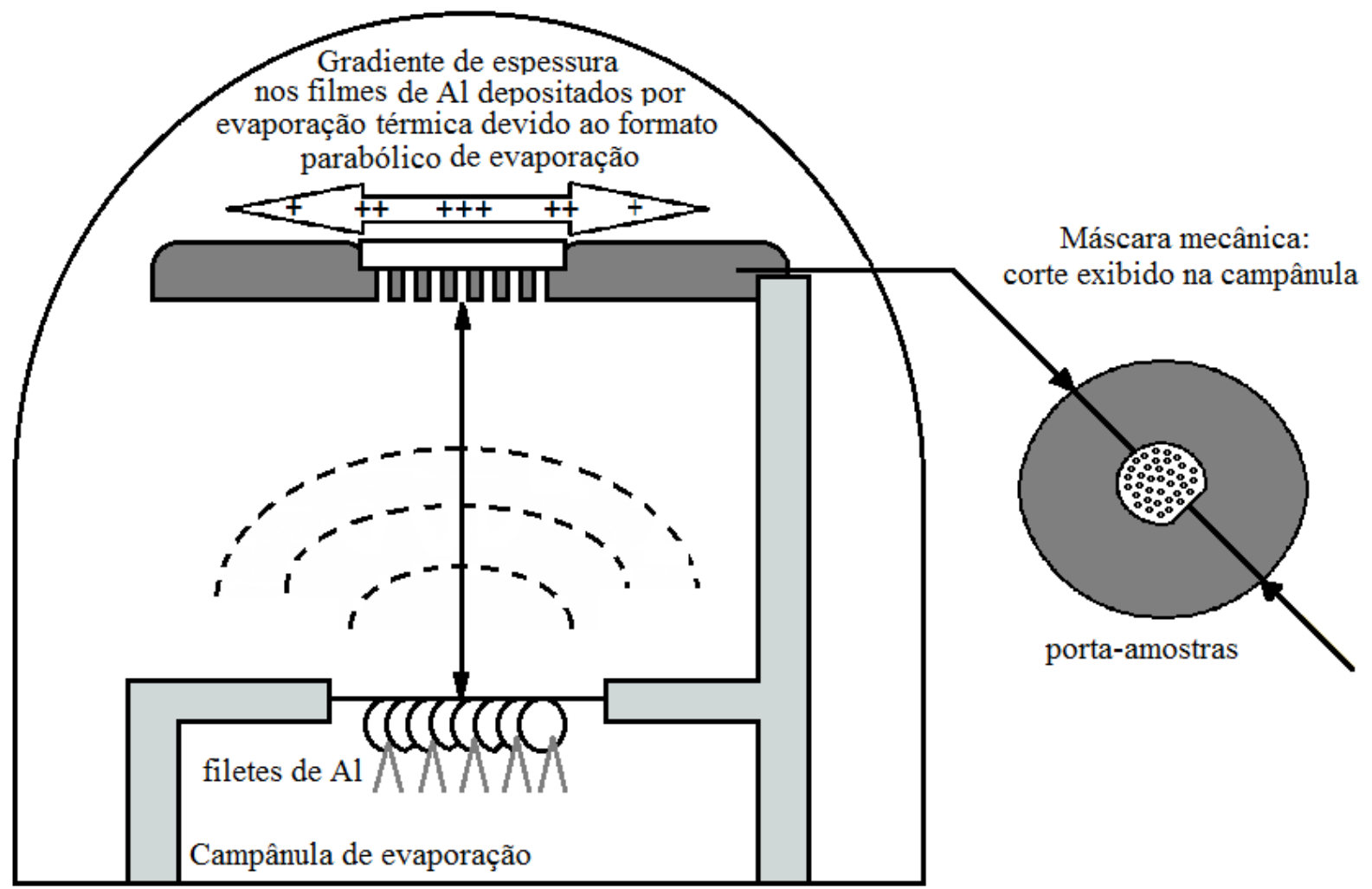

Fonte: Adaptado (CHRISTIANO, 2012).

Para a formação do contato elétrico no verso do substrato de silício, o óxido crescido foi removido em solução 10:1 de água deionizada e ácido fluorídrico, e, então, depositou-se outros $200 \mathrm{~nm}$ de alumínio, como descrito anteriormente. A estrutura física dos capacitores MOS segue representada na figura 3.6.

Figura 3.6 - Estrutura física dos capacitores MOS.

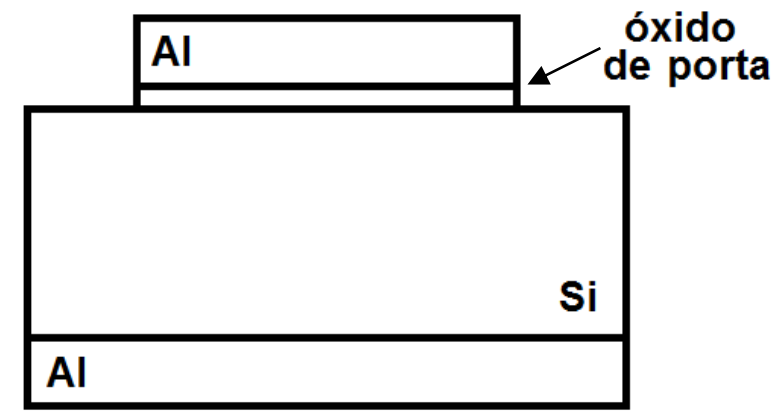

Fonte: Autor. 


\subsubsection{Medidas elétricas em capacitores MOS}

A caracterização elétrica dos capacitores MOS, com estrutura apresentada na figura 3.6, foi realizada por meio de curvas capacitância $x$ tensão $(C V)$ e corrente $x$ tensão (IV), medidas em equipamentos contidos em caixas pretas aterradas.

As curvas CV foram extraídas por meio do equipamento HP4280. As medidas foram efetuadas, inicialmente, na presença de luz, a fim de eliminar o efeito de depleção profunda, partindo da região de inversão para a região de acumulação. Todas as medidas foram realizadas com passo de $10 \mathrm{mV}$ e frequência de $1 \mathrm{MHz}$, como mostra o esquema de medida apresentado na figura 3.7 .

Figura 3.7 - Desenho esquemático do equipamento de medida CV para capacitores MOS.

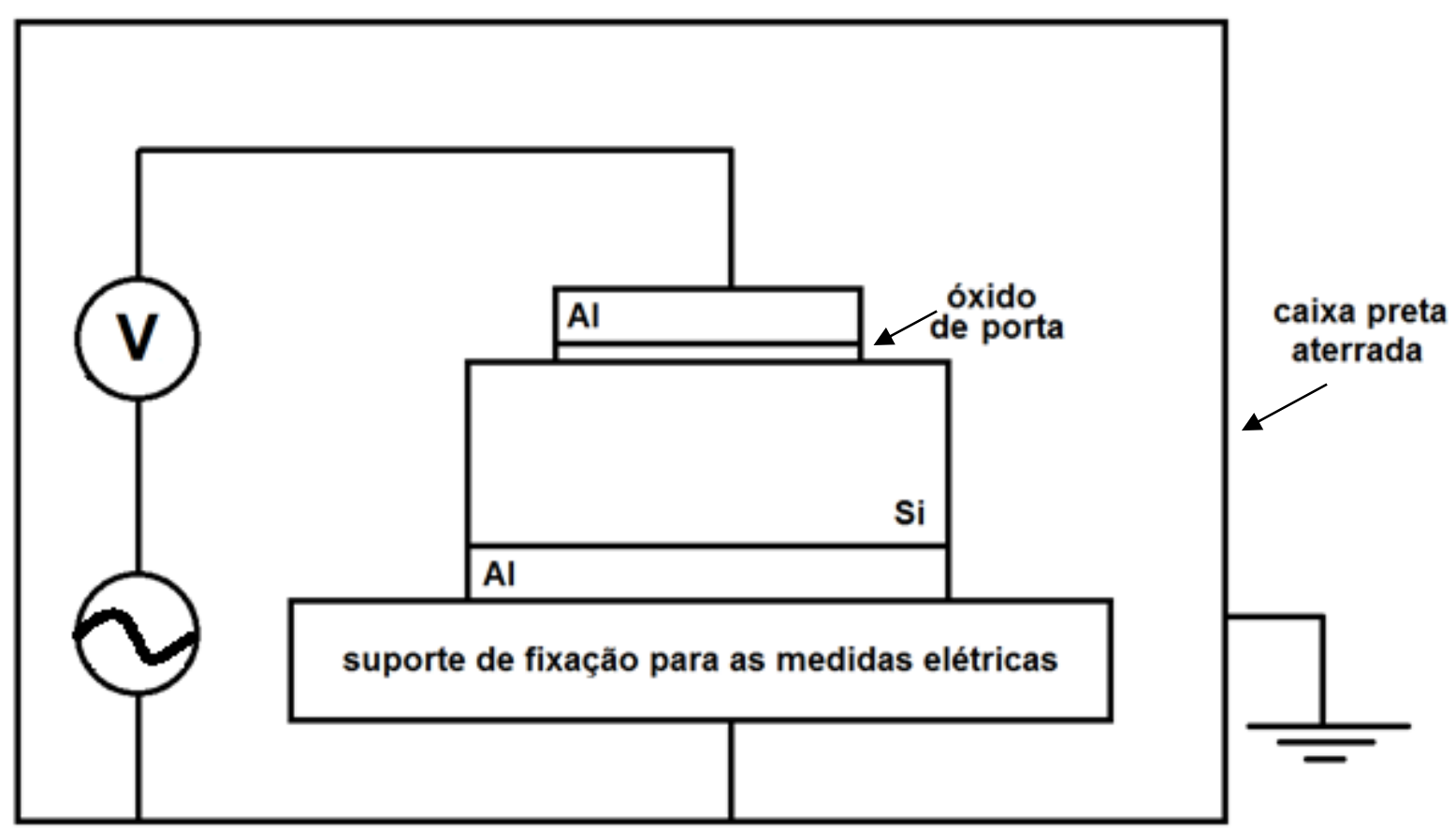

Fonte: Autor.

\subsection{Células Solares MOS}

Com base na análise preliminar das características elétricas dos capacitores MOS (apresentadas no capítulo 4.4), as receitas para fabricação de células solar MOS 
foram definidas, e seguem descritas nesse capítulo. Também, são apresentadas, as técnicas de análise adotadas para caracterizá-las.

\subsubsection{Fabricação das células solares MOS}

Para a fabricação de células solares MOS, foram utilizados substratos de silício CZ tipo $P$, orientação $\langle 100\rangle$, com resistividade de $0,2-1 \Omega \mathrm{cm}$ e $1-10 \Omega \mathrm{cm}$.

A oxidação térmica rápida descrita para os capacitores MOS foi seguida, mantendose a temperatura de aquecimento do forno em $850^{\circ} \mathrm{C}$, e o ambiente misto de nitrogênio e oxigênio em proporção $5 \mathrm{~N}_{2}: 1 \mathrm{O}_{2}$, e quanto ao tempo de processamento, este foi tipicamente $80 \mathrm{~s}$ com passivação em ambiente de $\mathrm{N}_{2}$ por mais $80 \mathrm{~s}$, e em testes específicos empregou-se também os tempos de processamento de $0,10,20,160 \mathrm{e}$ 220 s.

Após a oxidação térmica rápida, uma camada de $200 \mathrm{~nm}$ de alumínio foi depositada por toda a superfície da lâmina de 3 polegadas, de acordo com os padrões descritos para o capacitor MOS (capítulo 3.2.1). A definição da área $\left(A_{g}\right)$ das células solares MOS foi realizada por litografia, alcançando-se o padrão de imagem exibido na tabela 3.1., utilizando a estrutura de "espinha de peixe".

Tabela 3.1 - Geometria das células solares MOS: largura de linha (L), distância entre linhas (D), número de linhas $\left(N^{\circ} L\right)$, área $\left(A_{g}\right)$ e perímetro.

\begin{tabular}{|l|c|c|c|c|c|c|}
\hline & Dispositivo & $\begin{array}{c}\mathbf{L} \\
(\mu \mathrm{m})\end{array}$ & $\begin{array}{c}\mathbf{D} \\
(\mu \mathrm{m})\end{array}$ & $\mathbf{N}^{\circ} \mathbf{L}$ & $\begin{array}{c}\mathbf{A}_{\mathbf{g}} \\
\left(\mathbf{c m}^{\mathbf{2}}\right)\end{array}$ & $\begin{array}{c}\text { Perímetro } \\
(\mathbf{c m})\end{array}$ \\
\cline { 3 - 8 } & $\mathbf{5 0 \times 5 0}$ & 50 & 50 & 180 & 1,63 & 651,6 \\
\cline { 3 - 8 } & $\mathbf{5 0 \times 1 0 0}$ & 50 & 100 & 120 & 1,09 & 434,4 \\
\cline { 3 - 8 } & $\mathbf{1 0 0 \times 1 0 0}$ & 100 & 100 & 90 & 1,63 & 325,8 \\
\cline { 3 - 8 } & $\mathbf{1 0 0 \times 1 5 0}$ & 100 & 150 & 71 & 1,34 & 257,0 \\
\hline
\end{tabular}

Fonte: Autor.

Foram produzidas 49 lâminas de 3 polegadas de diâmetro, cada uma contendo 4 dispositivos com os detalhes de largura de linha (L) e da distância entre elas (D) 
indicados na tabela 3.1. Todos os dispositivos foram conectados em um pad de $300 \times 300 \mu \mathrm{m}^{2}$. A identificação de cada dispositivo ao longo do capítulo de resultados foi feita através da indicação largura $x$ distância $(L x D)$.

Como descrito para os capacitores MOS, no capítulo 3.2, o óxido crescido nas costas foi removido e uma nova camada de $200 \mathrm{~nm}$ de alumínio foi evaporada para formação do contato elétrico dos dispositivos.

Por fim, cabe mencionar que as características das células solares apresentadas no capítulo 4 são reprodutíveis pelo fato de que 49 lâminas com 4 dispositivos cada resultaram em um total de 196 células solares MOS fabricadas e analisadas ao longo do período de confecção desta tese, na qual também estão destacados todos os comportamentos típicos observados.

\subsubsection{Caracterização das células solares MOS}

A caracterização elétrica das células solares MOS, consistiu na extração de curvas corrente $x$ tensão (IV), medidas da região de acumulação para a região de inversão em equipamento Agilent $4556 \mathrm{C}$ de acordo com o esquema de medição apontado na figura 3.8. 
Figura 3.8 - Desenho esquemático do equipamento de medida IV para células solares MOS.

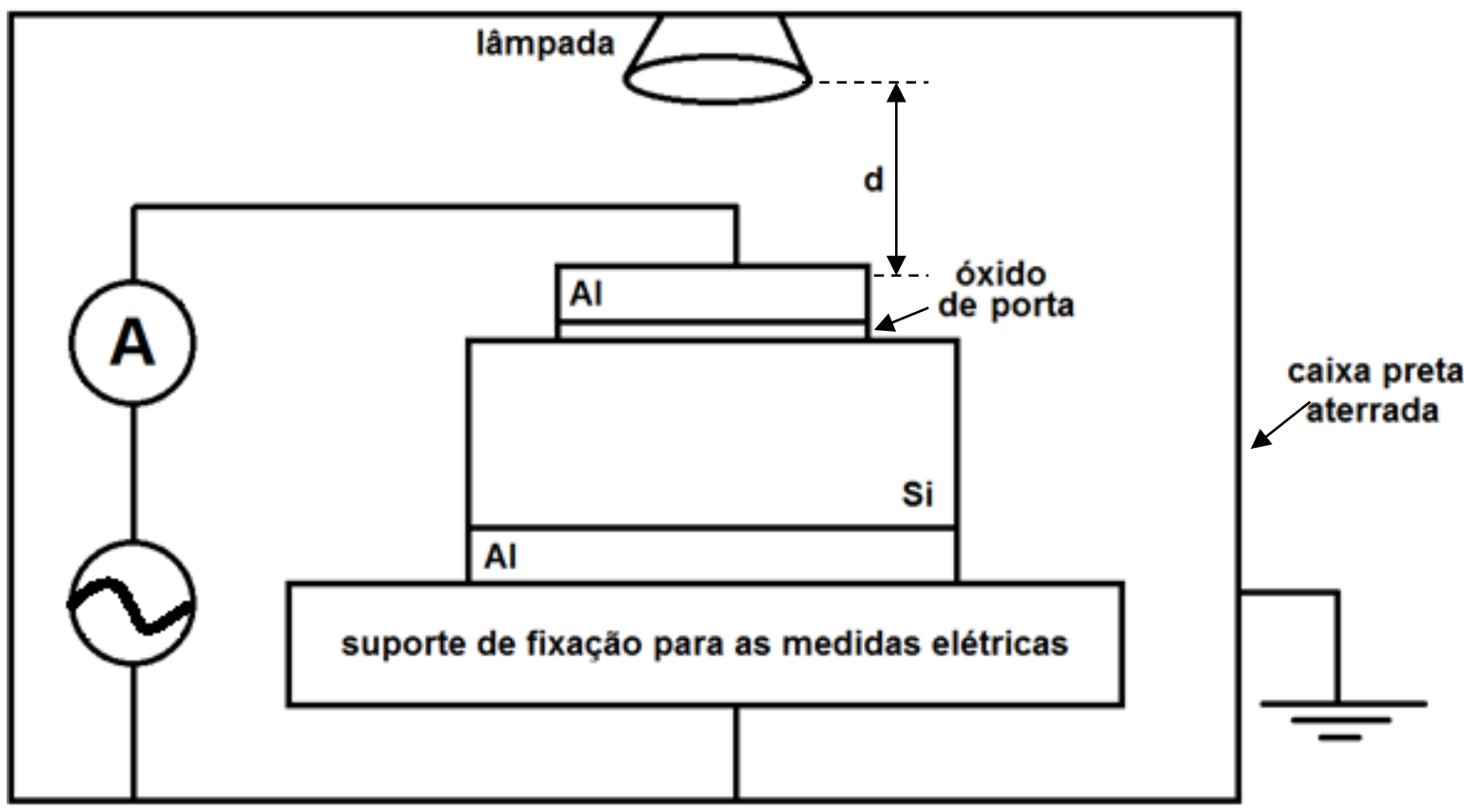

Fonte: Autor.

Assim como descrito para os capacitores MOS, mediu-se todas as curvas com uma rampa de tensão de $0,1 \mathrm{~V} / \mathrm{s}$ aplicada ao substrato da amostra, adotando-se uma varredura de $4 \mathrm{~V}$. Algumas medidas foram realizadas completamente no escuro, ou na presença de luz proveniente de lâmpadas dicroicas (LED ou halógena).

As lâmpadas dicroicas empregadas no presente trabalho foram adquiridas para operar com de 127V proveniente de fonte de alimentação constante e estável. As características individuais da lâmpada LED foram: potência 1,5W; corrente de alimentação de 0,023A e intensidade luminosa (IL) de $280 \mathrm{~cd}$; enquanto que as características da lâmpada halógena foram: potência de 50W; corrente de alimentação 0,36A e intensidade luminosa (IL) de 650cd. A literatura reporta que a relação entre a intensidade luminosa em candela (cd) e a intensidade radiante incidente sobre a amostra em $\mathrm{W} / \mathrm{cm}^{2}\left(I_{0}\right)$ é dada por:

$$
I_{o}=\frac{I L}{683} \cdot \frac{1}{d^{2}} \cdot \frac{\Delta \lambda}{\int_{\Delta \lambda} V(\lambda) d \lambda}=\frac{I L}{683} \cdot \frac{1}{d^{2}} \cdot f(\Delta \lambda)
$$


onde $d$ é a distância da fonte luminosa até a amostra conforme indicado na figura 3.8, $\Delta \lambda$ é a faixa de comprimentos de onda emitidos pela fonte luminosa e $V(\lambda)$ é a função de luminosidade monocromática que é um número adimensional menor que "1" e deve ser integrada em toda a faixa de comprimentos de onda emitidos pela fonte luminosa.

Os espectros típicos de emissão das lâmpadas LED e halógena estão indicados na figura 3.9.

Figura 3.9 - Espectros típicos de emissão da lâmpada LED (a) e lâmpada halógena comparada ao espectro solar sem influência da atmosfera (b).

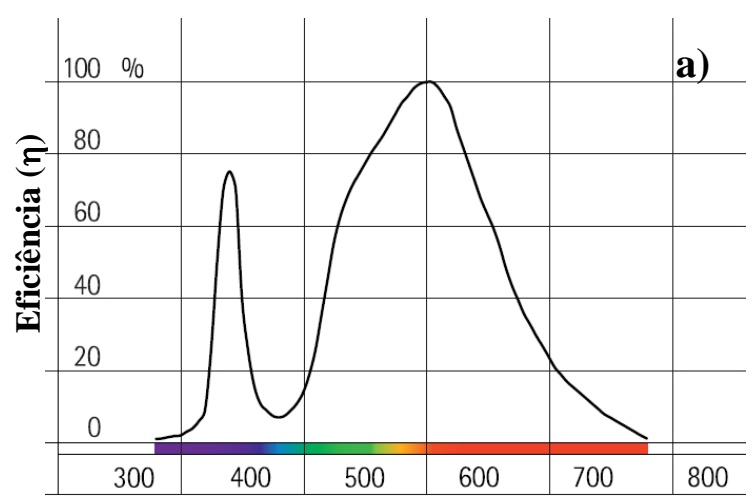

Comprimento de onda $(\lambda)$ em nm

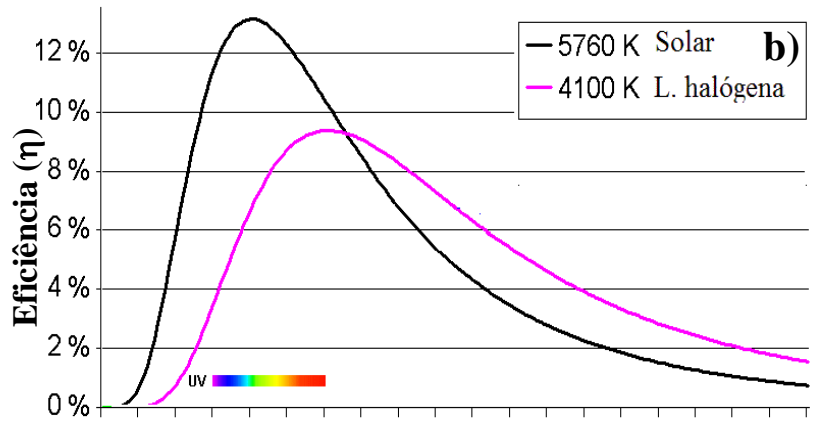

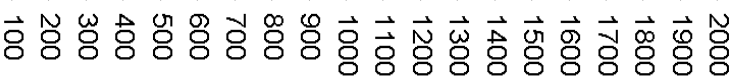

Comprimento de onda $(\lambda) \mathrm{em} \mathbf{~ n m}$

Fonte: Adaptado de (EUROLUX, 2015).

Observa-se na figura 3.9 que os espectros de emissão das lâmpadas LED branca e halógena são muito distintos sendo que a lâmpada halógena engloba também a faixa de infravermelho próximo e distante (>1000nm). É interessante também observar que a emissão da lâmpada halógena ocupa uma faixa de comprimentos de onda que vai desde o visível até o infravermelho distante a qual também é ocupada pelo espectro solar apesar dos mesmos não casarem quanto às suas intensidades.

Nos testes de iluminação das células solares foram utilizadas distâncias "d" (veja figura 3.8) entre a lâmpada halógena e a amostra de 3, 6 e $9 \mathrm{~cm}$. No caso das lâmpadas LED foi empregada apenas a distância de $3 \mathrm{~cm}$. Baseado nestas distâncias foi possível calcular através da equação 3.3 a intensidade radiante incidente por unidade de área $\left(I_{o}\right)$, conforme indicado na tabela 3.2, supondo o fator $f(\Delta \lambda)$ unitário o 
que significa admitir que a interação de toda a luz na faixa de comprimentos de onda emitidos pelas lâmpadas halógena e LED branca foi predominantemente superficial nas células solares MOS. Essa suposição será avaliada no capítulo 4.

Tabela 3.2 - Intensidade radiante incidente por unidade de área $\left(\mathrm{l}_{\mathrm{o}}\right)$ para a lâmpada halógena $(\mathrm{d}=3$, $6,9 \mathrm{~cm})$ e para a lâmpada LED branca $(\mathrm{d}=3 \mathrm{~cm})$

\begin{tabular}{|c|c|c|}
\hline $\boldsymbol{d}(\mathbf{c m})$ & Lâmpada & $\boldsymbol{I}_{\boldsymbol{o}}\left(\mathbf{m W} / \mathbf{c m}^{2}\right)$ \\
\hline \hline 9 & Halógena $(650 \mathrm{~cd})$ & 11,75 \\
\hline 6 & Halógena $(650 \mathrm{~cd})$ & 26,44 \\
\hline 3 & Halógena $(650 \mathrm{~cd})$ & 105,74 \\
\hline 3 & LED $(280 \mathrm{~cd})$ & 42,3 \\
\hline
\end{tabular}

Fonte: Autor. 


\section{RESULTADOS E DISCUSSÕES}

Este capítulo descreve os resultados e discussões sobre a fabricação de células solares MOS utilizando oxinitretos de silício obtidos por processamento térmico rápido. Após a descrição da adaptação de um forno térmico convencional para funcionar como um forno de processamento térmico rápido (RTP) conforme foi detalhado no item 3.1.1, serão mostrados na sequência os resultados e a discussão sobre a extração dos perfis temporais de temperatura durante os processos RTP, a caracterização das espessuras crescidas dos oxinitretos de silício em função do tempo de processamento, a caracterização das propriedades de tunelamento dos dielétricos crescidos através de capacitores MOS e as características das células solares MOS em áreas extensas $\left(\sim 3 \mathrm{~cm}^{2}\right)$ utilizando os dielétricos previamente caracterizados.

\subsection{Extração dos perfis temporais de temperatura durante os processos RTP}

A seguir são descritos os resultados sobre a extração dos perfis temporais de temperatura nos processos RTP para o tubo de quartzo nas situações com e sem deslocamento em relação ao banco de resistências de forma a obter duas temperaturas de partida distintas na "boca do forno" para a lâmina de silício: uma mais baixa para a situação em que o tubo de quartzo é deslocado $10 \mathrm{~cm}$ para fora em relação ao banco de resistências e outra mais alta na situação em que o tubo de quartzo não é deslocado. A figura 4.1 ilustra esse deslocamento e a correspondente compensação em distância percorrida pela vareta de quartzo para que a lâmina fique sempre no meio do forno. Além disso, uma nova marcação manual na vareta de quartzo foi realizada a fim de introduzir a lâmina $10 \mathrm{~cm}$ a mais à dentro do forno $\mathrm{e}$ assim compensar o deslocamento de $10 \mathrm{~cm}$ do tubo de quartzo para fora em relação ao banco de resistências. 
Figura 4.1 - llustração do deslocamento do tubo de quartzo em $10 \mathrm{~cm}$ para fora em relação ao banco de resistências.

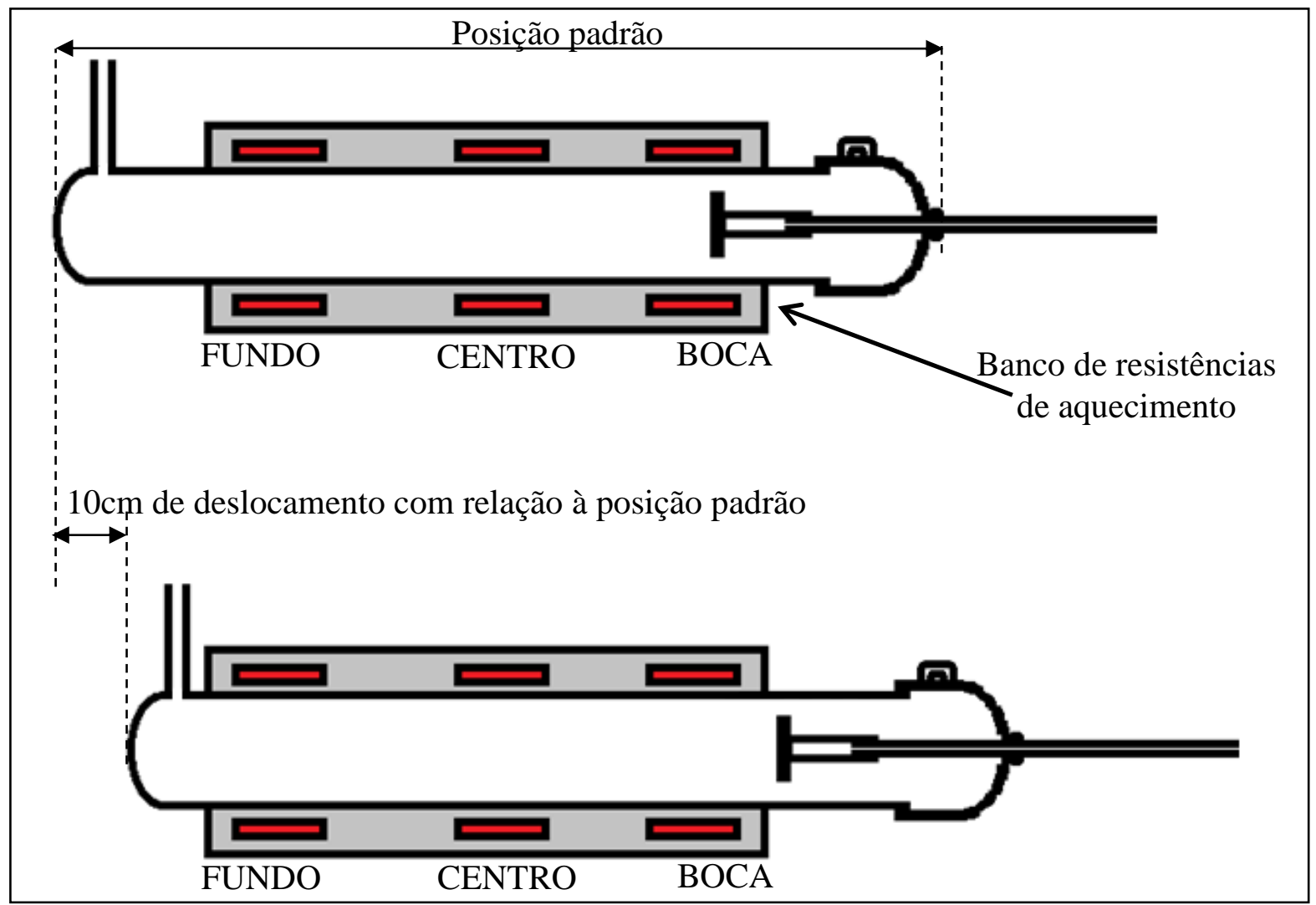

Fonte: Autor.

Desta forma, é imprescindível extrair o perfil de temperatura para o processo RTP a fim de estabelecer a influência da temperatura inicial da "boca" (entrada) do forno no crescimento dos filmes dielétricos.

O levantamento dos perfis temporais de temperatura para o forno em 700 e $850^{\circ} \mathrm{C}$ foi realizado como descrito no item 3.1.3, considerando o tubo de quartzo em seu posicionamento sem deslocamento ou posicionamento padrão (figura 4.2.a para $700^{\circ} \mathrm{C}$ e figura $4.2 . \mathrm{c}$ para $850^{\circ} \mathrm{C}$ ) e com o deslocamento de $10 \mathrm{~cm}$ (figura 4.2.b para $700^{\circ} \mathrm{C}$ e figura $4.2 . \mathrm{d}$ para $850^{\circ} \mathrm{C}$ ). Definimos o parâmetro "tempo de processamento" como sendo o tempo total em que a lâmina de silício fica posicionada no centro do forno. Portanto, o tempo de processamento engloba o tempo de subida e o tempo de patamar na figura 4.2 . 
Figura 4.2 - Imagem ampliada do perfil de temperatura para 80s de tempo de processamento nas temperaturas de $700^{\circ} \mathrm{C}$ e $850^{\circ} \mathrm{C}$ nas situações sem deslocamento do tubo de quartzo (a e b) e com deslocamento do tubo de quartzo (c e d), respectivamente.
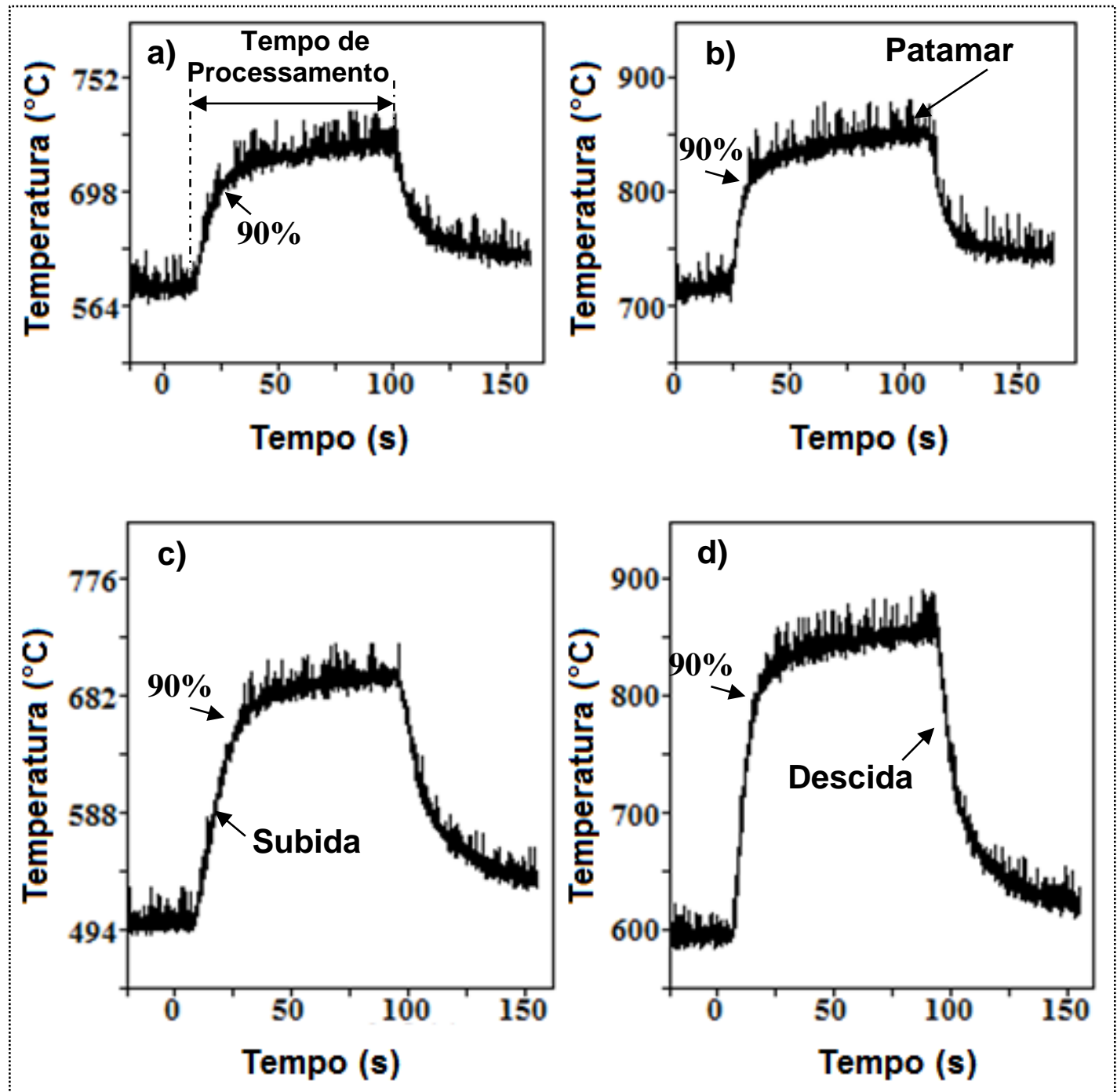

Fonte: Autor.

É importante destacar na figura 4.2 dois pontos importantes: a) a temperatura inicial na "boca" do forno passa de $565^{\circ} \mathrm{C}$ (sem deslocamento) para $494^{\circ} \mathrm{C}$ (com deslocamento de $10 \mathrm{~cm}$ ) para o forno pré-aquecido a $700^{\circ} \mathrm{C}$ e b) a temperatura inicial na "boca" do forno passa de $710^{\circ} \mathrm{C}$ (sem deslocamento) para $600^{\circ} \mathrm{C}$ (com deslocamento de $10 \mathrm{~cm}$ ) para o forno pré-aquecido a $850^{\circ} \mathrm{C}$.

Nas tabelas 4.1 e 4.2 estão apresentadas as temperaturas medidas após a estabilização no patamar de entrada na "boca" do forno (cerca de 3 min após a inserção da amostra), a 90\% da subida (durante a inserção da amostra no centro do forno) e após a estabilização no patamar de saída na boca do forno (ao fim do tempo 
de processo). Na tabela 4.1 são apresentados os valores medidos para o tubo de quartzo sem deslocamento aquecido a 700 ou $850^{\circ} \mathrm{C}$ e, na tabela 4.2, são exibidos os valores de temperatura medidos para o tubo de quartzo com deslocamento de $10 \mathrm{~cm}$ para fora em relação ao banco de resistências, para as mesmas temperaturas (700 ou $850^{\circ} \mathrm{C}$ ) e todos os tempos de processo empregados no crescimento dos óxidos. As medições foram todas realizadas através de termopar comercial colado na lâmina de silício como indicado na figura 3.3 .

Tabela 4.1 - Temperaturas medidas na entrada do forno, a $90 \%$ da rampa de subida do processo (centro) e novamente na entrada do forno após a saída da lâmina, estando o forno pré-aquecido a 700 ou $850^{\circ} \mathrm{C}$, para o tubo de quartzo sem deslocamento.

\begin{tabular}{|c|c|c|c|c|c|c|}
\hline \multirow{2}{*}{$\begin{array}{c}\text { Tempo de } \\
\text { oxidação }\end{array}$} & \multicolumn{4}{|c|}{ Temperaturas medidas para o tubo de quartzo sem deslocamento $\left({ }^{\circ} \mathbf{C}\right)$} \\
\cline { 2 - 6 }$(\mathbf{s})$ & \multicolumn{2}{|c|}{ Forno aquecido a 700 ${ }^{\circ} \mathbf{C}$} & \multicolumn{2}{c|}{ Forno aquecido a $850{ }^{\circ} \mathbf{C}$} \\
\cline { 2 - 7 } & entrada & centro & Saída & entrada & centro & saída \\
\hline $\mathbf{1 0}$ & 550 & 654 & 570 & 630 & 744 & 645 \\
\hline $\mathbf{2 0}$ & 570 & 653 & 580 & 640 & 756 & 665 \\
\hline $\mathbf{4 0}$ & 560 & 660 & 585 & 640 & 760 & 660 \\
\hline $\mathbf{8 0}$ & 560 & 668 & 580 & 645 & 765 & 670 \\
\hline $\mathbf{1 6 0}$ & 560 & 675 & 585 & 630 & 770 & 670 \\
\hline
\end{tabular}

Fonte: Autor.

Tabela 4.2 - Temperaturas medidas na entrada do forno, a $90 \%$ da rampa de subida do processo (centro) e novamente na entrada do forno após a saída da lâmina, estando o forno pré-aquecido a 700 ou $850^{\circ} \mathrm{C}$, para o tubo de quartzo com deslocamento de $10 \mathrm{~cm}$.

\begin{tabular}{|c|c|c|c|c|c|c|}
\hline \multirow{2}{*}{$\begin{array}{c}\text { Tempo de } \\
\text { oxidação } \\
(\mathbf{s})\end{array}$} & \multicolumn{6}{|c|}{$\begin{array}{c}\text { Temperaturas medidas para o tubo de quartzo com deslocamento de } \mathbf{1 0} \mathbf{~ c m} \\
\left({ }^{\circ} \mathbf{C}\right)\end{array}$} \\
\cline { 2 - 7 } & \multicolumn{2}{|c|}{ Forno aquecido a $\mathbf{7 0 0}{ }^{\circ} \mathbf{C}$} & \multicolumn{2}{c|}{ Forno aquecido a $\mathbf{8 5 0}{ }^{\circ} \mathbf{C}$} \\
\cline { 2 - 7 } & entrada & centro & Saída & entrada & centro & saída \\
\hline $\mathbf{1 0}$ & 475 & 610 & 490 & 530 & 738 & 540 \\
\hline $\mathbf{2 0}$ & 480 & 643 & 490 & 530 & 750 & 535 \\
\hline $\mathbf{4 0}$ & 480 & 665 & 500 & 530 & 755 & 535 \\
\hline $\mathbf{8 0}$ & 480 & 670 & 500 & 530 & 775 & 540 \\
\hline $\mathbf{1 6 0}$ & 480 & 680 & 515 & 530 & 780 & 540 \\
\hline
\end{tabular}

Fonte: Autor. 
Comparando os valores de temperatura na entrada do forno para $700^{\circ} \mathrm{C}$, nas tabelas 4.1 e 4.2, observa-se uma redução de cerca de $80^{\circ} \mathrm{C}$ quando há o deslocamento do tubo de quartzo em $10 \mathrm{~cm}$ para fora do banco de resistências de aquecimento. Para $850^{\circ} \mathrm{C}$, a redução de temperatura é ainda mais significativa, de aproximadamente $110^{\circ} \mathrm{C}$.

$\mathrm{Na}$ figura 4.3, são apresentadas as temperaturas medidas a $90 \%$ da rampa de subida da temperatura na lâmina de silício (logo que a amostra é inserida no centro do forno) para 700 e $850^{\circ} \mathrm{C}$, com e sem deslocamento do tubo de quartzo. Através da figura 4.3.a, observa-se que a variação na temperatura medida é mais significativa para os tempos de processamento de 10 e 20s porque não chega a ser atingido nenhum patamar de temperatura $\left(\sim 700^{\circ} \mathrm{C}\right)$ nesses casos. Isso significa que a medida foi feita a $90 \%$ da temperatura máxima que a lâmina atinge logo após o término do tempo de processamento (indicado no eixo horizontal da figura 4.3). Para a temperatura de $850^{\circ} \mathrm{C}$ (figura 4.3.b), observa-se o mesmo efeito, porém, menos acentuado do que para os $700^{\circ} \mathrm{C}$.

Figura 4.3 - Medidas de temperatura a $90 \%$ da subida da temperatura (medida a partir do momento em que a amostra é posicionada no centro do forno), considerando o tubo de quartzo nas situações sem deslocamento e com deslocamento de $10 \mathrm{~cm}$, para: a) $700^{\circ} \mathrm{C}$ e b) $850^{\circ} \mathrm{C}$.
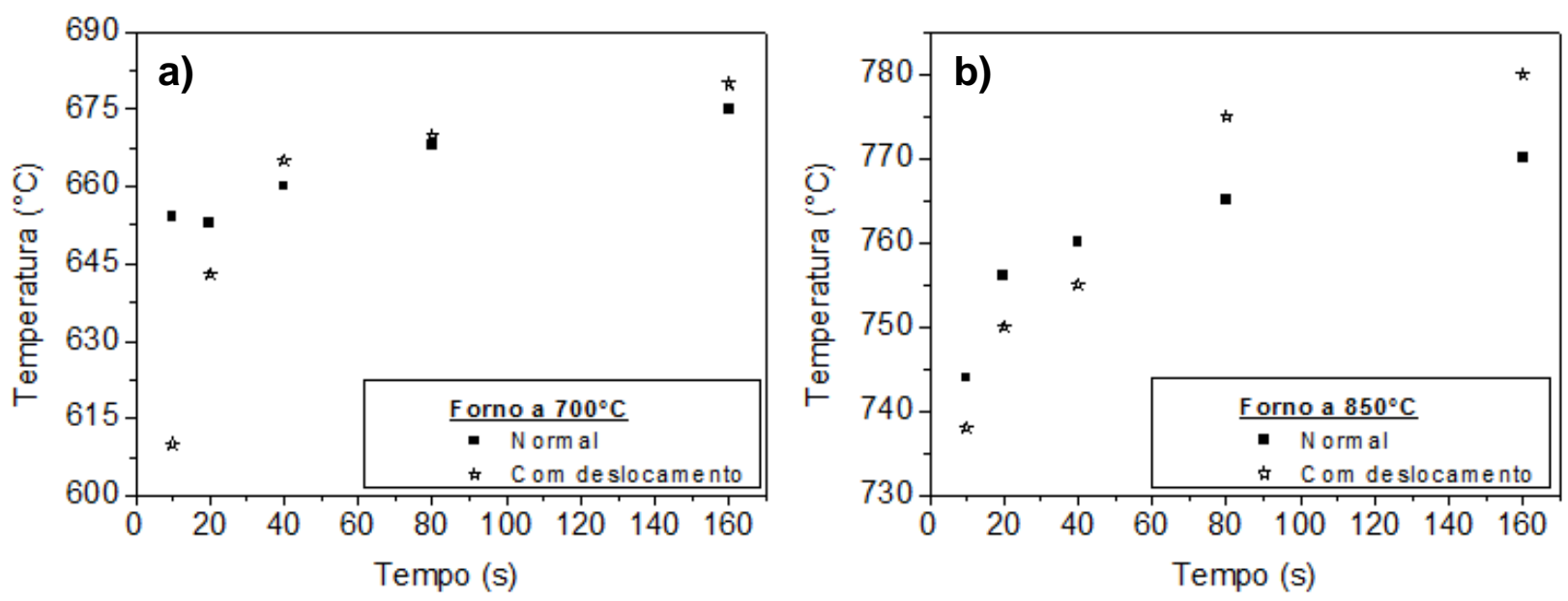

Fonte: Autor.

O perfil de temperatura da amostra foi também obtido para o forno pré-aquecido a $1150^{\circ} \mathrm{C}$. Neste caso, iniciou-se pelas medidas com o tubo de quartzo deslocado para 
fora em $10 \mathrm{~cm}$ e, na sequência, realizou-se o mesmo procedimento para o tubo de quartzo sem deslocamento conforme indicado na figura 4.1.

$\mathrm{Na}$ figura 4.4, é possível visualizar a evolução do perfil temporal de temperatura partindo do patamar de temperatura inicial na "boca" (extremidade) do forno, seguido da entrada via vareta de quartzo (veja figura 3.1) em 5 s e a oxidação por 70 s seguido de retirada rápida durante $5 \mathrm{~s}$ (figura 4.4.a). A figura 4.4b ilustra o mesmo processo, porém com retirada lenta em 5 min. Para a retirada lenta, observou-se que a amostra permanece com a mesma temperatura de processo por aproximadamente 3min, após o tempo de processamento. Em seguida, ela passa a decrescer a cada movimentação da vareta em direção à boca do forno. Este mesmo efeito pode ser visualizado para as amostras que foram oxidadas durante 140s. Este maior período com temperatura elevada implica em maior espessura das amostras que passam por retirada lenta.

Figura 4.4 - Perfis temporais de temperatura para o forno pré-aquecido a $1150^{\circ} \mathrm{C}$, tubo de quartzo com deslocamento de $10 \mathrm{~cm}$ e tempo de processo equivalente de $70 \mathrm{~s}$, com saída: a) rápida (normal realizada em $5 \mathrm{~s}$ ) ou b) lenta $(\mathrm{L})$.

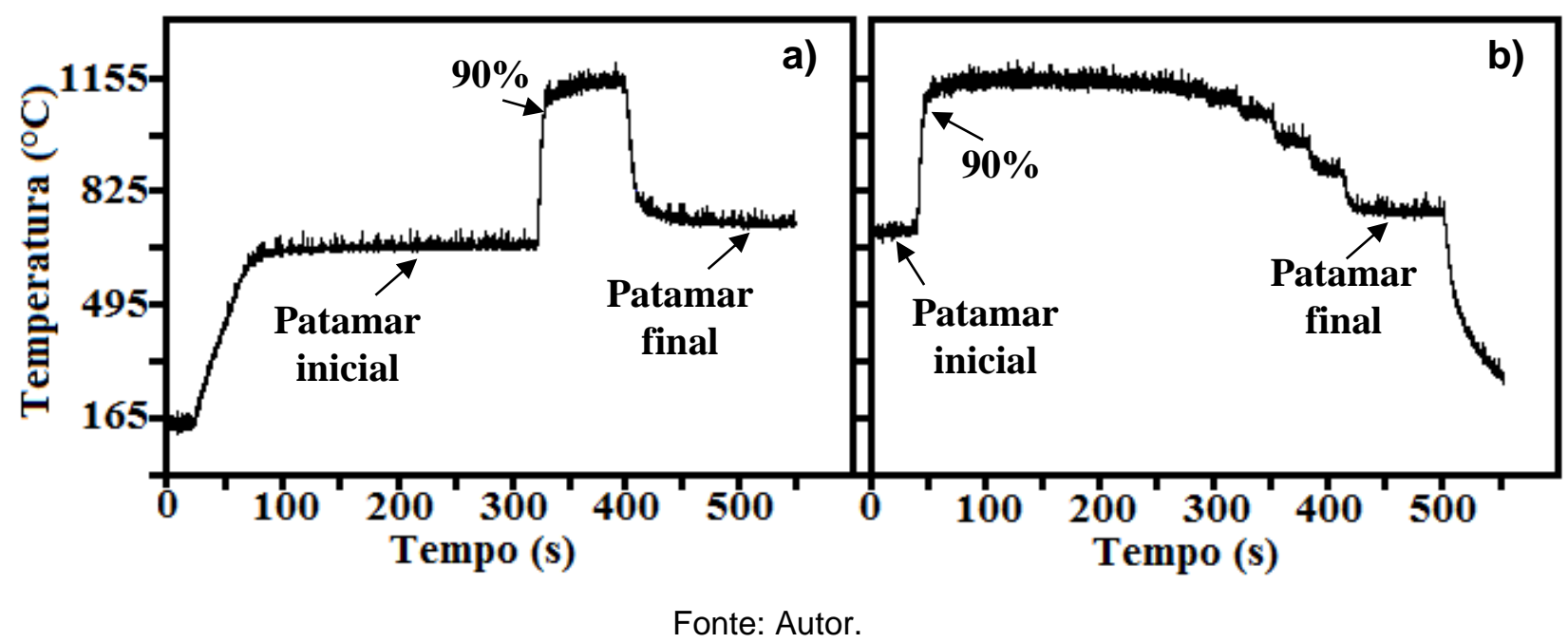

Foram obtidas também imagens ampliadas da rampa de subida da temperatura (figura 4.5.a) cujo tempo de subida resultou em aproximadamente $6 \mathrm{~s}$ e também para a rampa de descida (figura 4.5.b) onde o tempo de descida resultou em aproximadamente 9s quando a lâmina é retirada rapidamente a partir do centro do 
tubo de quartzo. Ou seja, a amostra atinge o patamar de temperatura de processo mais rapidamente comparado ao processo de descida da temperatura.

Figura 4.5 - Medidas de tempos de subida e descida para o forno pré-aquecido a $1150^{\circ} \mathrm{C}$.

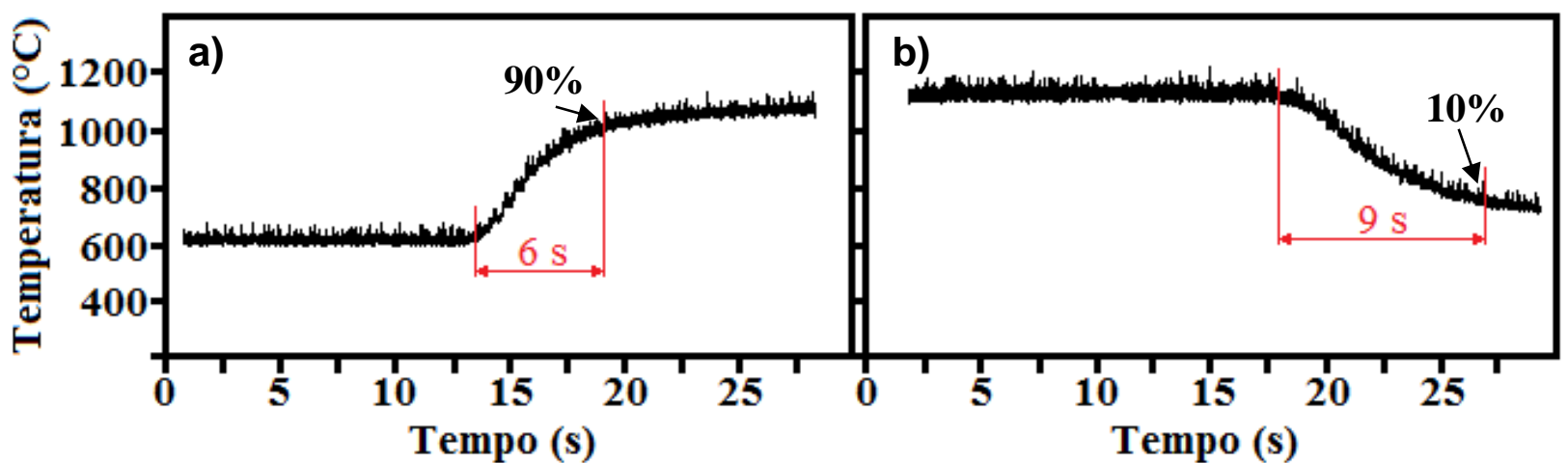

Fonte: Autor.

$\mathrm{Na}$ tabela 4.3, estão apresentados os valores de temperatura na entrada do forno após a saída da lâmina com termopar colado, e com a lâmina no centro do forno atingindo $90 \%$ da temperatura final no patamar de processo. Os valores de temperatura obtidos no centro do forno (a $90 \%$ da subida), para o tubo de quartzo sem deslocamento ou com deslocamento de $10 \mathrm{~cm}$, não apresentaram variação significativa, porém os valores de temperatura para a lâmina posicionada na entrada do forno apresentaram redução de aproximadamente $240^{\circ} \mathrm{C}$ quando o tubo de quartzo é deslocado para fora em $10 \mathrm{~cm}$.

Tabela 4.3 - Temperaturas medidas na entrada do forno, a 90\% da rampa de processo (centro) e na entrada do forno após a saída da lâmina com termopar, com tubo de quartzo deslocado de $10 \mathrm{~cm}$ e sem deslocamento.

\begin{tabular}{|c|c|c|c|c|c|c|}
\hline \multirow{2}{*}{$\begin{array}{c}\text { Tempo de } \\
\text { oxidação }\end{array}$} & \multicolumn{4}{|c|}{ Temperaturas medidas com o forno aquecido a $1150{ }^{\circ} \mathbf{C}\left({ }^{\circ} \mathbf{C}\right)$} \\
\cline { 2 - 7 }$(\mathbf{s})$ & \multicolumn{2}{|c|}{ Com deslocamento de 10 cm } & \multicolumn{3}{c|}{ Sem deslocamento } \\
\cline { 2 - 7 } & entrada & centro & saída & entrada & centro & saída \\
\hline $\mathbf{7 0}$ & 640 & 1040 & 700 & 892 & 1060 & 928 \\
\hline $\mathbf{7 0 L}$ & 640 & 1040 & 700 & 895 & 1060 & 915 \\
\hline $\mathbf{1 4 0}$ & 640 & 1060 & 690 & 885 & 1070 & 925 \\
\hline $\mathbf{1 4 0 L}$ & 630 & 1050 & 690 & 895 & 1070 & 930 \\
\hline
\end{tabular}

Fonte: Autor. 


\subsection{Resultados da espessura dos oxinitretos crescidos em função da temperatura e do tempo de processamento}

Inicialmente foi feita a limpeza química das lâminas de silício com 3 polegadas de diâmetro de acordo como o procedimento descrito no item 3.1.2. Foram fabricados três grupos de amostras intitulados: $\mathrm{G} 1$ = teste, $\mathrm{G} 2$ = sem deslocamento na boca do forno e G3 = com deslocamento na boca forno.

\subsection{1 - Grupo 1 (G1): Testes iniciais de oxidação.}

As amostras do grupo G1 foram oxidadas por processamento térmico rápido na temperatura de $700^{\circ} \mathrm{C}$ em quatro tempos de processamento, a saber: 10, 20, $40 \mathrm{e}$ 80s. $\mathrm{O}$ ambiente oxidante foi $\mathrm{O}_{2}$ puro, com fluxo de $1,5 \mathrm{~L} / \mathrm{min}$. As amostras foram nomeadas considerando o grupo pertencente e suas características de processos. No caso do grupo $\mathrm{G} 1$, o nome atribuído foi $\mathrm{G} 1$ seguido pelo número de imersões em solução diluída em HF ( 1 ou $2 x H F$ ), ao qual a amostra foi submetida na limpeza química (veja item 3.1 .2$)$, a temperatura $\left(700^{\circ} \mathrm{C}\right)$ e o tempo de processo $(10,20,40$ ou 80s).

$\mathrm{Na}$ tabela 4.4, são apresentados os valores médios de 9 pontos de espessura com desvio padrão, extraídos por elipsometria conforme descrito no item 3.1.4. É interessante observar que as espessuras das amostras submetidas a apenas uma imersão em HF são em média maiores do que as espessuras das amostras imersas duas vezes em HF. Neste caso, supõe-se que adicionar uma segunda imersão em HF ao final da limpeza química sature a quantidade de sítios de $\mathrm{Si}-\mathrm{H}$ na superfície do substrato de silício e, por consequência, a taxa de oxidação inicial na superfície do silício torne-se menor, o que está de acordo com o trabalho reportado por Kern (1990). 
Tabela 4.4 - Espessura média: G1 (teste).

\begin{tabular}{|c|c|c|c|}
\hline AMOSTRAS & ESPESSURA (nm) & AMOSTRAS & ESPESSURA (nm) \\
\hline G1-1xHF-700-10 & $1,27 \pm 0,03$ & G1-2xHF-700-10 & $1,20 \pm 0,04$ \\
\hline G1-1xHF-700-20 & $1,43 \pm 0,07$ & G1-2xHF-700-20 & $1,17 \pm 0,05$ \\
\hline G1-1xHF-700-40 & $1,71 \pm 0,01$ & G1-2xHF-700-40 & $1,20 \pm 0,05$ \\
\hline G1-1xHF-700-80 & $1,53 \pm 0,03$ & G1-2xHF-700-80 & $1,32 \pm 0,03$ \\
\hline
\end{tabular}

Fonte: Autor.

\subsubsection{Grupo 2 (G2): Oxinitretação (tubo de quartzo sem deslocamento)}

Através do grupo G2 foram iniciados os testes de oxinitretação em ambiente de $\mathrm{N}_{2}+\mathrm{O}_{2}$ com processamento no centro do forno conforme descrito no item 3.1.2. Durante o processamento RTP, tomou-se o cuidado para que a amostra estivesse posicionada no centro do forno onde a temperatura havia sido previamente calibrada para ser constante em uma extensão de cerca de $60 \mathrm{~cm}$. A limpeza química empregada foi a mesma do grupo $\mathrm{G} 1$, com apenas uma imersão final em solução diluída em HF como descrito no item 3.1.2.

A oxinitretação das amostras foi realizada nas temperaturas de 700,850 ou $1150^{\circ} \mathrm{C}$, em ambiente gasoso misto de $\mathrm{N}_{2}+\mathrm{O}_{2}$ (4:3). O processo de inserção e retirada das amostras está também descrito no item 3.1.2. Os tempos de processamento adotados para o RTP nas temperaturas de 700 e $850^{\circ} \mathrm{C}$ foram 10,20 , 40, 80 e 160s. Para $1150^{\circ} \mathrm{C}$, trabalhou-se com 70 s, com a retirada rápida ou lenta das lâminas de dentro do forno, como descrito anteriormente.

A nomenclatura das amostras é iniciada pela sigla do grupo 2 (G2), seguido pela temperatura e pelo tempo de processo. Para as amostras processadas a $1150^{\circ} \mathrm{C}$, a letra "L" que segue o tempo de processo indica que a retirada das amostras a partir do centro do forno foi lenta. 
Tabela 4.5 - Espessura média G2 (tubo de quartzo sem deslocamento).

\begin{tabular}{|c|c|c|c|}
\hline AMOSTRAS & ESPESSURA (nm) & AMOSTRAS & ESPESSURA (nm) \\
\hline G2-700-10 & $1,08 \pm 0,04$ & G2-850-10 & $1,71 \pm 0,05$ \\
\hline G2-700-20 & $1,19 \pm 0,02$ & G2-850-20 & $1,95 \pm 0,11$ \\
\hline G2-700-40 & $1,17 \pm 0,02$ & G2-850-40 & $1,99 \pm 0,08$ \\
\hline G2-700-80 & $1,33 \pm 0,03$ & G2-850-80 & $2,22 \pm 0,08$ \\
\hline G2-700-160 & $1,48 \pm 0,02$ & G2-850-160 & $2,53 \pm 0,04$ \\
\hline G2-1150-70 & $11,36 \pm 0,24$ & G2-1150-70L & $15,14 \pm 0,52$ \\
\hline
\end{tabular}

Fonte: Autor.

Na tabela 4.5 são apresentadas as espessuras médias de 9 pontos e os desviospadrão obtidos por elipsometria para as amostras do grupo G2. Observa-se que as amostras produzidas a $850^{\circ} \mathrm{C}$ são em média $0,83 \mathrm{~nm}$ mais espessas do que as amostras produzidas a $700^{\circ} \mathrm{C}$. Nas amostras obtidas a $1150^{\circ} \mathrm{C}$, a retirada lenta implicou em maior espessura média e maior desvio-padrão.

\subsubsection{Grupo 3 (G3): Oxinitretação (tubo de quartzo deslocado em $10 \mathrm{~cm}$ )}

No grupo 3 (G3), foram produzidas amostras mantendo as características de limpeza e oxidação descritas para o G2. O que distingue o G3 do G2 é um deslocamento de $10 \mathrm{~cm}$ realizado no tubo de quartzo com relação ao banco de resistências de aquecimento (figura 4.1), implicando em menor temperatura na entrada do forno. Além disso, uma nova marcação na vareta de quartzo foi realizada a fim de realizar o avanço de $10 \mathrm{~cm}$ para o centro do forno (veja figura 3.10) para que a lâmina de silício estivesse posicionada no centro do forno durante o processamento térmico rápido como no caso no grupo G2.

A nomenclatura das amostras pertencentes a este grupo segue o mesmo padrão dos demais grupos, iniciando pela sigla do grupo 3 (G3), seguido pela temperatura de processo e o tempo de processo. Para as amostra produzidas a $1150^{\circ} \mathrm{C}$, acrescentamos o ambiente de processo $\left(\mathrm{N}_{2}+\mathrm{O}_{2}\right.$ ou $\left.\mathrm{O}_{2}\right)$ após a temperatura de processo e no caso da retirada lenta, acrescentou-se a letra "L".

$\mathrm{Na}$ tabela 4.6 são apresentadas as espessuras médias do grupo G3 para 700 e $850^{\circ} \mathrm{C}$, obtidas por elipsometria. As amostras produzidas a $700^{\circ} \mathrm{C}$ têm espessuras 
médias na faixa de 0,97 a $1,54 \mathrm{~nm}$. Para as amostras produzidas a $850^{\circ} \mathrm{C}$, a espessura média obtida em 10 s é semelhante à espessura média da amostra produzida a $700^{\circ} \mathrm{C}$ em 160s. Sendo que a maior espessura obtida para $850^{\circ} \mathrm{C}$ foi de $2,39 \mathrm{~nm}(160 \mathrm{~s}$ de processo).

Tabela 4.6 - Espessura média de lâminas produzidas a 700 ou $850{ }^{\circ} \mathrm{C}$ : amostras G3 (com deslocamento na boca do forno).

\begin{tabular}{|c|c|c|c|}
\hline AMOSTRAS & ESPESSURA (nm) & AMOSTRAS & ESPESSURA (nm) \\
\hline G3-700-10 & $0,97 \pm 0,03$ & G3-850-10 & $1,53 \pm 0,04$ \\
\hline G3-700-20 & $1,08 \pm 0,02$ & G3-850-20 & $1,61 \pm 0,03$ \\
\hline G3-700-40 & $1,18 \pm 0,01$ & G3-850-40 & $1,77 \pm 0,06$ \\
\hline G3-700-80 & $1,32 \pm 0,02$ & G3-850-80 & $2,09 \pm 0,08$ \\
\hline G3-700-160 & $1,54 \pm 0,02$ & G3-850-160 & $2,39 \pm 0,08$ \\
\hline
\end{tabular}

Fonte: Autor.

Na figura 4.6 são apresentados os gráficos da espessura em função do tempo de processo para as amostras dos grupos G2 e G3. As diferenças de comportamento na evolução das espessuras das amostras dos dois grupos estão associadas à temperatura inicial de processo mais reduzida do grupo G3, influenciando diretamente no crescimento dos filmes obtidos. De forma geral, observa-se no grupo G2 (figura 4.6a) a espessura evoluindo quase que linearmente para os tempos de processamento empregados na faixa de 20 a 160s o que significa um mecanismo de crescimento predominantemente governado por taxa de reação superficial enriquecida constante de acordo com a equação 2.1.3.9. O primeiro ponto para o tempo de processamento de 10 s para cada gráfico da figura 4.6a apresentou espessura fora do comportamento geral, aproximadamente linear, em virtude do fato de que para esse tempo de processamento não foi atingido um patamar de temperatura (veja figura 4.2). É importante destacar que o tempo de processamento empregado incluiu o tempo de subida, isto é, o tempo de processamento corresponde ao tempo total no centro do forno e engloba o tempo de subida mais o tempo de patamar.

A figura 4.6b mostra a evolução da espessura em função do tempo de processamento do grupo G3 nas temperaturas de $700^{\circ} \mathrm{C}$ e $850^{\circ} \mathrm{C}$. Como já 
mencionado, o perfil temporal de temperatura do grupo G3 apresentou menor temperatura inicial na entrada do forno comparado ao grupo G2 conforme indicado na figura 4.2. Nesse caso, o regime de oxidação é compatível com taxa de oxidação enriquecida variando com o tempo de acordo com a equação 2.1.3.11. As diferenças de regime enriquecido de oxidação apresentadas na figura 4.6 podem ser atribuídas às diferenças dos perfis temporais de temperatura onde no grupo G2 ocorre menor intervalo de transição entre a temperatura inicial na entrada do forno e a temperatura final no centro do forno comparado com o grupo G3 o que pode estar significando menor influência do transiente de temperatura na taxa de oxidação enriquecida que é função do tempo na equação 2.3.1.11. Não foi possível aplicar esta última equação aos dados da figura 4.6b dada à complexidade do processo que envolve o transiente de temperatura. $\mathrm{O}$ ajuste indicado foi meramente polinomial a fim de indicar a não linearidade.

Figura 4.6 - Comparação entre as espessuras das amostras do grupo G2 (a) com o grupo G3 (b), obtidas a 700 e $850^{\circ} \mathrm{C}$.
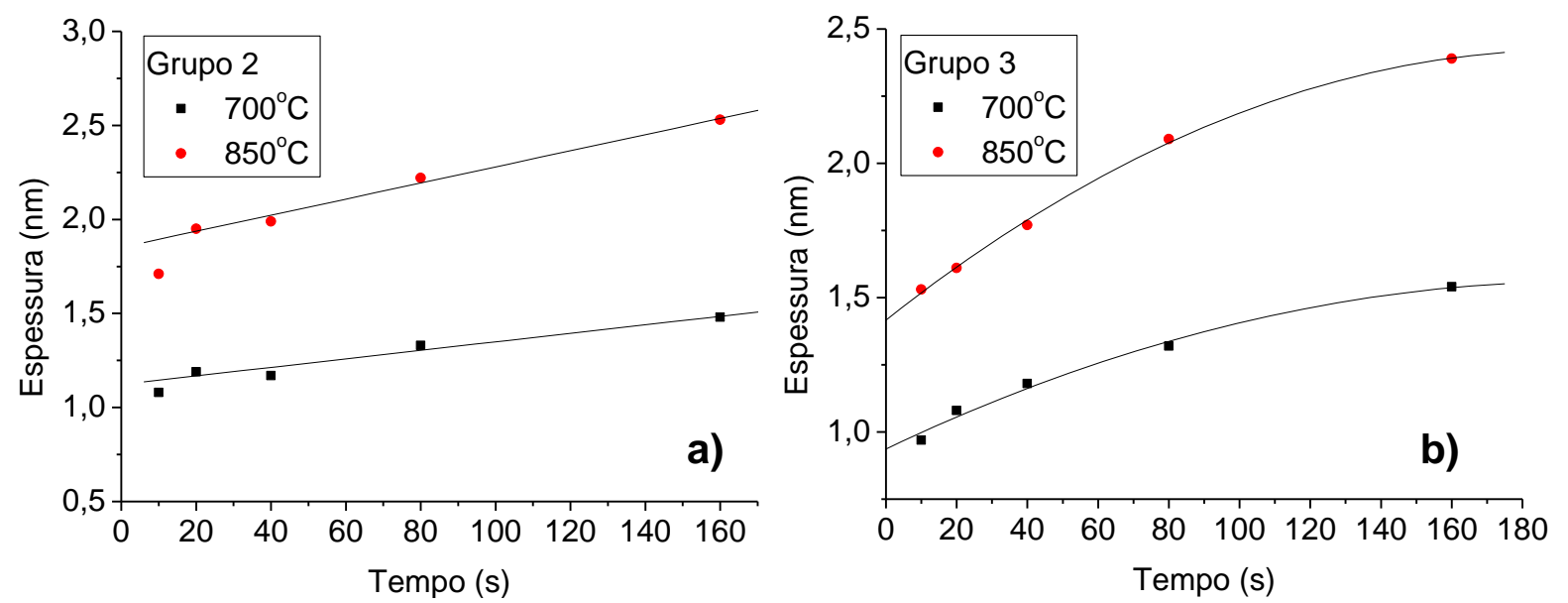

Fonte: Autor.

Quanto à microrugosidade, a figura 4.7 ilustra uma comparação entre as imagens de AFM obtidas nos modos contato (figura 4.7.a) e contato-intermitente (figura 4.7.b) para amostra processada por $700^{\circ} \mathrm{C}$ durante $10 \mathrm{~s}$. Observa-se melhor definição de detalhes na imagem correspondente ao AFM no modo contato-intermitente, sendo 
possível visualizarmos inclusive marcas de polimento da superfície do substrato de silício.

Figura 4.7 - Imagens de AFM nos modos contato (a) e contato intermitente (b) da superfície da amostra G3-700-10.

a)

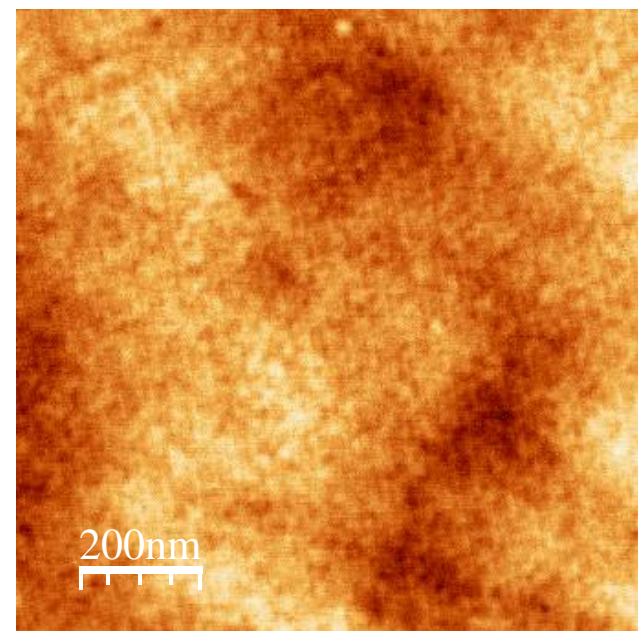

b)

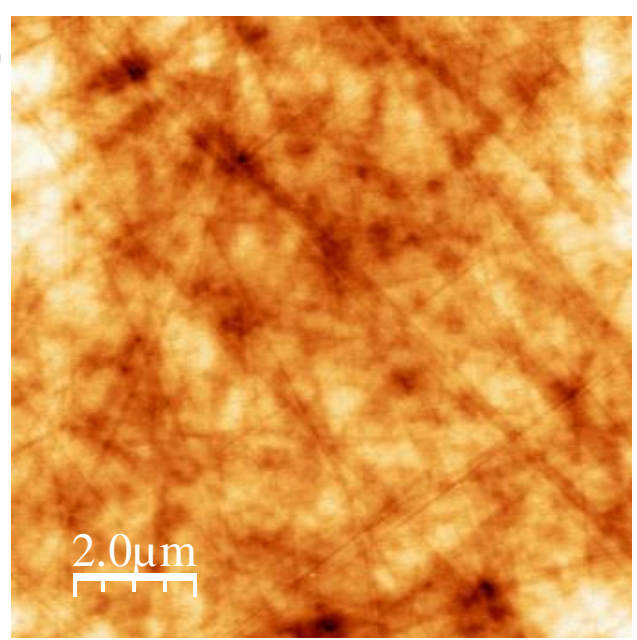

Fonte: Autor.

Figura 4.8 - Rugosidade RMS em função do tempo de processamento para as temperaturas de $700 \mathrm{e}$ $850^{\circ} \mathrm{C}$.

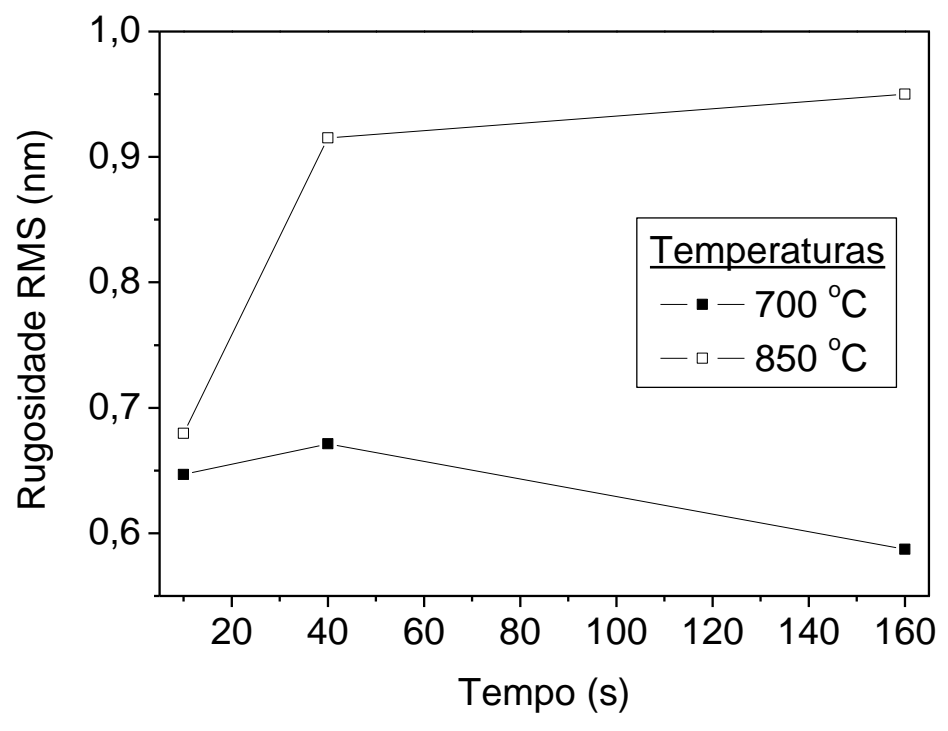

Fonte: Autor.

A figura 4.8 mostra a rugosidade média quadrática (RMS) para as amostras crescidas a 700 e $850^{\circ} \mathrm{C}$ do grupo G3. Para as amostras crescidas a $850^{\circ} \mathrm{C}$ observou- 
se um aumento de rugosidade em função do aumento da espessura, porém, para as amostras produzidas a $700^{\circ} \mathrm{C}$ verificou-se um decréscimo no valor da rugosidade RMS com o aumento do tempo de processamento. Apesar da menor rugosidade observada em $700^{\circ} \mathrm{C}$ comparado a $850^{\circ} \mathrm{C}$, em ambos os casos de temperatura, houve aumento da rugosidade de uma ordem de grandeza em relação ao substrato de partida original (0,033nmRMS) como já observado nos trabalhos de Santos (1996) e Toquetti (2005).

Por outro lado, na tabela 4.7, são apresentadas as amostras do grupo G3 produzidas a $1150^{\circ} \mathrm{C}$. Para as amostras produzidas em ambiente gasoso misto de $\mathrm{N}_{2}$ + $\mathrm{O}_{2}$ (4:3), observa-se um aumento médio de espessura de aproximadamente 4nm, na retirada lenta em relação a normal, para os tempos de processamento de 70 e 140s.

Tabela 4.7 - Espessura média de lâminas produzidas a $1150^{\circ} \mathrm{C}$ em diversas condições gasosas: amostras G3 (tubo de quartzo com deslocamento de $10 \mathrm{~cm}$ ).

\begin{tabular}{|c|c|c|c|}
\hline AMOSTRAS & ESPESSURA (nm) & AMOSTRAS & ESPESSURA (nm) \\
\hline G3-1150- $\mathrm{N}_{2}+\mathrm{O}_{2}-70$ & $10,07 \pm 0,26$ & G3-1150- $\mathrm{N}_{2}+\mathrm{O}_{2}-140$ & $15,72 \pm 1,45$ \\
\hline G3-1150- $\mathrm{N}_{2}+\mathrm{O}_{2}-70 \mathrm{~L}$ & $14,01 \pm 0,62$ & G3-1150- $\mathrm{N}_{2}+\mathrm{O}_{2}-140 \mathrm{~L}$ & $20,27 \pm 1,00$ \\
\hline G3-1150- $\mathrm{O}_{2}-70$ & $12,52 \pm 0,40$ & G3-1150- $\mathrm{O}_{2}-140$ & $20,84 \pm 0,38$ \\
\hline G3-1150- $\mathrm{O}_{2}-70 \mathrm{~L}$ & $20,68 \pm 0,78$ & G3-1150- $\mathrm{O}_{2}-140 \mathrm{~L}$ & $28,37 \pm 0,73$ \\
\hline
\end{tabular}

Fonte: Autor.

Para ambiente de $\mathrm{O}_{2}$ puro (1,5L/min.) com entrada e retirada em ambiente inerte, observou-se um aumento médio de espessura de aproximadamente 8nm comparando a retirada lenta em com a retirada rápida, para os tempos de processamento de 70 e 140 s.

Comparando o ambiente misto de $\mathrm{N}_{2}+\mathrm{O}_{2}$ com o ambiente de $\mathrm{O}_{2}$ puro, observa-se como era de se esperar que as espessuras dos filmes crescidos foram maiores para o ambiente de $\mathrm{O}_{2}$ puro dado que a pressão parcial do oxigênio foi maior nesse caso. 


\subsection{Obtenção da concentração de nitrogênio nos oxinitretos de silício}

A técnica de espectroscopia por emissão de fotoelétrons (XPS) foi empregada para obter a concentração de nitrogênio nos filmes de oxinitreto crescidos por processamento térmico rápido em ambiente de $\mathrm{N}_{2}+\mathrm{O}_{2}$.

A figura 4.9 mostra os espectros XPS onde estão indicados os sinais $N$ 1s e $O$ 1s em escalas horizontais expandidas. $O$ sinal $O 1$ s é devido principalmente às ligações do oxigênio com o silício ( $\mathrm{Si}-\mathrm{O}$ ) em $536,6 \mathrm{eV}$ e o sinal $\mathrm{N}$ 1s corresponde ao nitrogênio ligando ao oxigênio ( $\mathrm{N}-\mathrm{O}$ ) em $402,4 \mathrm{eV}$. O aparecimento desses dois sinais no espectro XPS apontaram para a formação de $\mathrm{SiO}_{\mathrm{x}} \mathrm{N}_{\mathrm{y}}$.

Figura 4.9 - Espectro XPS para a lâmina oxinitretada na temperatura de $850^{\circ} \mathrm{C}$ onde estão indicados os picos correspondentes às ligações N-O e Si-O.

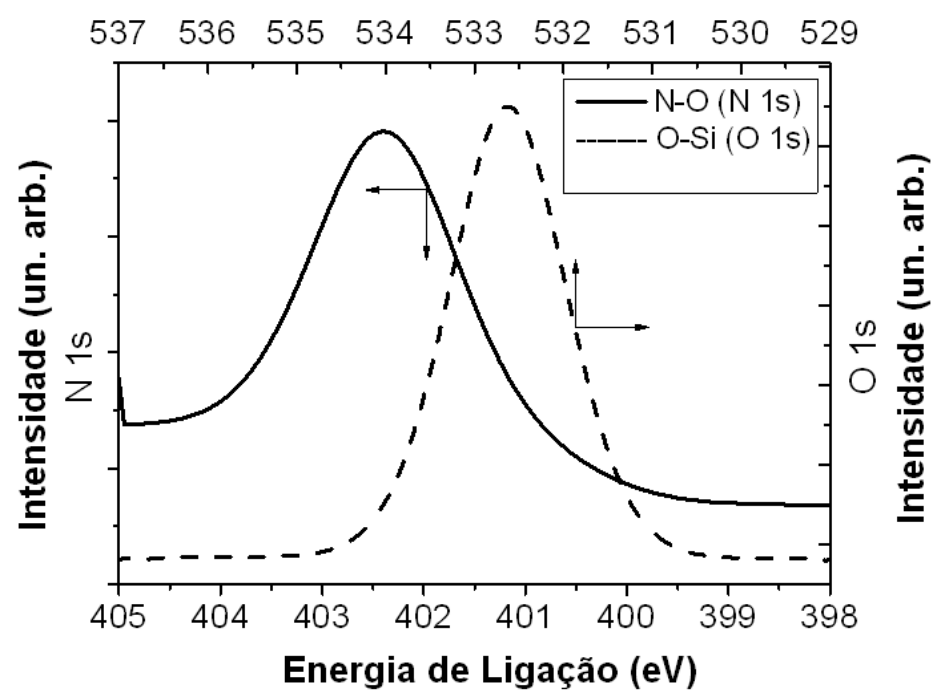

Fonte: Autor.

A tabela 4.8 apresenta as porcentagens de silício $S i 2 p$, oxigênio $O 1 s$, nitrogênio $\mathrm{N}$ 1s juntamente com as porcentagens de $\mathrm{Si}^{4+}$ que entra na composição do $\mathrm{SiO}_{2}$ estequiométrico e do oxigênio que entra na composição das ligações Si-O. As amostras escolhidas para análise foram dielétricos crescidos a $700^{\circ} \mathrm{C}$ por $40 \mathrm{~s}$, a $850^{\circ} \mathrm{C}$ para tempos de processamento de 10,40 e 160 s e a $850^{\circ} \mathrm{C}$ por $40 \mathrm{~s}$ + passivação em $\mathrm{N}_{2}$ por 80 s. Diferentes relações $\mathrm{N}_{2}: \mathrm{O}_{2}$ foram empregadas a saber: $4 \mathrm{~N}_{2}: 3 \mathrm{O}_{2}, 3 \mathrm{~N}_{2}: 1 \mathrm{O}_{2}$, $5 \mathrm{~N}_{2}: 1 \mathrm{O}_{2}$ e $10 \mathrm{~N}_{2}: 1 \mathrm{O}_{2}$. 
A profundidade de penetração da análise XPS na amostra de Si com SiOx crescido termicamente é cerca de $9 \mathrm{~nm}$ onde grande parte do silício detectado é proveniente do substrato. Após ajuste do sinal do Si $2 p$ através de uma composição de gaussianas, foi possível extrair a contribuição percentual de $\mathrm{Si}^{4+}$ presente na camada de $\mathrm{SiOx}$. De forma análoga, foi feito o ajuste do sinal do $O$ 1s através da composição de 2 gaussianas: uma devido às ligações $\mathrm{C}-\mathrm{O}$ e a outra devido às ligações Si-O. Dessa forma, foi possível extrair a porcentagem de oxigênio na camada SiOx. Na sequência, de posse das porcentagens de $\mathrm{Si}$, O e $\mathrm{N}$ na camada $\mathrm{SiOx}$, foi obtida a relação $\mathrm{Si} / \mathrm{O}$ e a porcentagem atômica de nitrogênio $(\% \mathrm{~N})$, respectivamente, como indicado na tabela 4.8.

É importante destacar na tabela 4.8 que o parâmetro estequiométrico " $x$ " resultou crescente na faixa de 2,0 a 2,4 para tempos de processamento decrescentes na faixa de 160 a 10 s na temperatura de $850^{\circ} \mathrm{C}$ em ambiente $5 \mathrm{~N}_{2}: 1 \mathrm{O}_{2}$ sem a etapa de passivação. Esse fato indica que possivelmente parte das cadeias $\mathrm{O}-\mathrm{Si}-\mathrm{O}$ podem estar na forma $\mathrm{Si}-\mathrm{OH}$ devido a presença de água residual no gás de processo. Ainda, na tabela 4.8, é possível notar que a diminuição da temperatura provoca um aumento do parâmetro "x" para 2,6.

Por outro lado, a diminuição da porcentagem de $\mathrm{N}_{2}$ quando se utiliza a mistura $4 \mathrm{~N}_{2}: 3 \mathrm{O}_{2}$, sem a passivação em $\mathrm{N}_{2}$ por 80 s, resulta na diminuição do parâmetro estequiométrico " $x$ " ficando este na faixa de 1,6 a 2,2. Com exceção do tratamento a $850^{\circ} \mathrm{C}$ por $10 \mathrm{~s}$, a tendência para a mistura $4 \mathrm{~N}_{2}: 3 \mathrm{O}_{2}$ também foi o aumento do parâmetro estequiométrico com a diminuição do tempo de processamento sendo que a diminuição da temperatura também resultou em maior parâmetro estequiométrico ( $\mathrm{x}$ $=2,2)$.

Para as amostras passivadas por $80 \mathrm{~s}$ em $\mathrm{N}_{2}$ após o processamento nas misturas $3 \mathrm{~N}_{2}: 1 \mathrm{O}_{2}, 5 \mathrm{~N}_{2}: 1 \mathrm{O}_{2}$ e $10 \mathrm{~N}_{2}: 1 \mathrm{O}_{2}$, observou-se tendência do parâmetro estequiométrico " $x$ " aumentar com a diminuição da razão $\mathrm{N}_{2} / \mathrm{O}_{2}$ o que pode ser explicado pela maior facilidade de incorporação de umidade a medida que a concentração de nitrogênio é diminuída ou o processo é executado em mais baixa temperatura (BALK, 1988). 
Tabela 4.8 - Porcentagens atômicas de Si $2 p, 0$ 1s, N 1s, Si ${ }^{4+}$. e O-Si-O juntamente com o cálculo da relação $\mathrm{Si} / \mathrm{O}$.

\begin{tabular}{|c|c|c|c|c|c|c|c|c|}
\hline & \multicolumn{4}{|c|}{$\%$ atômica $\left(4 \mathrm{~N}_{2}: 3 \mathrm{O}_{2}\right)$} & \multicolumn{4}{|c|}{ \% atômica $\left(5 \mathrm{~N}_{2}: 1 \mathrm{O}_{2}\right)$} \\
\hline & $\begin{array}{c}\text { G3-700- } \\
40\end{array}$ & $\begin{array}{c}\text { G3-850- } \\
10\end{array}$ & $\begin{array}{c}\text { G3-850- } \\
40\end{array}$ & $\begin{array}{c}\text { G3-850- } \\
160\end{array}$ & $\begin{array}{c}\text { G3-700- } \\
40\end{array}$ & $\begin{array}{c}\text { G3-850- } \\
10\end{array}$ & $\begin{array}{c}\text { G3-850- } \\
40\end{array}$ & $\begin{array}{c}\text { G3-850- } \\
160\end{array}$ \\
\hline Silício (Si 2p) & 64,9 & 60,9 & 56,1 & 51,8 & 66,5 & 63,8 & 62,0 & 56,2 \\
\hline Oxigênio (0 1s) & 34,3 & 38,5 & 43,3 & 47,6 & 32,9 & 35,7 & 37,4 & 43,5 \\
\hline Nitrogênio (N 1s) & 0,8 & 0,5 & 0,6 & 0,6 & 0,8 & 0,5 & 0,6 & 0,3 \\
\hline $\mathrm{Si}^{4+}$ & 15,7 & 29,9 & 27,8 & 38,1 & 14,8 & 18,5 & 19,8 & 30,2 \\
\hline Si-O & 66,7 & 75,9 & 76,4 & 76,2 & 77,1 & 77,7 & 78,2 & 79,7 \\
\hline $\mathrm{Si} / 0=1 / x$ & $1 / 2,2$ & $1 / 1,6$ & $1 / 2,1$ & $1 / 1,8$ & $1 / 2,6$ & $1 / 2,3$ & $1 / 2,4$ & $1 / 2,0$ \\
\hline \%N no SiOx & 2,4 & 1,0 & 1,2 & 1,1 & 2,2 & 1,2 & 1,4 & 0,6 \\
\hline
\end{tabular}

\begin{tabular}{|c|c|c|c|}
\hline & \multicolumn{3}{|c|}{$\begin{array}{c}\text { \% atômica }\left(5 \mathrm{~N}_{2}: 1 \mathrm{O}_{2}\right) \\
\left(850^{\circ} \mathrm{C} \text { com } 40 \text { s de processo }+80 \mathrm{~s}\right. \\
\text { de passivação })\end{array}$} \\
\hline & $3 \mathrm{~N}_{2}: 1 \mathrm{O}_{2}$ & $5 \mathrm{~N}_{2}: 1 \mathrm{O}_{2}$ & $10 \mathrm{~N}_{2}: 1 \mathrm{O}_{2}$ \\
\hline Silício (Si 2p) & 63,0 & 65,5 & 65,0 \\
\hline Oxigênio (0 1s) & 34,2 & 33,7 & 32,3 \\
\hline Nitrogênio (N 1s) & 0,8 & 0,8 & 0,7 \\
\hline $\mathrm{Si}^{i^{4+}}$ & 16,8 & 17,0 & 17,4 \\
\hline Si-O & 79,8 & 75,8 & 75,1 \\
\hline $\mathrm{Si} / \mathrm{O}=1 / \mathrm{x}$ & $1 / 2,6$ & $1 / 2,3$ & $1 / 2,1$ \\
\hline \%N no SiOx & 2,1 & 2,1 & 1,9 \\
\hline
\end{tabular}

Fonte: Autor.

A porcentagem atômica de nitrogênio em nível residual observada na tabela 4.8 é apontada por Chang (2004) como positiva em óxidos de silício enriquecidos com nitrogênio, pois melhora as características elétricas de interface da estrutura MOS no que se refere à diminuição da densidade de estados de interface. Em particular, comparando-se os tempos de processamento de 40 s na temperatura de $850^{\circ} \mathrm{C}$, observou-se um aumento da \%N no $\mathrm{SiO}_{x}$ de cerca de 1,2-1,4\% para 1,9-2,1\% após a etapa de passivação mostrando que o aumento do pacote térmico em $\mathrm{N}_{2}$ promove o aumento da concentração de nitrogênio no filme conforme previsto na literatura (CHANG, 2004; YANG, 2014). 
Por outro lado, Yang (2014) reporta que o nitrogênio está predominantemente localizado na interface dielétrico-silício e, também, pode promover níveis elevados de armadilhas dentro do dielétrico crescido devido à quebra das cadeias Si-O-Si. A existência de ligações incompletas na interface dielétrico-silício (dangling bonds) cria uma grande quantidade de defeitos (estados de superfície) entre as bandas de condução e de valência que agem como centros de recombinação SRH (YANG, 2014). Em particular, a presença das ligações do tipo $\mathrm{Si} \equiv \mathrm{N}$ na interface dielétricosilício geram os centros $K$ que podem armazenar cargas de todas as polaridades dependendo da forma de ocupação pelos elétrons e lacunas como mencionado no item 2.4. Esse ponto será retomado a seguir para justificar os mecanismos de tunelamento nos capacitores e células solares MOS construídos no âmbito do presente trabalho.

\subsection{Resultados dos capacitores MOS}

O procedimento empregado na fabricação dos capacitores MOS foi descrito no item 3.2.1. A seguir serão apresentados os resultados sobre as características $C-V_{G}$ dos dielétricos nitretados empregados no presente trabalho para implementação das células solares MOS em áreas extensas de até $4 \mathrm{~cm}^{2}$ conforme descrito nos procedimentos experimentais. O objetivo desta apresentação sobre capacitor MOS com áreas de $(250 \times 250) \mu \mathrm{m}^{2}$ foi o de servir como amostra de controle para obtenção das células solares em áreas extensas. $O$ comportamento dos centros $K$ carregados positivamente foi explorado na dissertação de mestrado de Alandia (2016) e os capacitores MOS fabricados no âmbito da presente tese foram um ponto de partida no estudo das células solares MOS as quais se baseiam na mesma fenomenologia, porém agora expandido para áreas substancialmente maiores.

Os dielétricos de porta foram crescidos por processamento térmico rápido (RTP) na temperatura de $850^{\circ} \mathrm{C}$, para diferentes proporções de ambiente gasoso proveniente de mistura entre nitrogênio e oxigênio $\left(4 \mathrm{~N}_{2}: 3 \mathrm{O}_{2}, 3 \mathrm{~N}_{2}: 1 \mathrm{O}_{2}, 5 \mathrm{~N}_{2}: 1 \mathrm{O}_{2}\right.$ e $10 \mathrm{~N}_{2}: 1 \mathrm{O}_{2}$ ) para tempos de processamento de 80 ou 160s. Adicionalmente, algumas amostras passaram por uma passivação em ambiente de $\mathrm{N}_{2}$ na mesma temperatura de processo $\left(850^{\circ} \mathrm{C}\right)$ por $80 \mathrm{~s}$. 
A figura 4.10 mostra as curvas $\mathrm{C}-\mathrm{V}_{\mathrm{G}}$ típicas de capacitores MOS fabricados por meio de máscara mecânica $\left(A_{g 1}=2,12 \times 10^{-2} \mathrm{~cm}^{2}\right)$ e por litografia $\left(A_{g 2}=(250 \times 250) \mu m^{2}\right.$ $=6,25 \times 10^{-4} \mathrm{~cm}^{2}$ ), utilizando as misturas $3 \mathrm{~N}_{2}: 1 \mathrm{O}_{2}$ e $5 \mathrm{~N}_{2}: 1 \mathrm{O}_{2}$.

Figura 4.10 - Características $C-V_{G}$ típicas de capacitores MOS produzidos em ambiente misto com diferentes proporções de $\mathrm{N}_{2}: \mathrm{O}_{2}$ e diferentes áreas de porta $\left(\mathrm{A}_{\mathrm{g} 1}=2,12 \times 10^{-2} \mathrm{~cm}^{2}\right.$ e $A_{g 2}=(250 \times 250)$ $\left.\mu \mathrm{m}^{2}=6,25 \times 10^{-4} \mathrm{~cm}^{2}\right)$.

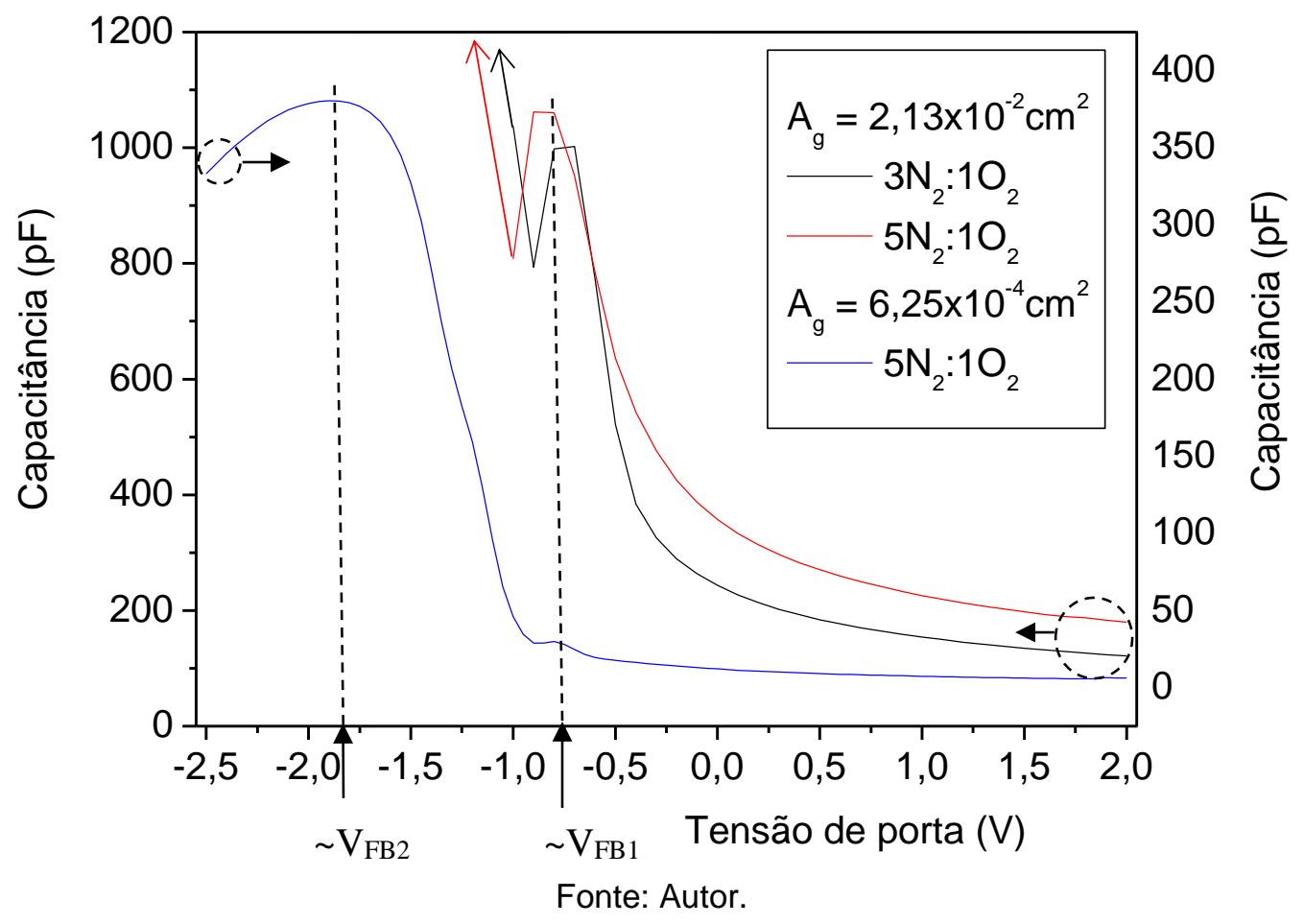

Para ambas as áreas de porta observa-se uma região de depleção profunda que se estende de $-0,8 \mathrm{~V}$ a $2 \mathrm{~V}$. No potencial $\mathrm{V}_{\mathrm{FB} 1} \approx-0,8 \mathrm{~V}$ observou-se um primeiro pico de capacitância e em uma segunda tensão de faixa plana para tensões mais negativas do que a primeira tensão de faixa plana $\left(\mathrm{V}_{\mathrm{FB} 2} \approx-1,5 \mathrm{~V}\right)$, um segundo pico de capacitância. Esses comportamentos na capacitância ocorreram de forma sistemática não apenas para as condições indicadas na figura 4.10, mas também para todas as outras misturas de $\mathrm{N}_{2}+\mathrm{O}_{2}$ testadas.

No trabalho de Alandia (2016) foi estabelecido que o primeiro pico de capacitância localizado em $\mathrm{V}_{\mathrm{FB} 1} \approx-0,8 \mathrm{~V}$ para capacitores MOS com porta de alumínio corresponde uma situação na qual deixa de existir o efeito de blindagem da região de depleção. $A$ partir desse ponto, para tensões mais negativas, a estrutura MOS tende a entrar em 
regime de acumulação, a corrente de tunelamento tende a subir e, concomitantemente, a capacitância tende a cair delineando dessa forma esse primeiro pico.

Porém, devido à existência dos centros $K$ localizados no dielétrico junto à interface dielétrico/silício, como descrito no item 2.4, estes passam a ficar carregados positivamente na acumulação e, por sua vez, induzem novamente uma região de depleção no silício. Nesse caso, volta a ocorrer um efeito de blindagem atribuído a essa nova região de depleção sendo que a corrente de tunelamento através do dielétrico volta a cair e a capacitância volta a subir.

Mais tarde, após o carregamento total dos centros $K$ com cargas positivas, a tensão de faixa plana passa para um valor mais alto $V_{F B 2}$ correspondente ao segundo pico (veja figura 4.10). Nesse caso, quando a tensão $V_{\mathrm{FB} 2}$ é atingida, deixa de existir novamente o efeito de blindagem da região de depleção. A partir desse ponto, para tensões mais negativas do que $\mathrm{V}_{\mathrm{FB} 2}$, a estrutura MOS tende a entrar em regime de acumulação dado que os centro $K$ já estão inteiramente carregados e a corrente de tunelamento tende a subir novamente. Concomitantemente, a capacitância tende a cair com o aumento expressivo da corrente de tunelamento, delineando dessa forma o segundo pico. O efeito de diminuição da capacitância de acumulação com o aumento expressivo da corrente é bem conhecido na literatura sendo que a ordem de grandeza da densidade de corrente atingida é de $10^{-2} \mathrm{~A} / \mathrm{cm}^{2}$ (TOQUETTI, 2005).

$\mathrm{O}$ primeiro pico de capacitância em $\mathrm{V}_{\mathrm{FB} 1} \approx-0,8 \mathrm{~V}$ está associado ao início de carregamento dos centros $K$ que passam a ficar carregados positivamente de acordo com o mecanismo representado pela equação 2.4.2. Ainda, no trabalho de Alandia (2016) foi mostrado que a movimentação de cargas nos centros $K$ interfaciais se daria através da estrutura $\mathrm{Si}(\mathrm{p}) / \mathrm{Si} \equiv \mathrm{N}$ conforme proposto por Chang (2004). A seguir será mostrado que o fato de existir a região interfacial carregada desencadeia o tunelamento de portadores através do dielétrico de porta.

\subsection{Resultados das células solares MOS fabricadas}

O procedimento empregado na fabricação das células solares MOS foi descrito no item 3.2.1. Os dielétricos de porta foram crescidos por processamento térmico rápido na temperatura de $850^{\circ} \mathrm{C}$, utilizando o ambiente misto de $5 \mathrm{~N}_{2}: 1 \mathrm{O}_{2}$ com tempos de 
processamento de $0,10,20,80,160$ e 220 s mais passivação em ambiente de $\mathrm{N}_{2}$ por mais 80 s no mesmo patamar de temperatura.

A escolha do ambiente misto de $5 \mathrm{~N}_{2}: 1 \mathrm{O}_{2}$ deveu-se ao fato da característica $C \times V_{G}$ da figura 4.10 apresentar melhor reprodutibilidade para um conjunto expressivo de medidas de capacitores ao longo da área de lâminas de 3 polegadas no que se refere tanto a posição do pico localizado ao redor de $\mathrm{V}_{\mathrm{FB} 1} \approx-0,8 \mathrm{~V}$ como também dos valores de capacitância para toda extensão da curva $\mathrm{CxV}_{\mathrm{G}}$.

Foram utilizados substratos de silício $\mathrm{CZ}$ tipo $\mathrm{P}$, orientação $<100>$ com resistividade de $1-10 \Omega \mathrm{cm}$ e, em alguns testes, foram também empregadas resistividades de 0,2$1 \Omega \mathrm{cm}$. As geometrias empregadas para definição das células MOS são aquelas indicadas na tabela $3.1 \mathrm{com}$ área total $\mathrm{A}_{\mathrm{g}}=3,24 \mathrm{~cm}^{2}$ a qual foi empregada no cálculo da densidade de corrente para todas as curvas $\mathrm{JxV}_{\mathrm{G}}$ extraídas. A razão para não descontarmos a área das linhas de alumínio onde a luz é refletida será discutida mais tarde.

A tabela 4.9 mostra os valores médios e o desvio padrão das espessuras extraídas por elipsometria para os oxinitretos crescidos por RTP na temperatura de $850^{\circ} \mathrm{C}$ para tempos de processamento de 0,10, 20, 80,120, 160 e 220s. Também foram crescidos dielétricos por oxidação térmica rápida na temperatura de $700^{\circ} \mathrm{C}$ em ambiente de $\mathrm{O}_{2}$ durante 300s (receita "Rap") como descrito nos procedimentos experimentais. É interessante destacar que as espessuras medidas por elipsometria não diferem mais que $5 \%$ em relação à espessura física real medida por TEM de acordo com o procedimento mostrado no item 3.1.4.

Tabela 4.9 - Espessura média das amostras oxidadas no forno RTP adaptado e convencional em função do tempo de processo.

\begin{tabular}{|c|c|c|}
\hline Forno & Tempo (s) & Espessura (nm) \\
\hline \multirow{4}{*}{ RTP $\left(850^{\circ} \mathrm{C}\right)$} & 0 & $1,61 \pm 0,06$ \\
\cline { 2 - 3 } & 10 & $1,65 \pm 0,06$ \\
\cline { 2 - 3 } & 20 & $1,73 \pm 0,06$ \\
\cline { 2 - 3 } & 80 & $2,10 \pm 0,05$ \\
\cline { 2 - 3 } & 120 & $2,34 \pm 0,06$ \\
\cline { 2 - 3 } & 220 & $2,47 \pm 0,16$ \\
\hline $\begin{array}{c}\text { Oxidação } \\
\text { térmica rápida } \\
\left(700^{\circ} \mathrm{C}\right)\end{array}$ & $\begin{array}{c}\text { 300 (Rap.) } \\
\text { c/entrada em N2 }\end{array}$ \\
\hline \multicolumn{3}{|c|}{ Fonte: Autor. } \\
\hline \multicolumn{2}{|c|}{} \\
\cline { 2 - 3 }
\end{tabular}


É importante destacar na tabela 4.9 que os processos realizados na temperatura de $850^{\circ} \mathrm{C}$ passaram por passivação em $\mathrm{N}_{2}$ por 80 s após o processamento em ambiente de $5 \mathrm{~N}_{2}: 1 \mathrm{O}_{2}$ pelos tempos indicados na tabela 4.9. Nesse caso, a evolução da espessura foi semelhante àqueles apontados na tabela 4.6 para o grupo $\mathrm{G} 3$, porém com um pequeno aumento de espessura para o caso com passivação.

A figura 4.11a mostra as curvas típicas de densidade de corrente em função da tensão de porta $\left(V_{G}\right)$ medidas no escuro (sem luz) para células solares MOS fabricada com linhas com largura $L=50 \mu \mathrm{m}$ e espaçamentos $\mathrm{D}=100 \mu \mathrm{m}$. Para $V_{G}<0$ a estrutura MOS opera em regime de acumulação onde a densidade de corrente de tunelamento através da estrutura MOS tende a ser maior do que no regime de depleção. Para $V_{G}>0$ a estrutura MOS opera em regime de depleção profunda como estabelecido nas medidas apresentadas na figura 4.10 e é importante destacar que a densidade de corrente apresenta patamar quase constante em torno de $5 \times 10$ ${ }^{7} \mathrm{~mA} / \mathrm{cm}^{2}$ para espessuras do dielétrico variando na faixa de 1,61 a 2,95nm. Portanto, a corrente de fundo (sem a presença da luz) é predominantemente limitada pela região de depleção formada que tem efeito de blindagem no sentido de que o nível de densidade de corrente é substancialmente menor comparado com os valores no regime de acumulação. Também, nesta região a densidade de corrente fica limitada pela geração de portadores na região de depleção profunda descrita no item 4.4 e é governada pelo mecanismo BTT descrito no item 2.2.2 o qual é basicamente o mecanismo SRH (item 2.2.1) ativado por um campo elétrico aplicado ao longo da região de depleção profunda.

Portanto, é importante chamar a atenção para dois fatos associados ao comportamento da estrutura MOS fabricada: a) ocorre depleção profunda na para $V_{G}$ $>0$ independentemente da rampa de tensão de medição, conforme mostrado na figura 4.10 e já observado por Alandia (2016) e b) a corrente de tunelamento de fundo através dos dielétricos é limitada pela geração de portadores na camada de depleção para todas as espessuras de dielétrico de porta testadas na faixa de 1,61 a 2,95nm.

Assim, a densidade de corrente de fundo característica das células solares MOS produzidas tem uma variação gradual perceptível na figura 4.11a que acompanha a variação da largura da região de depleção para $V_{G}>0$ conforme estabelecido por Alandia (2016) para capacitores MOS de áreas menores $\left(250 \times 250 \mu m^{2}\right)$. 
A seguir, mostra-se que as células solares MOS fabricadas ao serem iluminadas operam em regime de inversão controlado pelos centros $K$ positivamente carregados localizados dentro do dielétrico próximo à interface dielétrico/Si e isso significa que se fabricou um novo tipo célula solar MOS cuja característica $J x V_{G}$ desloca para a esquerda conforme mostrado na figura 4.11b (ALANDIA, 2016). Esse deslocamento implica no aparecimento de uma região na qual a célula MOS comporta-se como um gerador no trecho compreendido entre 0 e cerca de $-0,5 \mathrm{~V}$ conforme destacado na figura $4.11 \mathrm{~b}$.

Sob iluminação, os centros $K$ carregados positivamente induzem uma camada de depleção na qual ocorre fotogeração de portadores como indicado esquematicamente na figura 4.11c. É importante observar que na figura $4.11 \mathrm{~b}$ que, assim como, no caso sem luz, a corrente de tunelamento através dos dielétricos no caso com luz é limitada pela fotogeração na camada de depleção para os tempos de 0, 10 e 20s correspondendo às espessuras de dielétrico de 1,61, 1,65 e 1,73nm, respectivamente, como indicado na tabela 4.9. Já para os tempos maiores de 160 e 220 s com espessuras de 2,47 e 2,95nm, respectivamente, observa-se que não chega a formar uma região de patamar de densidade corrente na região para $V_{G}>0$ o que é um indicativo de que a corrente passa a ficar limitada pelo mecanismo de tunelamento através das camadas dos dielétricos de porta. 
Figura 4.11 - Curvas $\mathrm{JxV}_{\mathrm{G}}$ com características típicas de células solares MOS sem luz (a) e sob iluminação (b) de lâmpada halógena $\left(105,7 \mathrm{~mW} / \mathrm{cm}^{2}\right)$ com diversos tempos de processamento e geometria 50×100 e desenho esquemático da região de depleção formada devido aos centros $\mathrm{K}$ positivamente carregados com $Q_{i}(c)$.

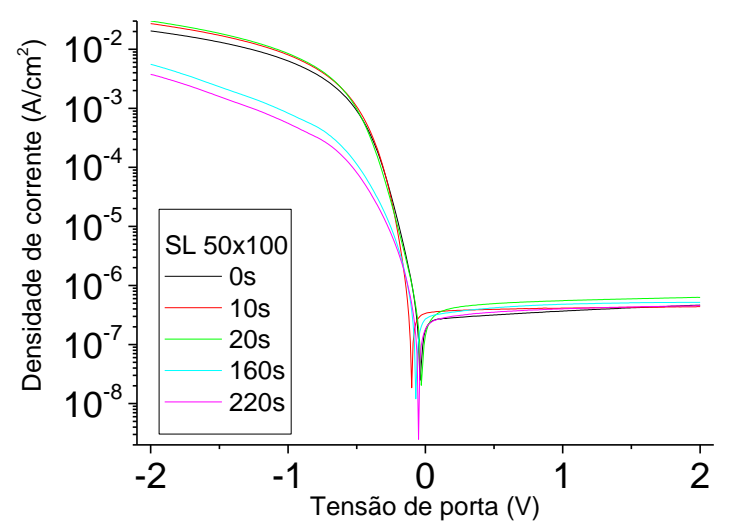

(a)

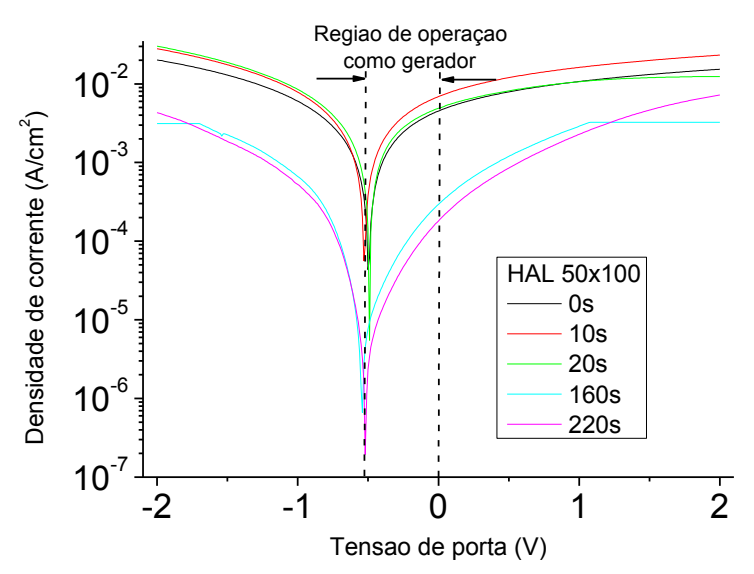

(b)

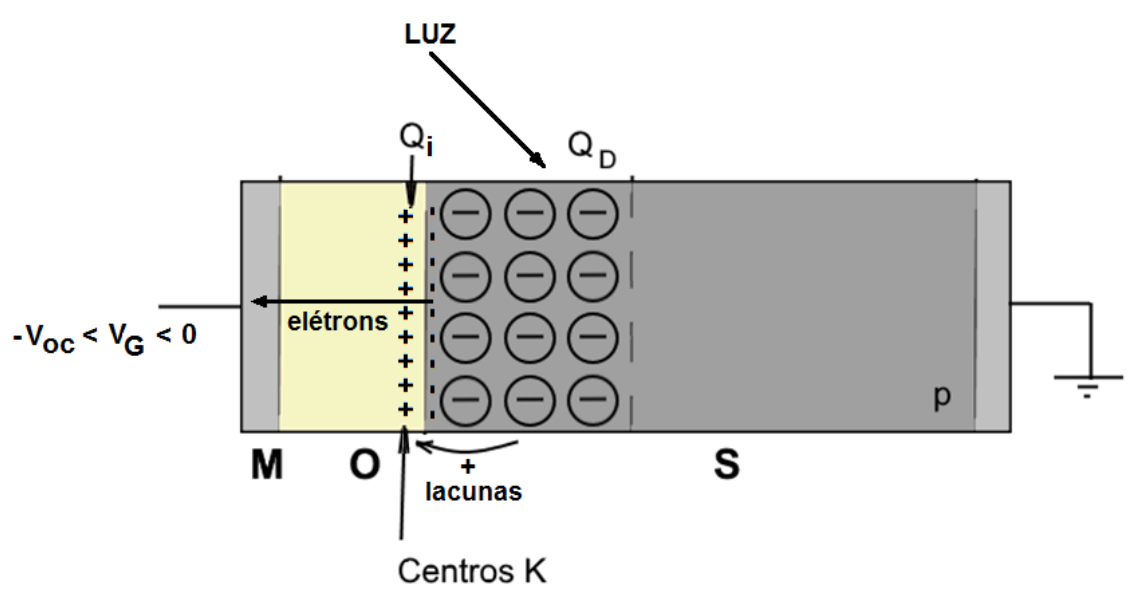

(c)

Fonte: Autor.

Os resultados apresentados a seguir referem-se às células solares MOS operando como gerador na região indicada na figura 4.11b. As células foram submetidas à iluminação por lâmpada halógena ou LED distanciadas das amostras de 3, 6 e $9 \mathrm{~cm}$ de acordo com a montagem experimental indicada na figura 3.8. as intensidades luminosas $(\mathrm{Cd})$ e intensidades radiantes incidentes $\left(\mathrm{W} / \mathrm{cm}^{2}\right)$ empregadas estão indicadas na tabela 3.2. Para facilidade de análise, todos os gráficos $\mathrm{Jx} \mathrm{V}_{\mathrm{G}}$ foram levantados para densidades de corrente e tensão de porta sempre em módulo para a célula solar MOS operando como gerador. 
A figura 4.12 mostra as curvas características $\mathrm{JxV}_{\mathrm{G}}$ típicas para célula solar MOS iluminada com lâmpada halógena a $3 \mathrm{~cm}$ da célula para tempos de processamento na faixa de 0 a 220s. Inicialmente é importante destacar que a curva obtida é muito diferente das curvas para células solares MOS convencionais apresentadas na figura 2.13 que apresentam um comportamento exponencial entre o ponto de cruzamento com o eixo das ordenadas (Jsc: corrente de curto-circuito) e ponto de cruzamento com o eixo das abcissas (Voc: tensão de circuito aberto). No caso da figura 4.12, o comportamento da curva entre os dois pontos de cruzamento, Jsc e Voc, respectivamente, aproxima-se de um comportamento linear limitado pelas resistências em série do substrato e da camada de inversão. A resistência em série do substrato foi estimada na faixa de 60 a $100 \Omega$ a partir da resistência de folha do substrato para células com área de $3,24 \mathrm{~cm}^{2}$.

Como já mencionado, as células solares MOS indicadas na figura 4.12 operam no modo inversão induzida pelos centros $K$ onde a densidade de corrente gerada pela luz é limitada primordialmente pela componente de geração de portadores dentro da região de depleção cuja largura aumenta com a raiz de $V_{G}$ conforme estabelecido no trabalho de Alandia (2016).

Por outro lado, verifica-se que a tensão de circuito-aberto (Voc) varia na faixa de 0,471 a $0,549 \mathrm{~V}$ e a densidade de corrente de curto-circuito (Jsc) tende a aumentar a medida em que as espessuras dos dielétricos de porta diminuem, com exceção do tempo de 20s cuja densidade de corrente resultou maior do que para $10 \mathrm{~s}$ o que foi atribuído à dispersão da resistência em série devida ao substrato. Outro ponto muito relevante observado é a pequena influência da geometria na densidade de corrente de curto-circuito para cada espessura empregada.

A tendência de aumento da densidade de corrente de curto-circuito com a diminuição da espessura ocorre porque os portadores gerados tem maior facilidade de tunelar através do dielétrico de porta. Já a relativa independência da densidade de corrente de curto-circuito com a geometria empregada indica que já existia uma camada de depleção de largura relativamente uniforme ao longo de toda a área da célula antes mesmo que a luz incidisse na área entre as linhas de alumínio. Assim, é possível supor que a camada de depleção pré-existente é devida a existência de estados $K$ interfaciais carregados positivamente em toda a extensão da célula solar 
pelo efeito da dopagem da lâmina $\mathrm{P}$ que pode ser considerada uma fonte infinita de cargas positivas.

Figura 4.12 - Curvas típicas $\mathrm{JxV}_{\mathrm{G}}$ utilizando luz halógena incidente para diversos tempos de processamento e geometrias: a) 50×50; b) $50 \times 100$; c) $100 \times 100$ e; d) $100 \times 150$.
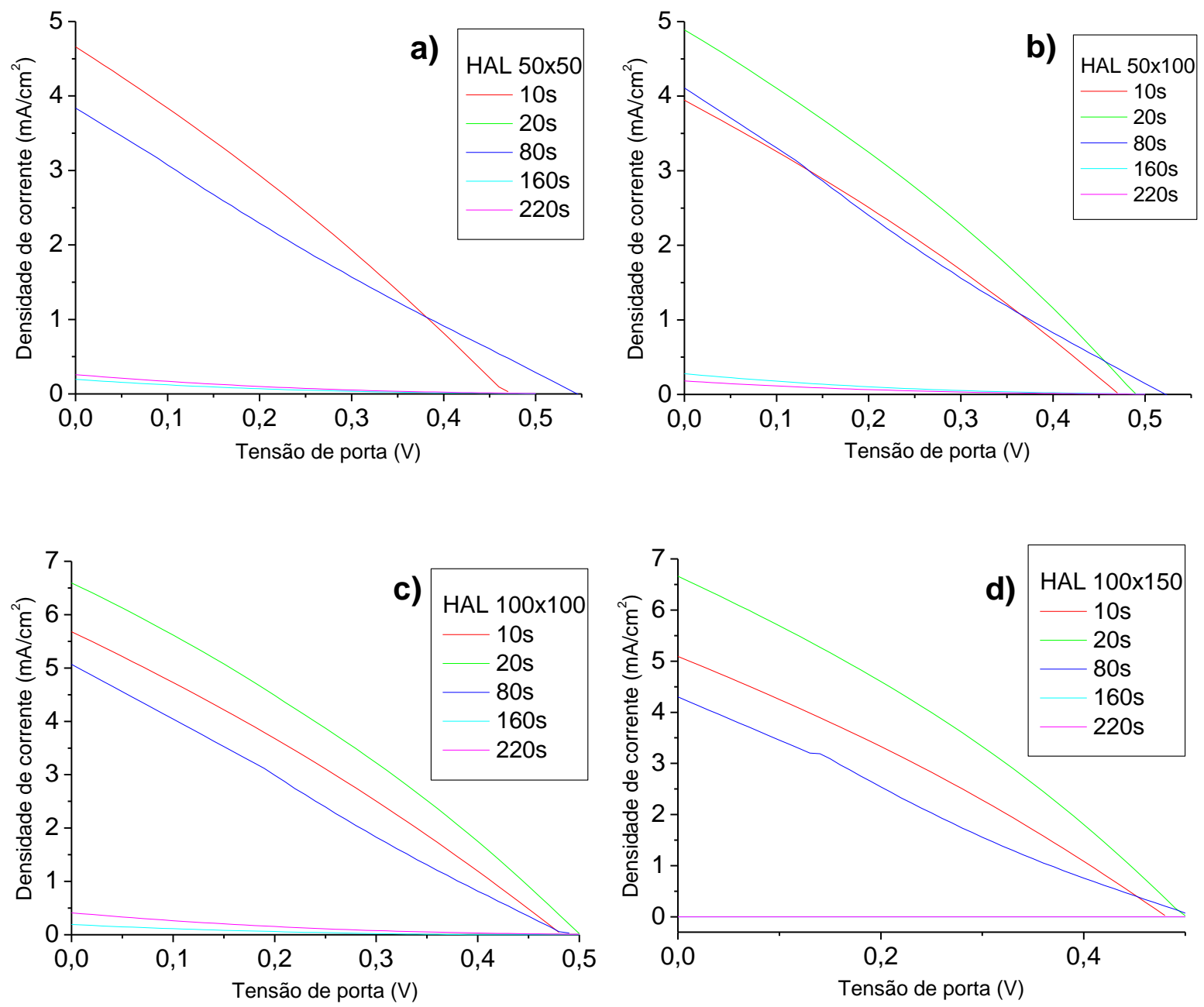

Fonte: Autor.

Também é importante destacar na figura 4.12 dois tipos de comportamentos nas características $\mathrm{JxV}_{\mathrm{G}}$ associados à concavidade que apesar de ser discreta, mostrouse sistematicamente orientada para cima para tempos de processamento acima de 80s para espessuras acima de 2,1nm (visível também em 160 e 220s quando as curvas são ampliadas). Já para os tempos de 10 e 20s, a concavidade mostrou-se sistematicamente orientada para baixo, também de forma discreta. A ligeira concavidade para cima pode ser entendida como uma influência de segunda ordem da maior espessura do dielétrico que acaba limitando a passagem de corrente para 
$V_{G}$ próximo de $V_{O c}$ onde os centros $K$ possivelmente tendem a ficar menos carregados positivamente com o acúmulo de elétrons na camada de inversão já que os elétrons passam a ter mais dificuldade de tunelar através do dielétrico de porta. Quando a espessura do dielétrico decresce abaixo de $2,1 \mathrm{~nm}$, passa a ocorrer o efeito contrário como observado para os tempos de 10 e 20s que correspondem às espessuras de 1,65 e $1,73 \mathrm{~nm}$, respectivamente.

A figura 4.13 ilustra a influência da distância da fonte luminosa do tipo lâmpada halógena ( 3,6 e $9 \mathrm{~cm})$ nas características típicas $J \times V_{G}$ para as diferentes geometrias empregadas. Observa-se que à medida que a distância " $d$ " aumenta, a intensidade radiante incidente diminui sobre a amostra e mesmo assim, não ocorre mudança significativa na forma e nos valores de Jsc e Voc. Essa observação pode ser explicada se considerarmos que a geração de portadores na região de depleção está ocorrendo predominantemente na superfície da amostra para as diversas intensidades radiantes incidentes. De forma geral, a densidade de corrente de curto circuito Jsc manteve-se na faixa de 3,29 a $5,09 \mathrm{~mA} / \mathrm{cm}^{-2}$, assim como a tensão de circuito aberto $V_{O c}$ variou apenas de 0,44 a $0,48 \mathrm{~V}$ (figura 4.13).

Por outro lado, a tabela 4.10, apresenta os cálculos da potência gerada máxima ( $P G$ máx) que foram realizados a partir das curvas nas figuras 4.12 e 4.13 através da obtenção do ponto de máximo da função $P_{G}\left(V_{G}\right)=J \times A_{G} \times V_{G}$ onde $A_{G}$ é a área da célula. Os valores de $P_{G \max }$ obtidos resultaram muito próximos de $V_{G}=V_{o c} / 2 \mathrm{como}$ era esperado (BEREUTER, 2016; TANABE, 2013; MATHEWS, 2015; EVANCZUK, 2015). 
Figura 4.13 - Curvas $\mathrm{JxV}_{\mathrm{G}}$ típicas utilizando a fonte luminosa halógena posicionada a 3, 6 e 9cm da

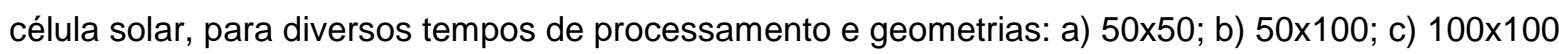
e; d) $100 \times 150$.
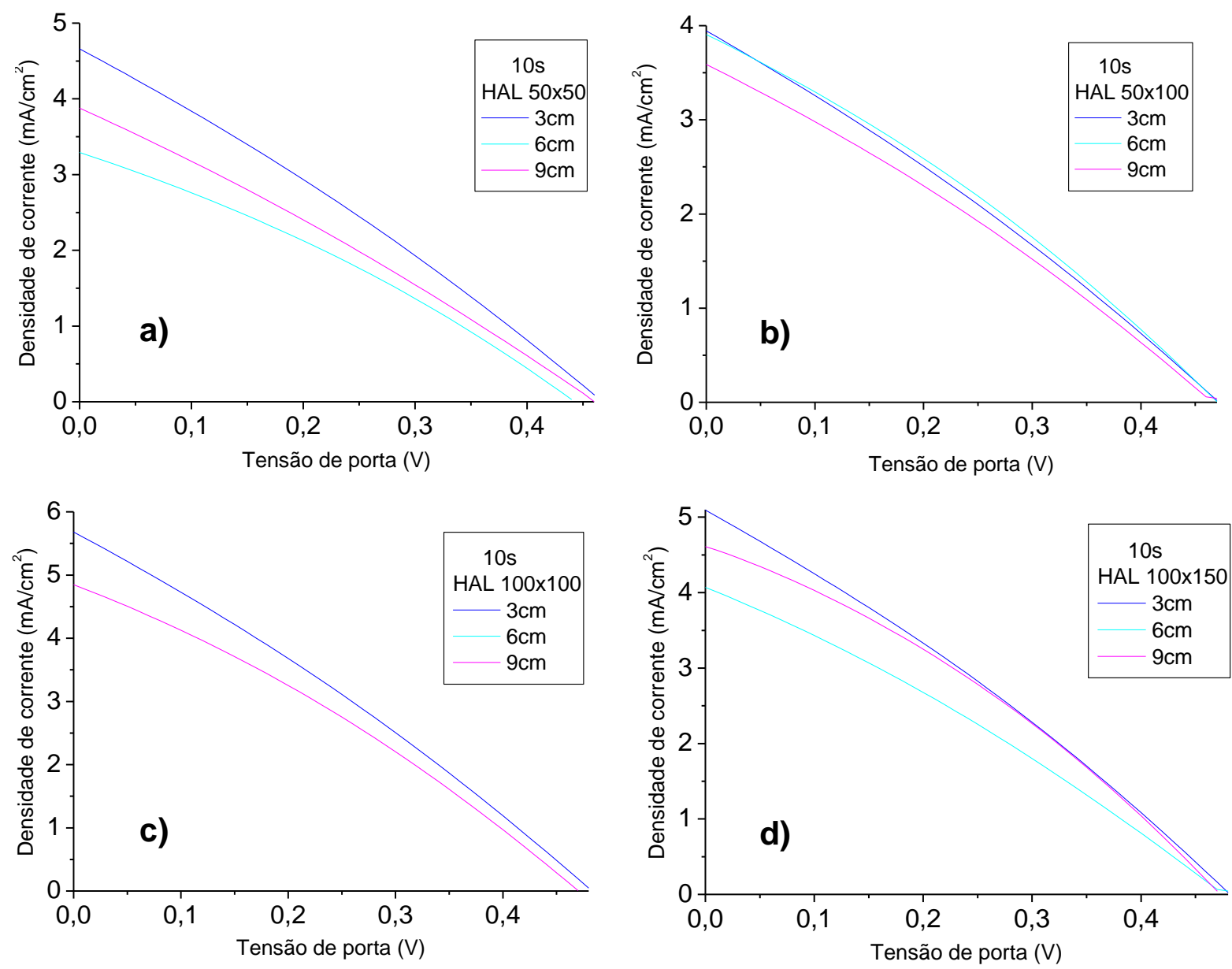

Fonte: Autor.

Tabela 4.10 - Potência gerada máxima $\left(P_{G \text { máx }}\right)$, densidade de corrente $\left(J_{m}\right)$ e tensão de porta $\left(V_{m}\right)$ no ponto de máximo da potência, em função das distâncias da lâmpada halógena em relação à célula $\operatorname{solar}(3,6$ e $9 \mathrm{~cm})$.

\begin{tabular}{|c|c|c|c|c|c|c|}
\hline & \multicolumn{3}{|c|}{$50 \times 50$} & \multicolumn{3}{|c|}{$50 \times 100$} \\
\hline & $\begin{array}{c}J_{m} \\
\left(m A / \mathrm{cm}^{2}\right)\end{array}$ & $\begin{array}{l}V_{m} \\
\text { (V) }\end{array}$ & $\begin{array}{c}P_{G \text { máx }} \\
\left(\mu \mathrm{W} / \mathrm{cm}^{2}\right)\end{array}$ & $\begin{array}{c}J_{m} \\
\left(\mathrm{~mA} / \mathrm{cm}^{2}\right)\end{array}$ & $V_{m}(V)$ & $\begin{array}{c}P_{G \text { máx }} \\
\left(\mu \mathrm{W} / \mathrm{cm}^{2}\right)\end{array}$ \\
\hline $3 \mathrm{~cm}$ & 2,45 & 0,25 & 611,6 & 2,1 & 0,25 & 524,9 \\
\hline $6 \mathrm{~cm}$ & 1,84 & 0,24 & 44 & 2,11 & 0,26 & 547,5 \\
\hline \multirow[t]{3}{*}{$9 \mathrm{~cm}$} & 2,07 & 0,24 & 496,7 & 1,92 & 0,25 & 480,9 \\
\hline & \multicolumn{3}{|c|}{$100 \times 100$} & \multicolumn{3}{|c|}{$100 \times 150$} \\
\hline & $\begin{array}{c}J_{m} \\
\left(\mathrm{~mA} / \mathrm{cm}^{2}\right)\end{array}$ & $\begin{array}{l}V_{m} \\
(V)\end{array}$ & $\begin{array}{c}P_{G \text { máx }} \\
\left(\mu \mathrm{W} / \mathbf{c m}^{2}\right)\end{array}$ & $\begin{array}{c}J_{m} \\
\left(m A / c^{2}\right)\end{array}$ & $V_{m}(V)$ & $\begin{array}{c}P_{G \text { máx }} \\
\left(\mu \mathrm{W} / \mathbf{c m}^{2}\right)\end{array}$ \\
\hline $3 \mathrm{~cm}$ & 2,99 & 0,26 & 777,6 & 2,72 & 0,2 & 707,2 \\
\hline $6 \mathrm{~cm}$ & 1,96 & 0,26 & 10,2 & 2,25 & 0,25 & 563,6 \\
\hline $9 \mathrm{~cm}$ & 2,65 & 0,26 & 688,0 & 2,78 & 0,26 & 698,0 \\
\hline
\end{tabular}

Fonte: Autor. 
Baseado na tabela 4.10, foram traçados os gráficos indicados na figura 4.14 onde foi possível observar os seguintes comportamentos: (a) a potência gerada máxima tende a aumentar com o aumento dos parâmetros largura das linhas " $L$ " ou espaçamentos entre as linhas "D" e (b) a potência gerada máxima é relativamente independente da distância "d" da lâmpada halógena em relação à célula solar. O primeiro comportamento (a) pode significar que possivelmente é mais fácil deixar os estados $K$ interfaciais mais carregados e, portanto, aumentar a largura da região de depleção para gerar mais corrente na situação em que "L" e "D" são maiores. O segundo comportamento mostra que apesar de haver uma variação de uma ordem de grandeza na intensidade radiante incidente como indicado na tabela 3.2 (11 a $\left.106 \mathrm{~mW} / \mathrm{cm}^{2}\right)$, a potência máxima gerada resultou em valores da mesma ordem de grandeza (450 a $\left.700 \mu \mathrm{W} / \mathrm{cm}^{2}\right)$.

Figura 4.14 - PGmáx médio em função das dimensões da célula a) "L" e b) “D”, e c) da distância célulalâmpada.
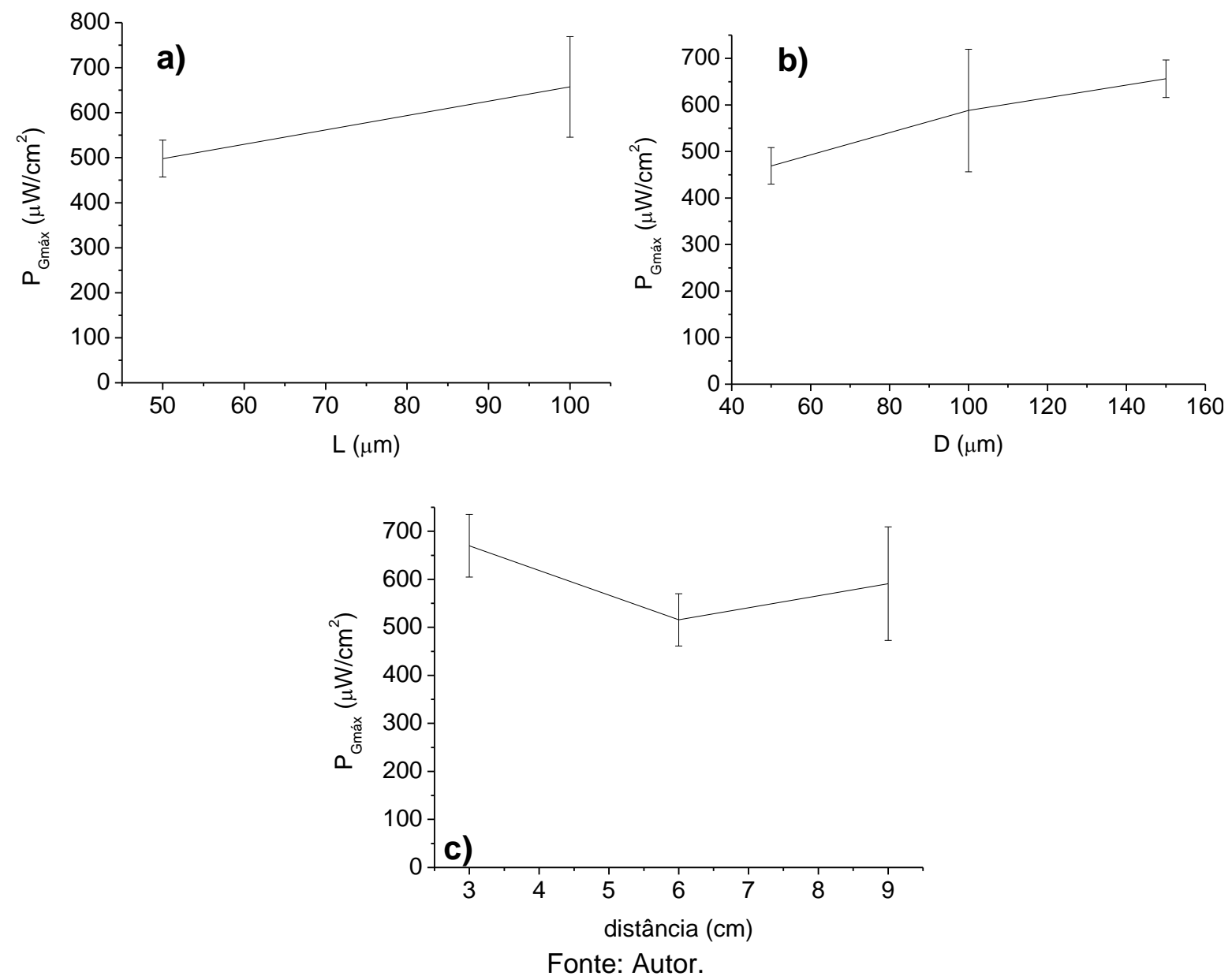

Fonte: Autor. 
Na figura 4.15, observa-se que a potência gerada máxima praticamente não varia em relação à potência incidente da lâmpada halógena (produto da intensidade radiante da tabela 3.2 pela área da célula solar). Como resultado, um fato muito relevante e particular desse tipo de célula solar MOS refere-se ao rendimento de conversão luminosa $\left(\mathrm{P}_{\mathrm{Gmax}} / \mathrm{P}_{\mathrm{in}}\right)$ que aumenta a medida que a potência incidente diminui. No caso da célula MOS apresentada na figura 4.15, o rendimento de conversão luminosa passa de $0,5 \%$ para $4,1 \%$ quando a potência incidente varia de 105,74 para $11,75 \mathrm{~mW} / \mathrm{cm}^{2}$. Esse fato mostra que esse tipo de célula pode ser empregado com vantagem em aplicações de Energy Harvesting. O máximo valor de rendimento obtido dentre todas as amostras fabricadas até o momento foi de 5,5\% sem a utilização de camada antirefletora a qual, se otimizada adequadamente, poderia conduzir a valores próximos de $14 \%$.

Figura 4.15 - PGmáx versus Pin (potência incidente).

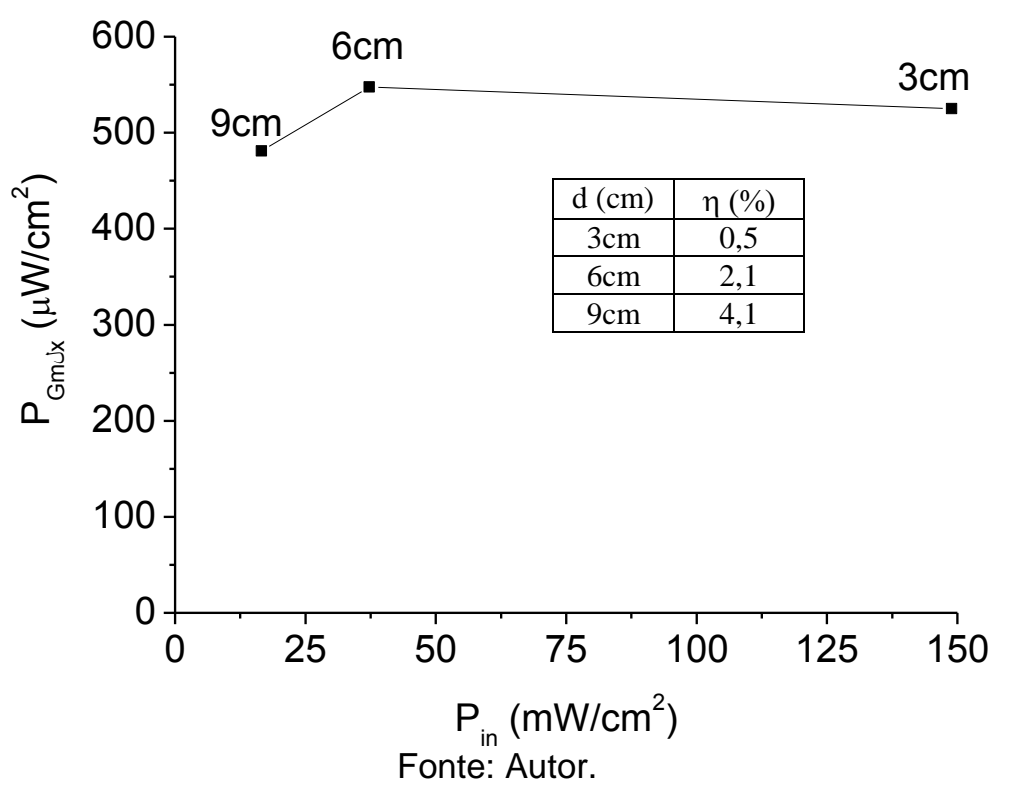

A figura 4.16 mostra as curvas $\mathrm{Jx} \mathrm{V}_{\mathrm{G}}$ para a geometria $50 \times 100$, utilizando como fonte luminosa a lâmpada halógena distante da célula solar de 6 e $9 \mathrm{~cm}$, respectivamente. É interessante observar que não ocorreu variação apreciável nos parâmetros Jsc e Voc para as amostras produzidas com tempos de processamento de 10 e 80 s. Nessa situação inferimos que uma variação de espessura de $1,65 \mathrm{~nm}$ para $2,1 \mathrm{~nm}$ não foi capaz de alterar significativamente o desempenho da célula solar MOS. Tal fato acaba 
tornando menos crítico o processo de fabricação da célula solar MOS operando em regime de inversão induzido por cargas positivamente carregadas na interface comparado com a célula solar MOS com operação convencional.

Figura 4.16 - Curvas $J x V_{G}$ típicas utilizando lâmpada halógena como fonte luminosa a 6 e $9 \mathrm{~cm}$ da célula solar, com geometria 50×100 e tempos de processamento: a) 10s e; b) 80 s.
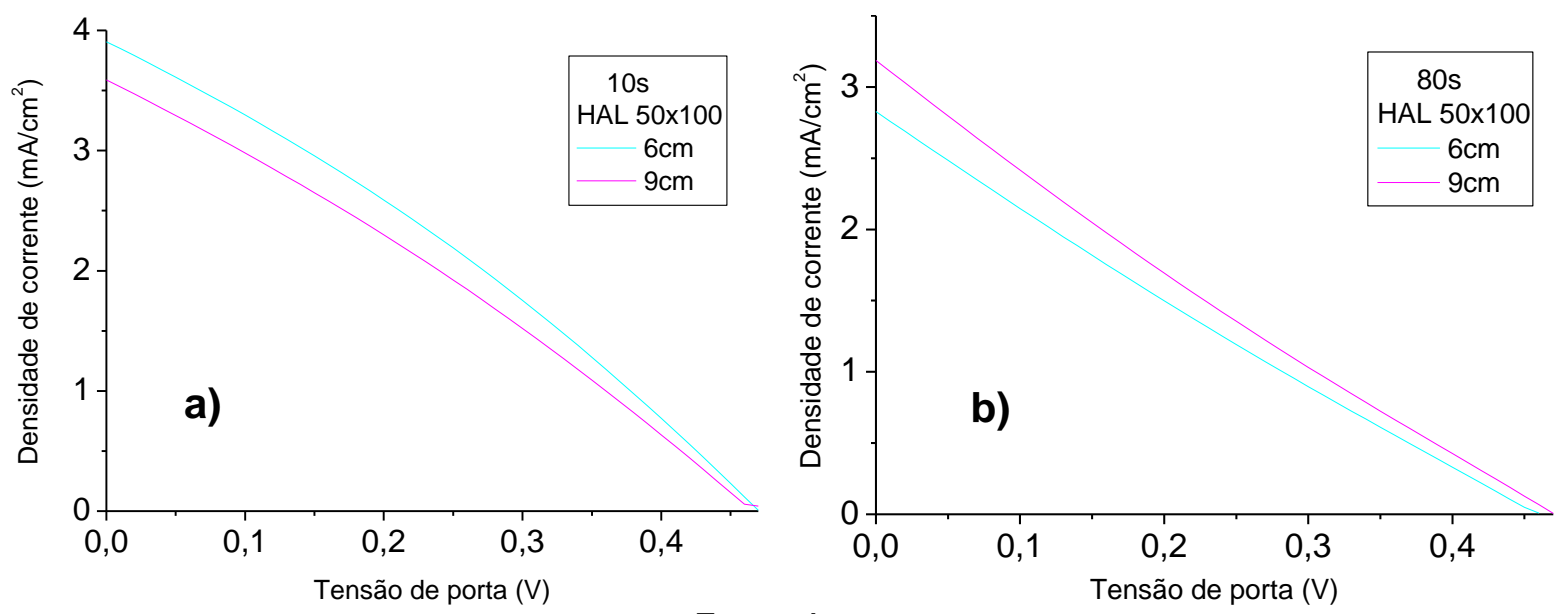

Fonte: Autor.

Como já mencionado, também foram crescidos dielétricos por meio da receita "Rap" descrita nos procedimentos experimentais para a temperatura de $700^{\circ} \mathrm{C}$. A lâmina foi inicialmente mantida na entrada do forno por $5 \mathrm{~min}$ em ambiente de $\mathrm{N}_{2}+\mathrm{O}_{2}(1,5 \mathrm{~L} / \mathrm{min})$. $\mathrm{Na}$ sequência, o $\mathrm{N}_{2}$ foi desligado e foi feita a inserção rápida da lâmina por $5 \mathrm{~s}$ até o centro do forno onde permaneceu por 300 s, em seguida, foi feita a retirada rápida em $5 \mathrm{~s}$ até a entrada do forno onde permaneceu por mais $5 \mathrm{~min}$ em ambiente de $\mathrm{N}_{2}$. As lâminas obtidas de acordo com a receita "Rap" foram comparadas com a receita padrão realizada na temperatura de $850^{\circ} \mathrm{C}$ para tempo de processamento de $10 \mathrm{~s}$. Nessa comparação foram utilizadas lâmpadas halógenas a 3cm da amostra $(105,7$ $\left.\mathrm{mW} / \mathrm{cm}^{2}\right)$. Observa-se na figura 4.17 comportamentos semelhantes para as lâminas processadas segundo a receita padrão por RTP comparado ao caso da receita rápida (Rap) dado que as espessuras dos dielétricos obtidos resultaram muito próximas entre si $\left(1,65 \mathrm{~nm}\right.$ para a receita padrão a $850^{\circ} \mathrm{C}$ por 10 s e $1,69 \mathrm{~nm}$ para a receita "Rap" em $700^{\circ} \mathrm{C}$ ). Observa-se que os valores de Jsc e Voc são semelhantes independentemente da geometria do capacitor. Esse resultado permite afirmar que a permanência da lâmina de silício em ambiente de $\mathrm{N}_{2}+\mathrm{O}_{2}$ na entrada do forno e em parte no período 
de inserção, quando o $\mathrm{N}_{2}$ acabou de ser desligado, foi possivelmente suficiente para gerar ligações do tipo $\mathrm{Si} \equiv \mathrm{N}$ responsáveis pelos centros $K$ na interface $\mathrm{SiO}_{2} / \mathrm{Si}$.

Figura 4.17 - Curvas $\mathrm{JxV}_{\mathrm{G}}$ típicas para células MOS processadas por 10s (RTP adaptado) e receita

Rap. (forno convencional) utilizando lâmpada halógena distante em $3 \mathrm{~cm}$ da célula solar, para

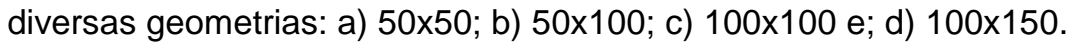
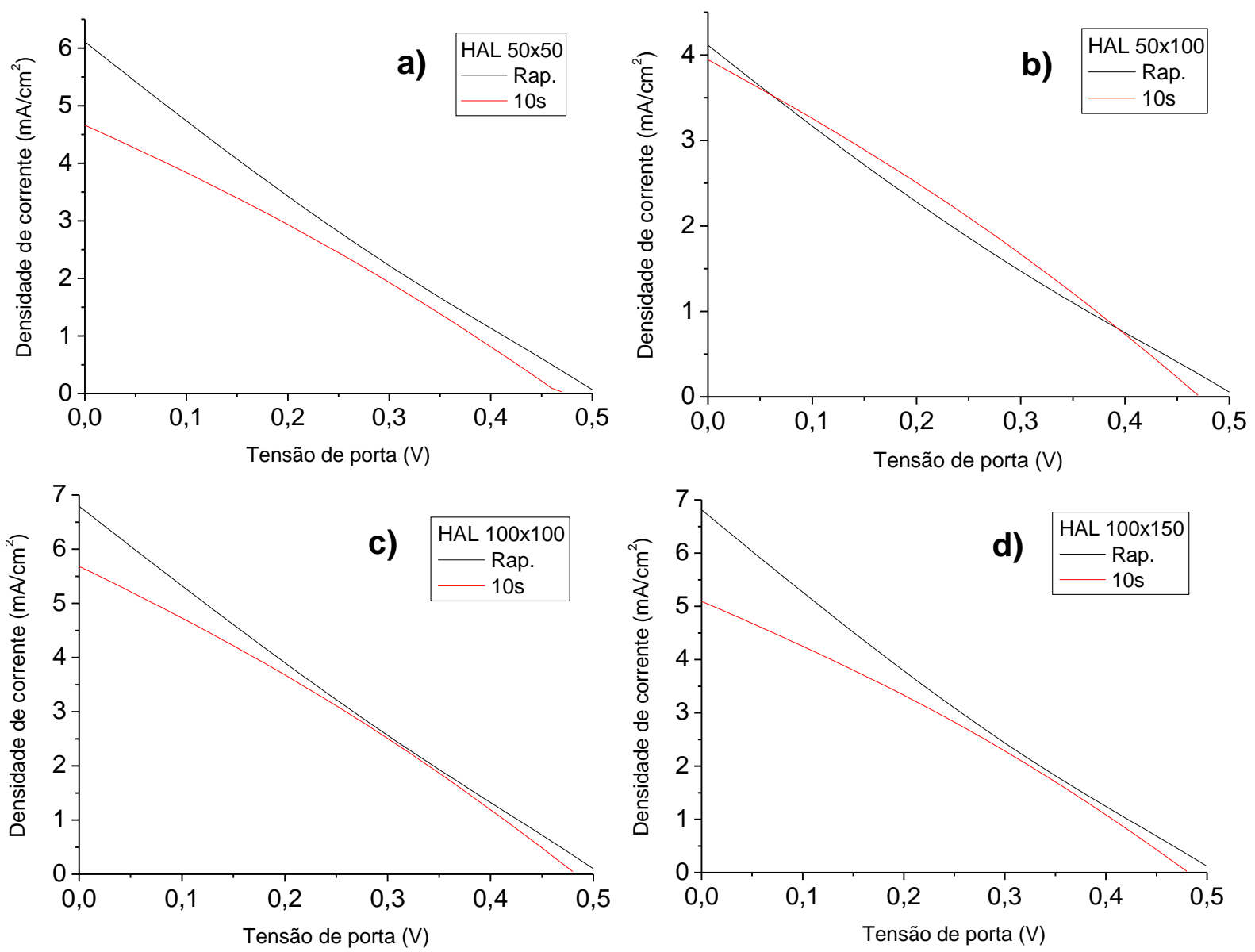

Fonte: Autor.

Adicionalmente, foram empregados substratos tipo $\mathrm{P}$ com resistividade em duas faixas distintas: $0,2-1 \Omega \mathrm{cm}$ e $1-10 \Omega \mathrm{cm}$. A figura 4.18 mostra as densidades de correntes em níveis inferiores para resistividade na faixa de $0,2-1 \Omega \mathrm{cm}$ comparado a faixa de $1-10 \Omega \mathrm{cm}$. Tal comportamento ocorreu porque a espessura do dielétrico obtida para o substrato menos resistivo acabou resultando maior apesar de ter sido empregada a mesma receita de oxinitretação $(2,15 \mathrm{~nm}$ contra $2,10 \mathrm{~nm})$. A evidência de espessura ligeiramente maior é corroborada pelo grau de concavidade maior na 
característica $\mathrm{JxV}_{\mathrm{G}}$ para o substrato menos resistivo comparado ao substrato mais resistivo. Por outro lado, a exposição à luz LED de menor intensidade luminosa $\left(42,3 \mathrm{~mW} / \mathrm{cm}^{2}\right)$, como esperado, apresentou nível de densidade de corrente menor comparado às amostras que foram expostas à lâmpada halógena (veja intensidades das lâmpadas na Tabela 3.2).

Figura 4.18 - Curvas $\mathrm{JxV}_{\mathrm{G}}$ típicas de célula solar MOS produzida por 80 s distantes em $3 \mathrm{~cm}$ da fonte de luz (halógena ou led), para resistividades do substrato dentro das faixas de 0,2-1 e 1-10 $\mathrm{cm}$, para

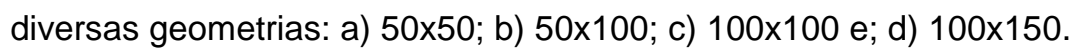
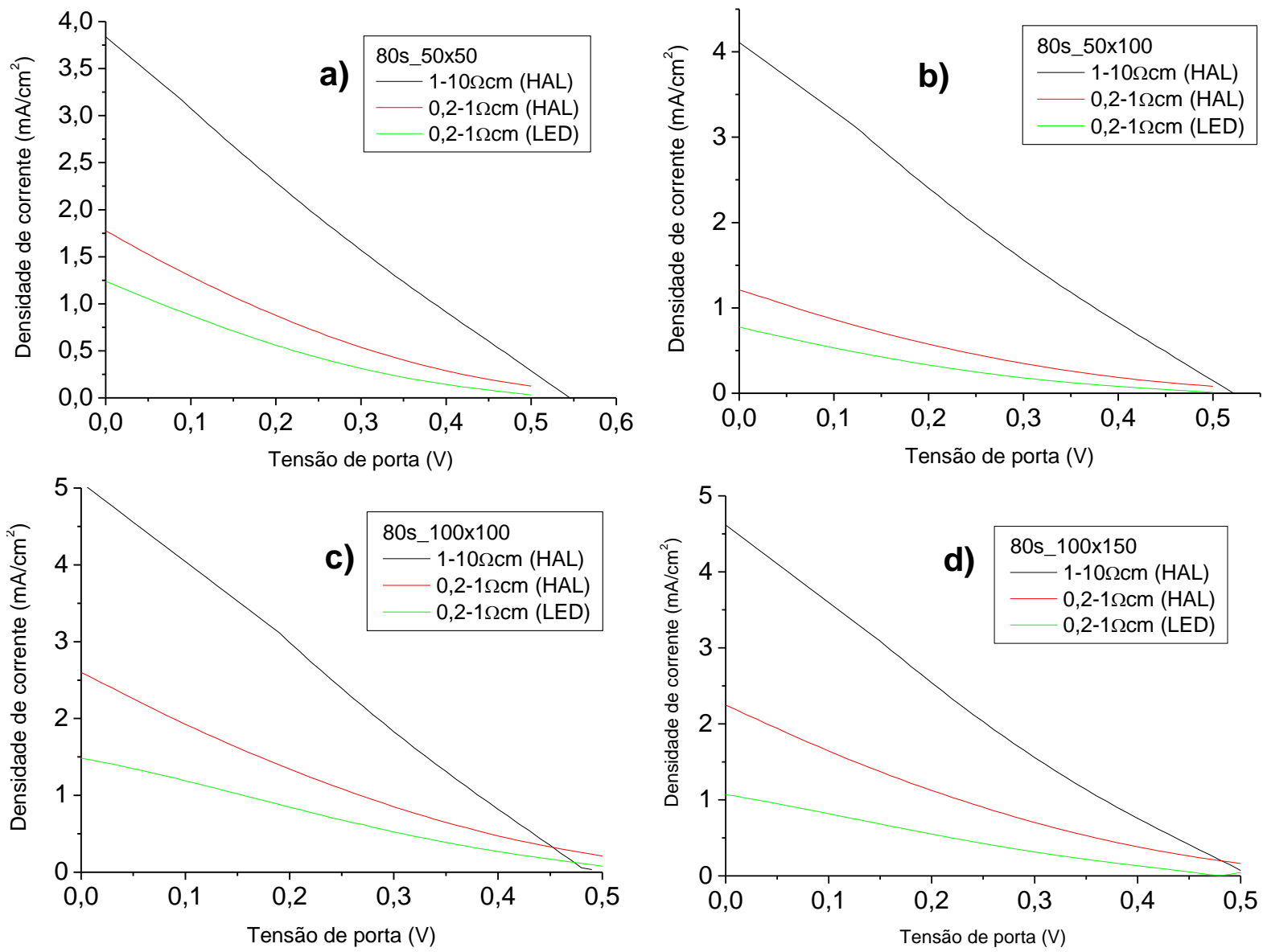

Fonte: Autor. 


\section{CONCLUSÕES E PERSPECTIVAS FUTURAS}

As conclusões sobre os resultados e discussão são apresentadas em três itens. $\mathrm{Na}$ sequência são feitas algumas considerações sobre possíveis perspectivas futuras de continuação do trabalho realizado até o momento.

\subsection{Conclusões sobre a obtenção de oxinitretos crescidos por processamento térmico rápido}

Neste trabalho foi abordado o crescimento de óxidos de silício enriquecidos com nitrogênio através de processamento térmico rápido (RTP) realizado em forno térmico convencional adaptado. Portanto, é importante destacar a inovação tecnológica produzida neste doutoramento resultando em uma maneira de crescer filmes finos com baixo custo agregado e mantendo a característica de baixa massa térmica dos fornos RTP o que permite maior homogeneidade de temperatura na superfície do substrato durante o crescimento térmico rápido, resultando em filmes finos mais uniformes em espessura.

As espessuras médias foram obtidas por elipsometria com índice de refração fixo em 1,460 e confirmadas por microscopia eletrônica de transmissão (TEM). Foram crescidos filmes finos em ambiente misto de $\mathrm{N}_{2}: \mathrm{O}_{2}$ em diversas proporções e em ambiente de $\mathrm{O}_{2}$, para diversas temperaturas e tempos de processo, resultando em espessuras variando na faixa de 1,00 a $2,95 \mathrm{~nm}$, que se enquadram nos valores reportados para que haja a passagem de corrente por tunelamento em células solares MOS (SHEWCHUN, 1997). Através de análises de microscopia de força atômica, verificou-se baixa microrrugosidades superficiais $(<0,95 \mathrm{nmRMS})$.

A espectroscopia de emissão por fotoelétrons (XPS) foi empregada para comprovar a incorporação de nitrogênio nos filmes crescidos. A porcentagem atômica de $\mathrm{N}_{2}$ obtida por XPS ficou na faixa de 1,0 a 2,1\% a qual é reportada por (CHANG, 2004) como eficaz na melhoria das características elétricas da interface $\mathrm{Si} / \mathrm{SiO}_{2}$. 


\subsection{Conclusões sobre os capacitores MOS}

As curvas características capacitância-tensão (CV) típicas dos capacitores MOS produzidos com diferentes proporções de $\mathrm{N}_{2}: \mathrm{O}_{2}$, e diferentes áreas de porta, apresentaram funcionamento em regime de depleção profunda para $V_{G}>V_{F B 1}$, tendo um pico de capacitância para $\mathrm{V}_{\mathrm{FB} 1} \approx-0,8 \mathrm{~V}$ que representa a transição da região de depleção para a região de acumulação e está associado a existência de centros K, ou seja, armadilhas interfaciais do tipo $K$ carregadas positivamente.

Foi mostrado em trabalho anterior do grupo (ALANDIA, 2016) que os centros $K$ localizam-se junto à interface óxido de silício-substrato e são induzidos durante o processo de oxinitretação, que em nosso caso, consiste no processamento térmico rápido em ambiente misto de $\mathrm{N}_{2}+\mathrm{O}_{2}$. A existência de ligações $\mathrm{Si} \equiv \mathrm{N}$ na interface $\mathrm{Si} / \mathrm{SiO}_{2}$ permite o aparecimento dos centros $K$ em grande quantidade que passam a estar carregados positivamente para $\mathrm{V}_{\mathrm{G}}>\mathrm{V}_{\mathrm{FB} 1}$ permitindo o funcionamento da célula solar MOS como um conversor de energia luminosa em energia elétrica.

\subsection{Conclusões sobre as células solares MOS operando no modo inversão induzido pelos centros $K$}

Primeiramente, observou-se que a corrente de fundo independe da geometria (LXD) da célula solar MOS. Enquanto que a corrente de curto-circuito (Jsc) aumenta progressivamente $\left(1-8 \mathrm{~mA} / \mathrm{cm}^{2}\right)$ para dielétricos de porta com espessura menor do que cerca de $2 \mathrm{~nm}$, a tensão de circuito aberto $\left(\mathrm{V}_{\mathrm{oc}}\right)$ praticamente não varia $(\sim 0,5 \mathrm{~V})$. $\mathrm{A}$ curva característica $\mathrm{JxV}_{\mathrm{G}}$ da célula solar iluminada apresentou comportamento aproximadamente linear para diferentes níveis de intensidade radiante incidente $(11,8$ $\left.105,7 \mathrm{~mW} / \mathrm{cm}^{2}\right)$.

As potências geradas máximas ( $P_{G m a ́ x}$ ) foram calculadas na faixa de centenas de $\mu \mathrm{Wcm}^{-2}$ para tensão de porta $\mathrm{V}_{\mathrm{G}}$ em torno de $\mathrm{V}_{\mathrm{oc}} / 2$, sendo aproximadamente independente da geometria adotada e apresentando pequena variação em função da potência incidente $\left(11,8-107,7 \mathrm{~mW} / \mathrm{cm}^{2}\right)$. A faixa de centenas de $\mu \mathrm{Wcm}^{-2}$ é compatível com aplicações em circuitos miniaturizados subcutâneos, como por exemplo, em circuitos de marca-passos, circuitos eletrônicos para casas inteligentes ou, até mesmo 
para o monitoramento de banco de dados (BEREUTER, 2016; TANABE, 2013; MATHEWS, 2015; EVANCZUK, 2015).

\subsection{Perspectivas futuras}

Como continuação do presente trabalho, propomos estudar a sistematicamente a influência de outras variáveis de processo incluindo a dopagem do substrato, as diversas proporções do ambiente misto de oxidação em $\mathrm{N}_{2}: \mathrm{O}_{2}$ e/ou de temperaturas de processo, variações da área de porta das células solares MOS, o acréscimo de camada anti-refletiva e até mesmo a sinterização da estrutura.

Em relação à caracterização elétrica das células solares MOS, propomos também a utilização de equipamento que simule o espectro solar com padrão AM1,5 para consolidar os resultados discutidos nessa tese como, por exemplo, os publicados por (GODFREY, 1978; HAR-LAVAN, 2013) que caracterizam seus dispositivos no padrão AM1,5. 


\section{BIBLIOGRAFIA}

ALANDIA, B. S.; Fabricação e Caracterização Experimental de Diodos Túnel MOS $\mathrm{Al} / \mathrm{SiO}_{x} \mathrm{~N}_{\mathbf{y}} / \mathrm{Si}(\mathrm{p})$ e TiN/SiO $\mathrm{N}_{\mathbf{y}} / \mathrm{Si}(\mathbf{p})$. Dissertação (mestrado) - Escola Politécnica, Universidade de São Paulo, São Paulo, 2016.

ARAUJO, C. A. P de; Gallegos, R. W.; Huang, Y. P. Kinetics of rapid thermal oxidation. Journal of Electrochemical Society, v. 136, n. 9, p. 2673-2676, 1989.

AUTO89. AutoEI MS Manual (NIR3), Rudolph Research Inc. 1989.

BALK, P. The Si-SiO 2 System (Materials Science Monographs), Elsevier Science LTD, 1988.

BEREUTER, L, et al. Energy Harvesting by Subcutaneous Solar Cells: A LongTerm Study on Achievable Energy Output. Annals of Biomedical Engineering, 2016.

BEYER, A.; Ebest, G.; Reich, R. Metal-insulator-semiconductor solar cells with silicon oxynitride tunnel insulator by using rapid thermal processing. Applied Physics Letters, v. 88, p. 508-510, 1996.

CAMPBELL S.A, The Science and Engineering of Microelectronic Fabrication, $2^{\text {nd }}$ ed., Oxford University Press, 2001.

CHRISTIANO, V. Caracterização física e elétrica de filmes dielétricos de $\mathrm{Al}_{2} \mathrm{O}_{3} \mathrm{e}$ $\mathrm{Al}_{x} \mathrm{Hf}_{1-\mathrm{x}} \mathrm{O}_{\mathrm{y}}$ para estruturas high k MOS. Dissertação (Mestrado) - Escola Politécnica Universidade de São Paulo, 2012.

CHANG, K.M.; Yang, W.C.; Hung, B.F. "The changing effect of $\mathrm{N}_{2} / \mathrm{O}_{2}$ gas flow rate ratios on ultrathin nitrogen-enriched oxynitride gate dielectrics". Journal of the Electrochemical Society, v. 151, n.5, p. F118-F122, 2004.

CHANG, K.M.; Yang, W.C.; Chen, C.F. "1.0 nm oxynitride dielectrics prepared by RTP 
in mixtures of $\mathrm{N}_{2}$ and $\mathrm{O}_{2}$ ambient" Electrochemical and Solid State Letters, v. 7, n. 6, p. G119-G121, 2004(b).

CHEN, C.-H.; Hong, C.-C.; Hwu, J.-G.; Silicon Metal-Oxide-Semiconductor Solar Cells with Oxide Prepared by Room Temperature Anodization in Hydrofluosilicic Acid Solution, Journal Electrochemical Society., v. 149, n. 6, p. G362-G366, 2002.

CHIOU, Y.L.; Sow, C. H.; Li, G. Growth characteristics of silicon dioxide produced by rapid thermal oxidation processes. Applied Physics Letters, v. 57, n. 9, p. 881-3, 1990.

CRESESB Centro de Referência para as Energias Solar e Eólica Sérgio Brito. Disponível em: <http://www.cresesb.cepel.br/>. Acesso em: 15 set 2017.

CUEVAS, A. Multicrystalline silicon: the photovoltaic material by excellence, Materials Forum, v. 27, p. 1-8, 2004.

XPS-ESCA. Disponível em : <http://www.dsif.fee.unicamp.br/ furio/IE607A/XPSESCA.pdf>. Acesso em: 27 jan. 2012.

DEAL, B. E.; Grove, A. S.General relationship for the thermal oxidation of silicon. Journal of Applied Physics, v. 36, n. 12, p. 3770-3778, 1965.

DEATON, R.; Massoud, H. Z. Manufacturability of rapid thermal oxidation of silicon: oxide thickness, oxide thickness variation and system dependency. IEEE Transactions on Semiconductor Manufacturing, v. 5, n. 4, p. 347-357, 1992.

DEPAS, M.; Meirhaeghe, R. L. V.; Laflère, W. H.; Cardon, F. Tunnel oxides grown by rapid thermal oxidation. Microelectronic Engineering, v. 22, p. 61-64, 1993.

DHANDA, H.K., et. al. Conversion Efficiency Optimization of CdTe-DdS Heterojunction Based Solar Cell for Different Substrate Materials. Journal of Nanoelectronics and Optoelectronics, v.12, p. 247-253, 2017. 
DOSHI, P.; Rohatgi, A.; 18\% Efficient Silicon Photovoltaic Devices by Rapid Thermal Diffusion and Oxidation, IEEE Trans. On Electron Devices, v. 45, n. 8, p. 1710-1716, 1998.

EVANCZUK, S. Specialized ICs, PV Enable Energy Harvesting from Indoor Lighting. Digi-Key Electronics. Electronic Products 2015-02-04, 2015

GALDINO, M.A.; Lima, J.H.G.; Ribeiro, C.M.; Serra, E.T. O contexto das energias renováveis no Brasil. Revista Direng, p. 17-25, 2006.

GAVARTI, J.L.; Shugler, A.L.; Foster, A.S.; Bersuker, G.I. The role of nitrogen-related defects in high-K dielectric oxides: density-functional studies. Journal of Applied Physics, v. 97, p. 053704, 2005.

GASPARIN, F.P. Desenvolvimento de um traçador de curvas características de módulos fotovoltaicos. Dissertação de mestrado. Universidade Federal do Rio Grande do Sul, 2009.

GEHRING, A. Simulation of tunneling in semiconductor devices. $\mathrm{PhD}$ (doctorate), Technischen Universität Wien, Viena, Austria, 2003.

GODFREY, R.B.; GREEN, M.A. A 15\% efficient silicon MIS solar cell, Appl. Phys. Lett. v. 33, n. 7, p. 637-639, 1978.

GROVE, G. A. Physics and Technology of Semiconductor Devices. New York: Wiley, 1967.

HAR-LAVAN R., D. CAHEN, 40 years of Inversion-Layer Solar Cells: From MOS to Conduct Polymer/Inorganic Hybrids, IEEE Journal of Photovoltaics, v. 3, n. 4, p. 1443-1459, 2013.

HEYNS, M.; Hasenack, C.M.; De Keersmaecker, R. Impact of silicon surface characteristics on MOS device yield for ULSI. Microelectronic Engineering, v. 10, p. 
235-57, 1991.

HEYNS, M.M.; Meuris, M.; Verhaverbeke, S.; Mertens, P.W.; Schmidt, H.F.; Rotondaro, A.L.P.; Hurd, T.Q.; Hatcher, Z.; Gräf, D. Cleaning technology for highly reliable gate oxides. International Conference on Advanced Microeletronic Devices and Processing, Sendai, Japan, March 3-5, 1994 (invited), in Proceedings of the International Conference on AMDP (Komiyama Printing Co., Japan), p. 59.

HURKX, G. A. M.; Graaff, H. C. de; Kloosterman, W. J.; Knuvers, M. P. G. A new analytical diode model including tunneling and avalanche breakdown. IEEE Transaction Electron Devices, v. 39, p. 2090-2098, 1992.

IBALDO, A. P. Estudo de materiais, estruturas de dispositivos e fenômenos de transporte em sistemas fotovoltaicos híbridos orgânico-inorgânico. Tese de doutorado. Universidade de São Paulo, 2010.

IEA PVPS. International Energy Agency. TRENDS 2015 In Photovoltaic Applications. Survey Report of Selected IEA Countries between 1992 and 2014. Edition $20^{\text {th }}, 2015$.

KERN, W.; Puotinen, D.A. Cleaning solution based on hydrogen peroxide for use in silicon semiconductor technology. RCA Review, v. 31, p. 187-205, 1970.

KERN, W. The evolution of silicon wafer cleaning technology. Journal Electrochemical Society, v. 137, n. 6, p. 1887, 1990.

KERN Jr., F.W.; Mitsushi, M.; Kawanabe, I.; Miyashita, M.; Rosenberg, R.W.; Ohmi, T. Metallic contamination of semiconductor devices from processing chemicals: The unrecognized potential. In: Proceedings of the 37th Ann. Tech. Mtg., Proceedings. San Diego, CA, Institute of Enviromental Sciences, 1991. 
LIN, C.-H.; Hsu, B.-C; Lee, M. H.; Liu, C. W. A comprehensive study of inversion current in MOS tunneling diodes. IEEE Transaction Electron Devices, v. 48, p. 21252130, 2001.

LU, Z. H.; Tay, S. P.; Cao, R.; Piametta, P. The effect of rapid thermal $\mathrm{N}_{2} \mathrm{O}$ nitridation on the oxide/Si (100) interface structure. Applied Physics Letters, v. 67, p. 28362838, 1995.

MATHEWS, I. Performance of III-V Solar Cells as Indoor Light Energy Harvesters. IEEE Journal of Photovoltaics, 2015.

Ministério de Minas e Energia. Resenha Energética Brasileira. Exercício de 2015. Edição: Maio, 2016.

MOSLEHI, M.M.; Kermani, A. Process uniformity and electrical characteristics of thin gate dielectrics grown by ramped-temperature transient rapid thermal oxidation of silicon. In: Mat. Res. Soc. Symp., 1988. Proceedings. Pittsburgh, MRS, 1989. v. 146, p. $405-12$.

MURALI, V.; Murarka, S. P. Knetics of ultrathin $\mathrm{SiO} 2$ growth. Journal of Applied Physics, v. 60, n. 6, p. 2106-2114, 1986.

NOVUS, Controlador Universal N1100, 2013. Disponível em http://www.novus.com.br/site/default.asp?TroncolD=621808\&SecaolD=946383\&Sub secaolD=0\&Template =../catalogos/layout produto.asp\&ProdutolD=504417\#Downloa d. Acesso em 26 de Fevereiro de 2013.

NULMAN, J.; Krusius, J.P.; Shah, N.; Gat, A.; Baldwin, A. Ultrathin gate dielectrics on $150 \mathrm{~mm} \mathrm{Si}$ wafers via rapid thermal processing. Journal Vacuum Science Technology., v. 4, n. 3, p.1005-8, 1986.

PULFREY D. L. MIS Solar Cells: A Review, IEEE Transactions on Electron Devices, DOI 0018-9383/78/1100-1308\$00.7, p. 1308-1317, 1978. 
RUNYAN, W. R. Semiconductor measurement and instrumentation, Tokyo, McGraw-Hill Kogakusha LTD., 1975, p.58. (Texas Instrument Electronics Séries).

SANTOS, S. G. dos F.; Hasenack, C.M.; Salay, L.C.; Mertens, P.W. A less critical cleaning procedure for silicon wafers using diluted HF dip and boiling in isopropyl alcohol as final steps. Journal Electrochemical Society, v. 142, n. 3, p. 902-7, 1995.

SANTOS, S. G. dos F; Hasenack, C.M. Achievement of high quality thin gate oxides grown by rapid thermal oxidation. Journal of Solid-State Devices and Circuits, v. 3, n. 1 , p. $1-9,1995(b)$.

SANTOS, S.G. dos F.; Hasenack, C.M.; Lopes, M.C.V.; Baranauskas, V. Rapid thermal oxidation of silicon with different thermal annealing cycles in nitrogen: Influence on surface micro-roughness and electrical characteristics. Semiconductor Science and Technology, v. 10, p. 990-6, 1995(c).

SANTOS, S. G. dos F. Oxidação térmica rápida do silício: influência dos procedimentos de limpeza e dos perfis temporais de temperatura na qualidade dos óxidos de porta MOS. 1996. 224 p + Anexos. Tese (Doutorado) - Escola Politécnica, Universidade de São Paulo, São Paulo, 1996.

SCHMELA, M. Global Market Outlook For Solar Power / 2016 - 2020. SolarPower Energy. Webinar, 7 July, 2016.

SCOFIELD, J. H. Hartree-Slater subshell photoionization cross-sections at 1254 and $1487 \mathrm{eV}$. Journal of Electron Spectroscopy and Related Phenomena. v. 8, n. 2, p. 129-137, 1976

SHEWCHUN, J.; Singh, R.; Green, A.; Theory of Metal-Insulator-Semiconductor Solar Cells. Journal Applied Physics, v. 48, p. 765-770, 1977. 
SHIRLEY, D. A. High resolution X-ray photoemission spectrum of the valence band of gold. Physical Review B. v. 5, p. 4709-4714, 1972.

SOUZA, R. Fabricação e caracterização de óxidos de porta MOS ultrafinos crescidos sobre superfícies planas com degraus empregando processos: convencional e pirogênico. 2006. 122 p. Dissertação (Mestrado) - Escola Politécnica, Universidade de São Paulo, 2006.

SZE, S. M. Physics of Semiconductor Devices. 2nd ed. New York: Wiley, 1981

SWANSON, R.M. A vision of crystalline silicon photovoltaics. Progress in Photovoltaics: Research and Applications, v. 14, n. 6, p. 443-453, 2006.

TANABE, N. Dye-Sensitized Solar Cell for Energy Harvesting Applications. Fujikura Technical Review, 109-113, 2013.

TOQUETTI, L.Z. and Santos Filho, S.G. Estudo Experimental da Obtenção de Oxinitretos de Silício Ultrafinos para Porta MOS. Tese de Doutoramento - Escola Politécnica da USP - 2005.

VERHAVERBEKE, S.; Teerlinck, I.; Vinckier, C.; Stevens, G.; Cartuyvels, R.; Heyns, M. M. The etching mechanisms of $\mathrm{SiO}_{2}$ in hydrofluoric acid. Journal of Electrochemical Society, v. 141, p. 2852, 1994.

VILLALVA, M.G.; Gazoli, J.R. Energia fotovoltaica: conceitos e aplicações. São Paulo. Ed.Érica, 2012.

WEI, Z.; et. al (2016). The effect of additional súlfur on solution-processed purê sulfide Cu2ZnSnS4 solar cell absorver layers. MRV Advances, (41), 2815-2820. Doi:10.1557/adv.2016.425.

YANG, Q. Charged Silicon Nitride Films: Field-Effect Passivation of Silicon Solar Cells and a Novel Characterization Method through Lifetime Measurements. 
MSc. (mestrado) - ARIZONA STATE UNIVERSITY, Arizona, 2014.

YAO, Z. Q.; Harrison, H. B.; Dimitrijev, S.; Yeow, Y. T. The electrical properties of sub5-nm oxynitride dielectrics prepared in a nitric oxide ambient using rapid thermal processing. IEEE Electronic Devices Letters, v.15, n. 12, p. 516-518, 1994.

YEH, C.F.; Chen, C.L.; Lin, G.H.; Journal Electrochemical Society, v. 141, p. 3177, 1994.

YEH, C.F.; Lin, S.S.; Fan, C.L.; Thinner Liquid Phase Deposited Oxide for Polysilicon Thin-Film Transistor, IEEE Electron Device Letters, v. 18, p. 473-475, 1995.

YOU, K.-F.; Wu, C.-Y. A new quasi-2-D model for hot-carrier band-to-band tunneling current. IEEE Transaction Electron Devices, v. 46, p. 1174-1179, 1999.

ZAININGER, K. H.; Revesz, A.G. Ellipsometry - a valuable tool in surface research. RCA review, p. 85-115, 1964. 
[1] HUANCA, D. R. ;Christiano, V.; ADELMANN, C. ; VERDONCK, P. ; Santos Filho, S. G. . Physical characterization of hafnium aluminates dielectrics deposited by atomic layer deposition. JICS. Journal of Integrated Circuits and Systems (Ed. Português), v. 10, p. 49-52, 2015.

[2] CHRISTIANO, V.; DOS SANTOS FILHO, SEBASTIAO G. Physical characterization of ultrathin silicon oxynitrides grown by Rapid Thermal Processing aiming to MOS tunnel devices. In: International Conference on Solid Films and Surfaces (ICSFS 2014), 2014, Rio de Janeiro. IOP Conference Series: Materials Science and Engineering. IOP Publishing LTD., 2014. v. 76. p. 012002 - 5.

[3] Siano B; Huanca, D. R.; CHRISTIANO, V.; DOS SANTOS FILHO, SEBASTIAO G. Characterization of the semi-insulating properties of AlHfO3.5 for power devices. In: International Conference on Solid Films and Surfaces (ICSFS 2014), 2015, Rio de Janeiro. IOP Conference Series: Materials Science and Engineering. IOP Publishing Ltd., 2015. v. 76. p. $1-5$.

[4] Siano B; Huanca, D. R.; CHRISTIANO, V.; DOS SANTOS FILHO, SEBASTIAO G. Characterization of the semi-insulating properties of $\mathrm{Al} 2 \mathrm{O} 3$ and $\mathrm{AlHfO} 3.5$ for power devices. In: 2014 29th Symposium on Microelectronics Technology and Devices: Chip in Aracaju, SBMicro 2014, 2014, Aracaju. 2014 29th Symposium on Microelectronics Technology and Devices: Chip in Aracaju, SBMicro 2014. IEEE, 2014. v. 1. p. 1 - 1.

[5] CHRISTIANO, V.; SONNENBERG, V.; S.G. SANTOS. Modelo de corrente de fuga para aluminato de háfnio utilizando medidas de capacitância-tensão. Boletim Técnico da Faculdade de Tecnologia de São Paulo, v. BT/35, p. 22, 2013.

[6] CHRISTIANO, V.; DOS SANTOS FILHO, SEBASTIAO G. . RTP silicon oxynitrides to fabricate MOS tunnel diodes. In: 2013 Symposium on Microelectronics Technology and Devices (SBMicro), 2013, Curitiba. 28th Symposium on Microelectronics Technology and Devices (SBMicro 2013), 2013. p. 1. 
[7] HUANCA, DANILO R. ; VERDONCK, P. ; CHRISTIANO, V. ; KELLERMAN, G. ; DOS SANTOS FILHO, SEBASTIAO G. . Physical and chemical characterization of ultra low-k SiCOH films by X-ray reflectometry and GISAXS. In: 2013 Symposium on Microelectronics Technology and Devices (SBMicro), 2013, Curitiba. 28th Symposium on Microelectronics Technology and Devices (SBMicro 2013), 2013. p. 1.

[8] ChRISTIANO, V. ; SONNENBERG, VICTOR ; DOS SANTOS, SEBASTIAO G. . Leakage modeling of AlHfO3.5 semi-insulating dielectrics for power devices. In: 2013 Symposium on Microelectronics Technology and Devices (SBMicro), 2013, Curitiba. 28th Symposium on Microelectronics Technology and Devices (SBMicro 2013), 2013. p. 1.

[9] HUANCA, D. R. ; CHRISTIANO, V. ; C. Adelmann ; G. Kellermann ; VERDONCK, P. ; dos Santos Filho, S. G. . Hafnium Aluminates Deposited by Atomic Layer Deposition: Structural Characterization by X-ray Spectroscopy. In: 27th Symposium on Microelectronics Technology and Devices, 2012, 2012. 27th Symposium on Microelectronics Technology and Devices (SBMicro 2012), 2012. v. 49. p. 383-390.

[10] CHRISTIANO, V. ; Izumi, F.; Alândia, B. S. ; dos Santos Filho, S. G. Energy Harvesting by MOS solar cells. Submitted to Applied Phisics Letters. 